Florida International University FIU Digital Commons

$1-14-2014$

\title{
Gender In Motion: Negotiating Bengali Social Statuses Across Time and Territories
}

Mayurakshi Chaudhuri

mchau004@fiu.edu

DOI: $10.25148 /$ etd.FI14040874

Follow this and additional works at: https://digitalcommons.fiu.edu/etd

Part of the Gender and Sexuality Commons, Race, Ethnicity and Post-Colonial Studies Commons, Social and Cultural Anthropology Commons, and the Women's Studies Commons

\section{Recommended Citation}

Chaudhuri, Mayurakshi, "Gender In Motion: Negotiating Bengali Social Statuses Across Time and Territories" (2014). FIU Electronic Theses and Dissertations. 1251.

https://digitalcommons.fiu.edu/etd/1251 


\section{FLORIDA INTERNATIONAL UNIVERSITY}

Miami, Florida

GENDER IN MOTION: NEGOTIATING BENGALI SOCIAL STATUSES ACROSS

TIME AND TERRITORIES

A dissertation submitted in partial fulfillment of

the requirements for the degree of

DOCTOR OF PHILOSOPHY

in

GLOBAL AND SOCIOCULTURAL STUDIES

by

Mayurakshi Chaudhuri

2014 
To: Dean Kenneth G. Furton

College of Arts and Sciences

This dissertation, written by Mayurakshi Chaudhuri, and entitled Gender In Motion: Negotiating Bengali Social Statuses Across Time And Territories, having been approved in respect to style and intellectual content, is referred to you for judgment.

We have read this dissertation and recommend that it be approved.

$\begin{array}{r}\hline \text { Prushali Patil } \\ \hline \text { Ferial Maya Boutaghou } \\ \hline \text { Nathan Katz } \\ \hline \text { Sarah J. Mahler, Major Professor }\end{array}$

Date of Defense: January 14, 2014

The dissertation of Mayurakshi Chaudhuri is approved.

$\begin{array}{r}\begin{array}{r}\text { Dean Kenneth G. Furton } \\ \text { College of Arts and Sciences }\end{array} \\ \hline \begin{array}{r}\text { Dean Lakshmi N. Reddi } \\ \text { University Graduate School }\end{array}\end{array}$

Florida International University, 2014 


\section{DEDICATION}

To my grandparents 


\section{ACKNOWLEDGMENTS}

I could not have come through this process successfully without the encouragement, support, and love of many people. First, I thank my major professor and my dissertation committee. Professor Sarah Mahler, my major professor, advisor, and mentor, provided me with every kind of intellectual, professional, psychological, and moral support possible during the dissertation process. Her diligence, tenacity, and belief in me instilled the determination that I needed to achieve this goal. Her invaluable counsel, constructive criticisms and the purple pen, and unending patience, have all helped me become a critical thinker, an effective educator, and overall, a better scholar. I continue to be indebted to her for her generosity as my primary mentor in my academic career. Other committee members have also been there to generously offer their help and expert advice. Professor Vrushali Patil shared my regional interest, constantly encouraged me to exercise my critical feminist eye in exploring my research, and provided important feedback on my drafts. Professor Patricia Price encouraged my interest in ethnographic research. Professor Maya Boutaghou shared interest in my research population's history and cultural representation, and her expert advice and feedback have helped me chisel my research argument better. Professor Nathan Katz provided helpful and expert advice on my research population's historical and contemporary dynamics.

I have been fortunate to have strong funding for this dissertation. The TransAtlantic Summer Institute (TASI) in European Studies Fellowship, funded by the Center for German and European Studies at the University of Minnesota, and additionally funded by the German Academic Exchange Service (DAAD), at the University of 
Minnesota in 2010, provided me with important foundations for conducting my pilot research. The Morris and Anita Broad Research Fellowship and Travel Grant funded by the School of International and Public Affairs (SIPA) provided me with a scholarship that supported my travel to India for fieldwork in 2011. The FIU Dissertation Evidence Acquisition (DEA) Fellowship (2011-2012) provided me with a fellowship to conduct fieldwork as well as support myself during that process. Throughout my tenure as a graduate student in FIU, the Department of Global and Sociocultural Studies (GSS) has continuously supported me with teaching assistantships as I completed this dissertation. I specially thank my graduate program directors, Laura Ogden and Guillermo Grenier, and the department's Associate Chair, Juliet Erazo, for making sure that I have flow of funds especially during the writing stage.

I have benefitted from the reception and discussion of my work at several conferences and workshops that I have attended while conducting this research. I specially acknowledge the wonderful and critical feedback that I had from several intellectual interlocutors and scholars such as historian Donna Gabaccia and sociologist Mirijana Morokvasic at the TASI workshop in 2010, and from anthropologists Nina Glick Schiller, Karen Richman, Eugenia Georges, and Denise Brennan, at the American Anthropological Association meetings in Chicago, IL, in Nov, 2013. I thank my peer, Viola Thimm, for sharing the research platform with me and for motivating me in this journey.

I am grateful to all my interviewees at all the locations I have conducted research for this dissertation. When I first mentioned to everyone that I was working on a project on family relations and marriage, I was amazed at the number of people who 
spontaneously came forward and expressed keenest interests in participating in the project. They came forward with their views, arguments, and tangible assets such as marriage albums, photographs, memorabilia, and most importantly, their precious time in the midst of their very busy schedules. They have generously offered me with their time and entrusted me with their stories and perspectives. This research would have been impossible without their insights, beliefs, struggles, and accomplishments, which lie at the heart of this dissertation.

Throughout this journey, a network of friends, old and new, kept me sane, focused, and connected. To my friends, Basabdatta, Trishita, Shreemoyee, Rimi, Sudeshna, and Sourav, for their unconditional love and support, for their deep friendship and intellectual support, for making me rethink and unthink some deeply rooted but unquestioned notions about family, marriage and migration. I am also deeply thankful to my friends in graduate school for always supporting my research endeavors whether in the classroom or at a conference and providing important feedback on them. Finally, I am thankful for friends like Arpit, Evan, Krysty, Rajib, Sumit, and Zach for constantly reminding me that there is life outside the graduate school and making sure I live that life too!

None of these would have been possible without the love and support of my own family. To my wonderful parents, Minakshi and Sibadatta, for always believing in me and letting me be who I am. Chhotoma and Babai's unending trust in me and believing that I am capable of achieving anything provided that I am ready to commit myself to it have been my guiding pillars. They have given me the most precious gift parents can gift: the gift of support and experience. They have been and continue to be my two strongest 
pillars. I am thankful to my brother, Somu, for being such a lovely soul and perhaps my strongest critic. Somu always understands me -- even when I do not say anything. I thank the core of my Calcutta household support, especially to Papapu, Kanon di, and Bhanu da, - wherever you are, thank you for all your love.

I am thankful to have Himadri as my husband and confidant, especially during this journey. His inexhaustible patience, immaculate spirit, and unconditional love and support have been indispensable for me throughout this process. Thank you, Himadri, for just being who you are, and for each wonderful day.

I am thankful to my in-laws, Pranati and Usha Ranjan, for their love and support during this journey. Whether showering me with saris and jewelry or spending endless hours of enriching, wonderful discussions on a myriad of topics ranging from World literature, Indian History, to contemporary world politics, they have gifted me with some wonderful moments. I look forward to many more of such great moments in the future. To my brother-in-law, Bob, thank you for being a great friend.

Although inspired by readings in graduate seminars in graduate school, the fundamental foundations of family and marriage have been instilled in me long, long before, by some very special people in my life - my grandparents. My grandparents have taught me over the years what it takes to build a family and, more importantly, how to maintain it through thick and thin even though family members will not agree with each other every day. Being their only granddaughter in my generation in the family, I have been in the receiving end of ultimate love, care, pampering, and showering of blessings and warm wishes from them. All their life, my grandparents have been the pillars of our family. I am assured with each passing day that they particularly my grandmother, my 
Thamma, would have been the proudest of me at this point. While Thamma had seen the inception of this project, unfortunately she did not live to see the project's completion. She breathed her last on the night of Dec 31, 2012, a few months after I finished my fieldwork for this project. It is to my grandparents, and the beautiful memories that we share, that I dedicate this work. 


\section{ABSTRACT OF THE DISSERTATION \\ GENDER IN MOTION: NEGOTIATING BENGALI SOCIAL STATUSES ACROSS \\ TIME AND TERRITORIES}

by

Mayurakshi Chaudhuri

Florida International University, 2014

Miami, Florida

Professor Sarah J. Mahler, Major Professor

Hindu Indian Bengalis as an ethno-linguistic and transnational group have negotiated their social locations historically, contemporaneously, and transnationally. In this dissertation, I examine and argue how transnational migration is the most recent in a long line of Bengali strategies to negotiate their social location vis-à-vis other populations in India. Since the early years of the nineteenth century, in Bengal specifically, a series of socio-political dynamics have reshaped and reconstituted Bengali social status. These dynamics can be observed across various geographic scales - national, regional, and local -- and have continued to inform their contemporary gender relations. En route to this examination, the dissertation exposes assumptions about who constitutes families, problematizes family centrally en route to examining spousal relations among IndianBengalis. I have examined the lived realities and experiences of migrant spouses in the U.S. and their family living in India amidst differing — and often conflicting—imaginaries and practices of families. Through my work, I thus illustrate that family and marriage relations can be, and often are, strategic and fluid even as many people view them as structural and enduring. Over time, representations of the idealized Bengali family, of 
manhood and of womanhood have all shifted, reflecting sociopolitical and economic changes. A constant, however, has been the central role of gender in all these imaginaries and realized configurations.

In this dissertation, I employ a gendered optic, a heightened sensibility to what they communicate about gender. As I examine in my work, gendered boundaries amid the Bengali population can be found in a deeply rooted history, a colonial legacy, and one, although repackaged, that continues to be seen contemporaneously. Bengalis' transnational negotiations in family and marriage expand our understanding of transnational gender relations across broad social and historical scales, particularly the transnational. In this vein, the dissertation contributes significantly to the field of gender studies, specifically the field of feminist theorizing and intersectionality studies, postcolonial and South Asian studies, and to the scholarship on migration and transnational migration studies. 


\section{TABLE OF CONTENTS}

CHAPTER

PAGE

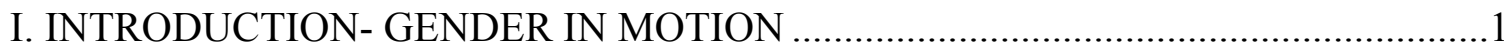

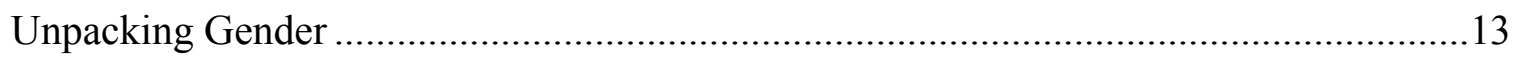

Gender in Migration and Transnational Migration Scholarship .......................................19

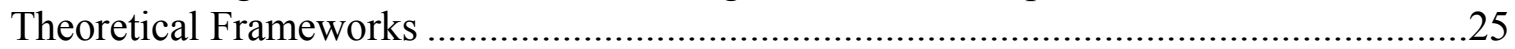

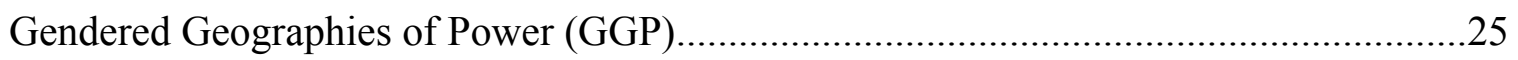

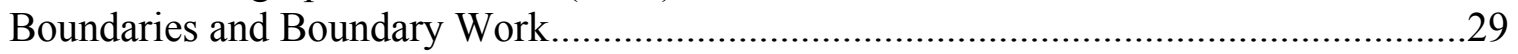

A Note on using Transnational as a Concept.................................................................

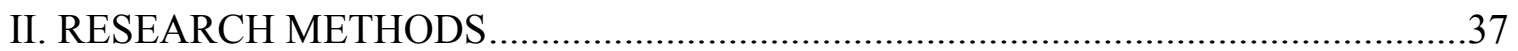

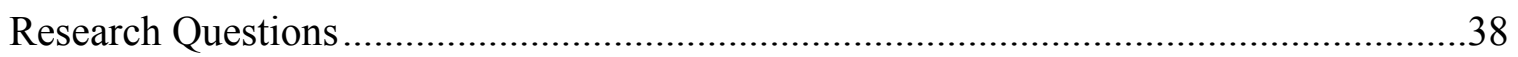

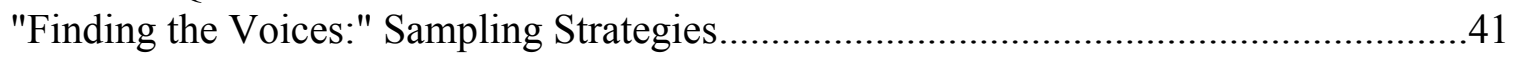

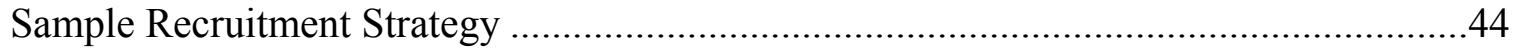

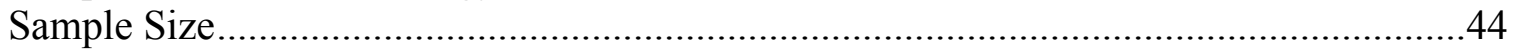

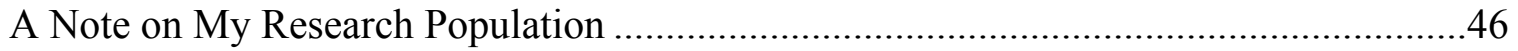

Choosing Representational Voices and Stories ............................................................4

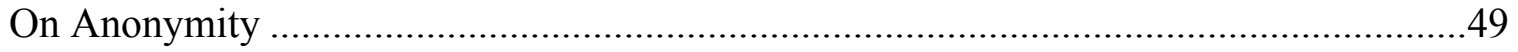

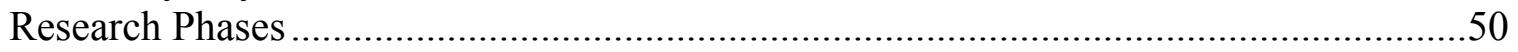

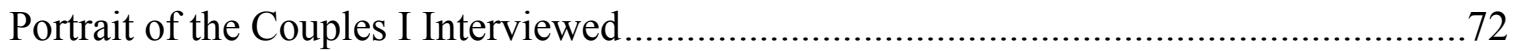

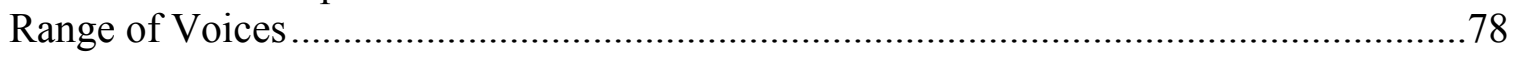

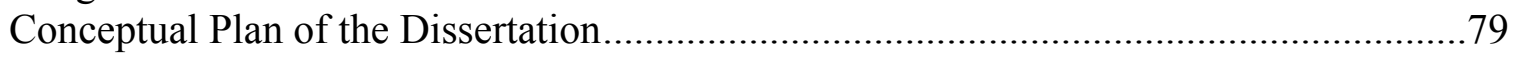

III. GENDERED GEOGRAPHIES IN NINETEENTH CENTURY BENGAL .................80

At the Geographic Scale of the Nation: The Prolonged Shadow of the Bengal

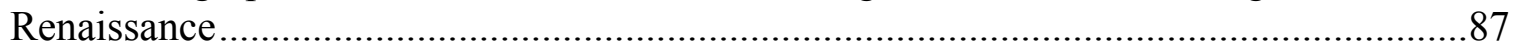

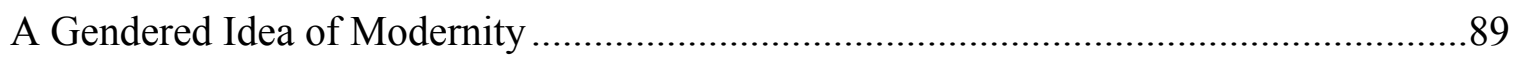

At the Geographic Scale of Bengalis as an ethno-linguistic group ..................................92

Bengali Men through a gendered kaleidoscope ...........................................................92

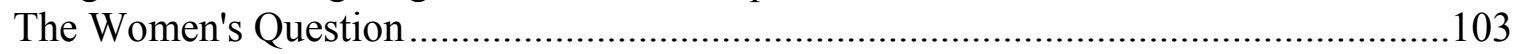

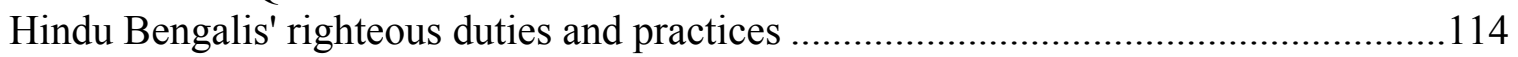

At the geographic scale of intimacy: Family, Marriage and the Home ............................123

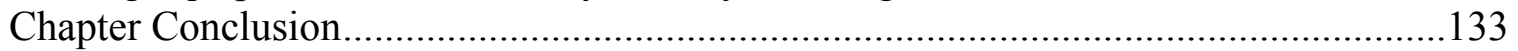

IV. GENDERED GEOGRAPHIES OF MARRIAGE AND THE FAMILY IN

BENGAL AFTER INDIAN INDEPENDENCE (1947) ................................................134

Marriage and the family at the supra-national geographic scales:

Nationalizing the joint family ..............................................................................134

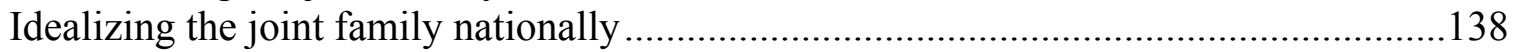

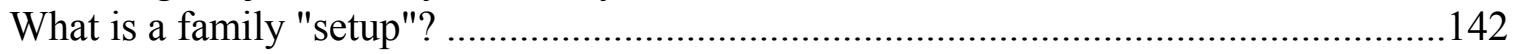

The "ideal" Bengali family in the twentieth century ………............................................149

Bengali Marriage and the family practices in the twentieth century …….......................152

Modernity and the Bengalis in the twentieth century ....................................................162 
Chapter Conclusion.

V. GENDERED GEOGRAPHIES OF CONTEMPORARY BENGALI FAMILY AND MARRIAGE ACROSS TRANSNATIONAL SPACES

Revisiting larger literatures on family negotiation and transnational migration

to the U.S. in perspective

South Asian Migration to the U.S. through the lens of gender.......................................177

Redefining Spousal Relations - Bringing in the Extended Family

Material and Symbolic Privilege across Transnational Spaces

Chapter Conclusion

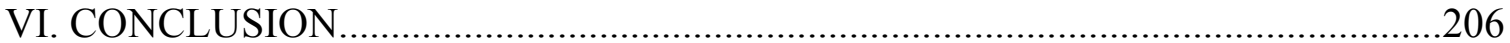

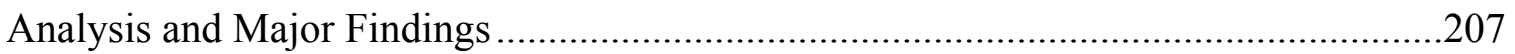

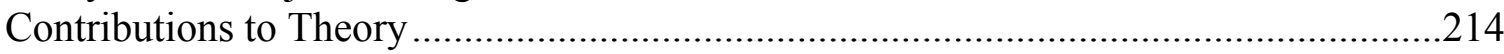

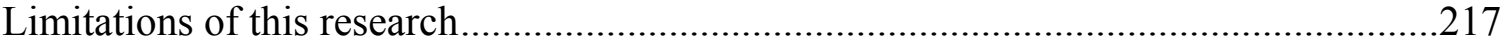

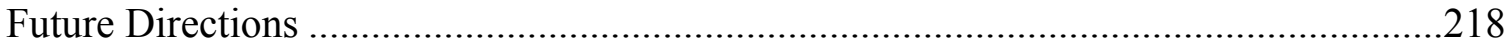

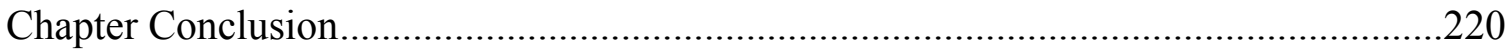

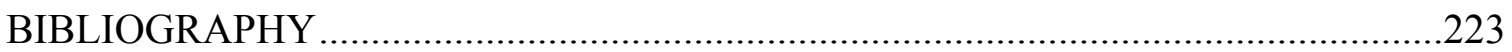

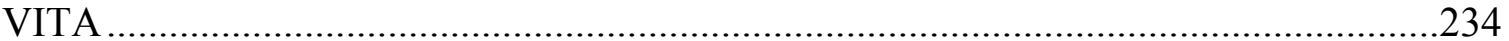




\section{LIST OF TABLES}

TABLE

PAGE

2.1 Research Questions, Data Sources, and Data Analysis

2.2 Interviews distribution by source, location and language. .45

2.3 Examples from Matrimonial websites ...............................................................51

2.4 Conceptual Category FAMILY and its properties ............................................67

2.5 Conceptual Category MARRIAGE and its properties............................................68

2.6 Conceptual Category SPOUSAL RELATIONS and its properties .........................69

2.7 Conceptual Category VALUES AND IDEOLOGIES and its properties ..................69

2.8 Conceptual Category MIGRATION and its properties ...................................... 70

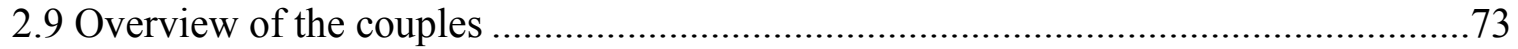




\section{LIST OF FIGURES}

FIGURE

PAGE

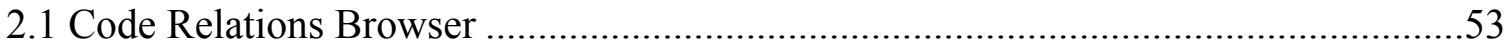

2.2 Cognitive Map produced using MAXMaps.....................................................55

2.3 My Data Collection and Analysis Log............................................................6

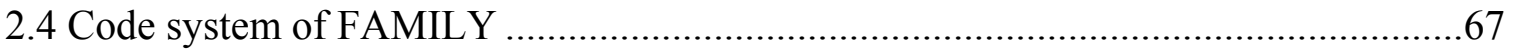

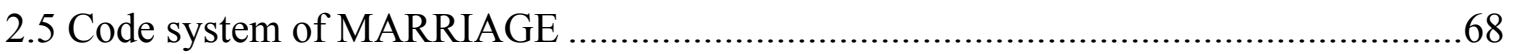

2.6 Code systems of SPOUSAL RELATIONS, VALUES /IDEOLOGIES, and

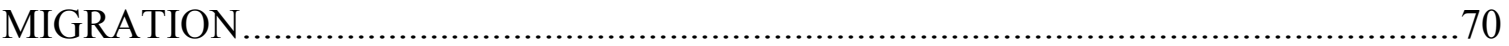

2.7 Code Relation Browser showing Relationship between Family and Family involvement in spousal relationship.................................................................. 71

2.8 Code Relation Browser showing relationship between Family and Extended

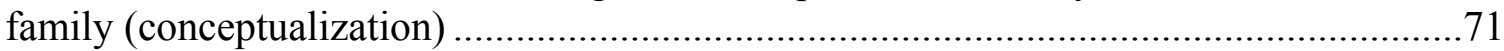

2.9 Code Relation Browser showing relationship between MIGRATION

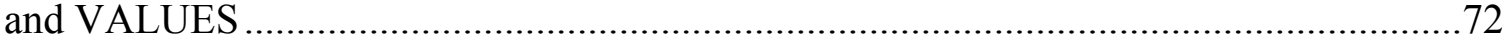

3.1 Folk art depicting a married Bengali woman as Grihalakshmi..............................120 


\section{CHAPTER I - GENDER IN MOTION}

Mili and Rahul are a married Bengali couple from Kolkata, a metropolitan hub of art, education, and literature in the eastern part of India. Mili was 26 when she married Rahul, and he was 29. Their marriage was not a typical arranged marriage by Indian standards; their families were not involved from the start. Rahul was Mili's cousin's friend. The couple met through the cousin, and after a few meetings, decided that they wanted to get married. Then they informed their families, and everything that followed after that was typical of any arranged marriage scenario in India: The two families met, decided on the date and wedding ceremonies, and exchanged gifts. Mili calls their marriage "an arranged love marriage," meaning that the couple's meeting and subsequent marriage was not formally organized by their families but the families were very much involved once the couple decided to marry. Soon after their marriage, Rahul's job contract brought the couple to the United States. Mili migrated as a dependent on a spousal visa which meant that she could not hold any employment in the United States. Rahul continued to work at a prestigious Multi National Company (MNC) in South Florida while Mili managed their home and took care of their daughters. Recently, however, Mili has begun to pursue higher education. She desires a career that she can call her own. The couple has been living in the U.S. for the last nine years while their family members continue to live in India, visiting them only occasionally. And yet, in almost all my interview sessions with Mili and Rahul, their stories about their family parents, siblings, in-laws, relatives, and even close friends - surfaced as if they all were all living with each other, in the same household as would be common in India. For purposes of this research, when I asked Mili to tell me more about her family, and their 
involvement in their migrant lifestyle, Mili replied, "I can tell you from my experience that family involvement continues very strongly after marriage, and even after migration. Two hundred percent. Yes. And whether I have been influenced by it? Yes. Anyone who says that it doesn't happen is lying. It happens. It is bound to happen. Any daughter or son would be affected by it. That really affects the relationships. The parents feel insecure, especially the mother-in-law."

After marrying Rahul and migrating with him to the U.S., Mili's life has passed through various gendered stages. Following their marriage and before she moved to the U.S., Mili used be nervous of her in-laws, specially her mother-in-law. Why? From Mili's response, it was evident that Rahul's mother, Ruma, behaved very roughly with Mili yet Mili never retaliated against any of Ruma's actions. Mili remained voiceless as a new bride in the family: she played the perfect grihalakshmi (meaning,"the good wife", see Chapter Three). Thus, Mili's first stage of engaging gender post-maritally was to find herself subjugated to her mother-in-law. However, once the couple started living in the U.S. their spousal dynamics and the dynamics between Mili and her in-laws changed in terms of gender as well. This stage could be termed "contested" and the complexities of this stage came to light when I was able to interview Rahul's parents, Ruma and Ajit, when they visited the couple for a few months in 2011 during my fieldwork. This provided me with a supplemental angle into the couple's "gendered geographies," one including the in-laws. By this time, Mili had started to attend a local university to pursue her higher education. She followed her own daily schedule, which was not necessarily dependent on Rahul's daily schedule, and yet the couple functioned without disruption in maintaining their hearth and home. Ruma and Ajit soon realized that Mili no longer 
totally depends upon Rahul and thus is less subject to their influences as well. This is because Mili is pursuing her own goals and career. In reaction to this realization, Ruma started to avoid direct communication with Mili while simultaneously communicating hostility towards Mili through her body language. Mili explains how: "She would not eat whenever I would cook. To her, I just do not exist. She will not tell me anything, but she will totally dismiss my existence as if I do not exist." Then one day, when it got to the extreme, Mili forced Ruma to talk to her. Mili wanted to know the reason for her cold shoulder. Ruma replied, "You [Mili] are not the kind of daughter-in-law I wanted. You are missing something. Previously I thought that you are not beautiful, or wealthy. But now I am also seeing that you are neither a good wife nor a good mother. So my son is missing the whole package because you are not perfect for him." Clearly, Ruma holds a particular view of gender and gender relations that Mili does not share. And Ruma's behavior in addition to this particular comment is evidence of what in this dissertation I will call "Boundary Work"; that is, the ways that people try to push others back into socially constructed categories (in this case that of proper gender behavior) when they are perceived as having transgressed those categories.

During her visit to Mili and Rahul, Ruma started to realize that Mili was challenging her position as mother-in-law. The contestation was not overt from either party which is why Ruma decided to respond using informal Boundary Work. Nor did Mili try to overwhelm Ruma but the visit showed the power imbalance in different ways. For example, neither Ruma nor Ajit can drive so for them to go anywhere they would depend either on Mili or on Rahul. Given that Rahul was away at work almost all the time, the onus of driving and taking them around automatically fell on Mili. This 
inverted the normal gendered dependency of the daughter-in-law. Moreover and more importantly, on a daily basis Ruma and Ajit witnessed Rahul consulting with Mili on most decision-making matters such as around finances, their daughters' schedules, or simply about their weekend plans. This collaboration did not characterize Rahul's parents' marriage. Ajit always served as the primary decision-maker over Ruma. Witnessing their son's relationship with Mili, thus, affected Ruma's views on Mili over time.

The third gendered stage commenced when Ruma began changing her behavior towards Mili again. This stage characterized Ruma's slow acceptance of Mili's different gendered relations with Rahul—but, and importantly, not her agreement with these changes. "[Ruma] no longer compares me with anyone else like she used to do before," Mili explained to me. "For example, earlier she used to think that I am not beautiful and she would constantly compare me with other women who she thinks are beautiful. All of that stopped." She saw that this Boundary Work tactic was not effective and began another tactic. "Once she started to realize this [that Mili is not a traditional Indian spouse], she realized she cannot completely ignore me. Why? Because no matter where we live, we are still family and I am still her daughter-in-law. So now, she is othering me," Mili continued referring to another common technique of Boundary Work. Instead of trying to draw Mili back into Ruma's preferred gendered category for a daughter-inlaw, she now begins to exclude Mili by drawing a bright boundary between herself (the good wife) and Mili (the bad wife). "She is now creating a boundary between me and her. A boundary that states 'You can never be like I am. You are bad, I am good.' Why am I bad? I do not observe religious rituals. I do not dress up the way she would like me 
to. I am not a good wife or a good mother (I do not know why she thinks that). I do not attend to her like an obedient daughter-in-law. Her entire vocabulary towards me has changed. She is othering me because she now realizes that she can neither ignore me nor accept me."

The visit of her in-laws, then, became a factor in Mili's gendered geographies of power. Not surprisingly, such gendered geographies also affected Mili and Rahul's spousal relations too. From Mili's experiences above, it appears that Rahul engages in a more companionate marriage with Mili than that between his parents whose relationship fits the more gender complementary model. Rahul attests this when I interviewed him, "To me, marriage is a relationship where compromise is the most essential element. Both spouses need to make that compromise. I do not think that any marriage is perfect. All marriages have their ups and downs. In spite of those ups and downs, if you can continue maintaining that bond with your partner, then that is the measure of success in a marriage." Rahul refers to a key element that he thinks characterizes marriage: flexibility. He explains, "Why do we get married? We do not get married only for benefits [referring to the experiences of some of his colleagues who married for benefits]. We marry to retain our relationships. Unlike here [U.S.], where people place a lot of importance on individual career than on their family, I believe that an integral part of our marriage is family. So if we are not flexible in those relationships [in marriage and in the family], then marriages would fall apart very frequently." From Rahul's response, he and Mili do not appear to enforce strict gender "roles" (discussed below) or boundaries between the male sphere of influence and the female. Yet, during his parents' visit Rahul, not surprisingly, was torn between his loyalties to the predominant women in his life. "I am 
very close to my mother," Rahul reflected. He carefully differentiated between the relationships that he shares with his parents, "I do not have that close a relationship with my father. In fact, I only discuss finances and property related matters with him. I have a distance with my father, just like he had a distance with his father. But how did I grow close to my mother? Circumstances. After my parents were married, my mother was very scared of her father-in-law because she was a daughter-in-law in the family and she had to play the perfect wife and bride. She had to be the grihalakshmi. She used to cover her head in front of her father-in-law and other elders all the time. She did not have any life outside her home. We were her only world. She is not highly educated, but she managed the large household perfectly. So I developed a closer relationship with my mother than with my father because she was always around, tending us." In his interview, Rahul did not definitively choose to side with either of the women in his life - Mili and Ruma. Perhaps this seemingly neutral stance reflected his realization that his relations are fluid with both women. Indeed, Mili had been pressing to go back to school for some time. Mili wanted to pursue a career, not really to become a breadwinner but more to be able to realize her own abilities. This desire of hers again pushed him into a situation where he felt betwixt and between two important gendered ideas about wives: should they largely serve their husbands and husbands' families (his mother's world) or should they have the right to pursue their own dreams? What does Rahul gain and lose from siding with one gendered model or the other? "You learn to gain different perspectives as you grow up," Rahul responded referring to his experiences around the time he finished his studies and was choosing a career path. "My lifestyle changed, and so did my perspectives. I moved to a different city, and eventually to a different country. However, your cultural 
upbringing stays with you for a very long time if not forever." Rahul explained why he thinks the way he thinks about gender relations in a marriage, like between him and Mili. "Here [U.S.], if I expect my wife to perform her duties exactly like my mother used to perform in India and still does as a wife and a daughter-in-law, that is not right."

However, in spite of Rahul's conscious responses against rigid gender "roles" in marriage, Mili paints a slightly different picture, "Rahul thinks I can no longer be a 'perfect' wife ever since I have started to attend graduate school," Mili explained to me as we discussed the dilemma her husband faces. "Who is a 'perfect' wife? One who takes care of the household in entirety, attends to her in-laws, takes care of the children, and cooks delicious meals for dinner after toiling in the kitchen." Clearly, Rahul's expectations of a "perfect wife" that Mili described are fashioned by Rahul's own experiences of observing his mother play the "perfect wife." However, there was an added gendered dimension that Mili brought out in her response. "With me joining the university, Rahul knows that he can no longer exercise a one way power relation over me. I can now resist his power."

Mili's response brings to the fore a central question that I have investigated in my dissertation - the "gendered geographies of power" between spouses and their families. "Had this been in the past," Mili explained, "my husband would have controlled much of my movements and behavior, especially around his parents. But he cannot do this anymore now. So I am sure that this will be a new power arrangement between me, my husband, and my in-laws which would not have happened if we had continued to live in Kolkata. It would neither have happened if we lived here [U.S.] and did not maintain any 
connection with them. It has happened because even though geographically we live in different places, somewhere we all connect as one big unit - the family - and therefore a lot of this springs from whether we are fulfilling each other's expectations or not." In other words, if Mili and Rahul had not been in touch with Rahul's parents, then the couple would have had a different gendered geography of power in their spousal relations. That gendered geography might have been guided more by placing spousal relations centrally than placing the family at the center and the relations becoming peripheral. In another context, if the couple had continued to live in India geographically closer to their family and in-laws, then, as Mili responded above, they would have a different gendered geography of power. This gendered geography of power, as my data indicate, would have been influenced by geographic proximity and constant familial meddling in spousal relations. Over $80 \%$ of my respondents have voiced the role of geographic proximity in family involvement in spousal relations and I will examine them in my following data chapters.

I begin the dissertation with Mili and Rahul's story because the experiences of this couple are far from unique and they illustrate the very gendered dynamics that this dissertation explores and explains. Over the course of twelve months that I spent collecting data for this dissertation in South Florida and in Kolkata, I have documented stories that echo similar themes: gendered geographies of family and marriage, living transnationally (for details, see chapter conclusion), and its added effects on gender, and family involvement in spousal relations. 
In addition to these gender relations' patterns and the Boundary Work surrounding their negotiations, there is another important facet in this family's dynamic that I did not anticipate in my research but which surfaced nonetheless. That facet is the central and strategic but not unitary role played by gender and mobilities in families' overall social status negotiations. At its core, Indian families struggle to achieve social status recognition that often involves migration of members abroad. The idea of using transnational ties as a strategy is not unknown in scholarship. For example, there is considerable literature examining how Tamil Brahmins use transnational connections and ties as a strategy to arrange marriages, how families from Andhra Pradesh use transnational ties as a strategy to demand higher dowry in marriage (for example, see Bannerjee 1999; Charseley 2005; Charseley and Shaw 2006; Del Rosario 2005 Kalpagam 2005). This, in turn, exposes migrants and sometimes their families to different gendered ideologies and practices that can undermine some "traditional" gender understandings. However, such undermining of "traditional" gender understandings must be tolerated, nonetheless, so that the families, and therefore not just their migrant members, can enjoy the heightened social status that accrues to those who go overseas. Both Mili and Rahul referenced this strategy in their interviews. Mili, however, best summed it up when she said, "You know that there is a popular belief among Bengalis that if you are in the U.S., it gives you a certificate, like an accomplishment, to do anything. This sense of accomplishment is so strong that often times we think we are Bengalis first, then Indians." Indeed, this sense of "accomplishment" that Mili and Rahul talked about is deeply rooted in a prolonged history of the Bengalis' negotiating their social locations, their social status, which I explore and explain in this dissertation. 
To summarize a key argument made in this dissertation, adopting a transnational lifestyle is the most recent of a long line of strategies that Bengalis have utilized as they have negotiated their social location vis- à -vis the larger Indian population. This history dates back to at least the colonial gender dynamics of nineteenth century Bengal (Chapter Three) and it courses through several important historical time periods including the Bengali renaissance, Indian independence and contemporary trends of transnational living (Chapter Four and Five). In each era, gender figures very prominently in Bengali families and national strategies to enhance their social status vis-à-vis other Indian “ethnic” populations. (Chatterjee 1993; Sinha 1995, 1997).

The ethnographic example of Mili and Rahul's experiences thus introduces the key issues that underlie this dissertation research. The purpose of this research, while being sensitive to the fact that ideals for families often differ from their real manifestations, is two-fold:

(1) By exposing assumptions about who constitutes families, this dissertation problematizes "family" centrally en route to examining spousal relations among IndianBengalis, who were married in India but have migrated to the U.S. where they live and are thus exposed to different concepts of family and their affiliated norms. In this dissertation, I examine the lived realities and experiences of Indian immigrant spouses and their family living amidst differing — and often conflicting-- imaginaries and practices of families. That is, through participant observation and in-depth interviews, I have not only collected data from couples living in the U.S. but also family members resident in both the U.S. and India, and by soliciting from different family members their 
understanding of "family" and family obligations and expectations. My field data on these family constellations have exposed me to ideas and practices circulating within and across various geographic scales - local, regional, national, and transnational. During my data collection I have found out about not only the ways in which members reproduce and reify cultural ideas and practices regarding the family and gender relations in particular, but also if and how they work to change them. Additionally, in the course of my data collection I have encountered information about how different family members interpret their cultural practices, the meanings that they attach to those practices, and compare them against historical ideals and practices. That is, although this is not a true longitudinal study, I have incorporated not only historical data but have also elicited and brought in respondents' views on how family and gender relations have shifted over time and in their lives. I did not intend specifically to handle information about changing ideas and practices in India stemming back more than a century but they inevitably arose in the course of my research and I therefore needed to incorporate these data into the whole dissertation's purview. However, it is important to clarify at the onset that the historical narrations by my informants are informed either by their direct experiences or by those of family members handed down from generation to generation. Thus, the historical narratives produced by my informants are socially constructed both through the efforts of historical agents and through the storytellers themselves. Moreover, this narrative explains how gender was constructed historically and also how that understanding has evolved over the centuries. In analyzing that historical construction of gender relations, I contribute to many scholars' work who have examined the Bengali family through a historical, colonial lens (for example, see Chatterjee 1993; Chatterjee 
2004; Sinha 1995, 1997). My work, in turn, adds in both contemporary and transnational lenses.

(2) In addition, I document how transnational migration is the most recent in a long line of Bengali strategies to negotiate their social location vis-à-vis other populations in India. This goal of the dissertation, then, is set within a larger, national dynamic - and one that is also tied to historical gendered geographies of family and marriage in Bengal. Since the early years of the nineteenth century, in Bengal specifically, a series of socio-political dynamics have reshaped and reconstituted Bengali gender relations. These dynamics can be observed at various geographic scales - national (between the colonizers and the colonized), regional (between Bengalis and other Indian regional groups), and local (within Bengalis themselves). Bengalis have used gender as an important factor in negotiating social status for all of these strategies across time and geographic scales. I thus illustrate that family and marriage relations can be, and often are, strategic and fluid even as many people view them as structural and enduring.

Throughout this dissertation, and as already illustrated through Mili and Rahul's experiences, family, marriage and spousal relations are constant gendered themes running through the lived realities of couples and their families as they negotiate their social status across transnational spaces. Not surprisingly, in doing so, participants both inflect and are inflected by gender. In this dissertation, I therefore examine this data through a "gendered optic," a heightened sensibility to what they communicate about gender. In the following section, therefore, I will discuss the scholarly literature on the central concept that constitutes my "gendered optic." I draw on scholarship across disciplines and engage 
in theories of gender, particularly as operative in family, marriage, and migration. Then I explain exactly what my "gendered optic" is and how I use that optic in this dissertation. This discussion will include a thorough explanation of the theoretical frameworks that I apply throughout this dissertation: Gendered Geographies of Power, and Boundary Work. I examine scholarship on the other central concepts in this dissertation, i.e. family and marriage, particularly focusing on South Asian contexts, in the following chapters as and when applicable and in relation to my data.

\section{Unpacking Gender}

From Sex Roles to Gender Relations

The last few decades have witnessed the publication of an exceptionally large amount of literature, both in academia and in popular press (newspapers, magazines, and print media such as novels and other fictions), which examines gender, gender differences and experiences in family, marriage, and within the larger society. Over the years, scholars have proposed, argued, explained and debated over the extent and meaning of such differences (for details, see Ferree 1999, 2010; Lorber 2004; Risman 2004). Early publications and debates were premised largely upon biological differences between the sexes (male versus female) rather than explaining how men and women relate to each other within the family or in society. The earlier approaches therefore generated theories about sex roles. That is, they generated theories about the biologically

rooted and thus presumably stable differences between girls and boys, women and men. While sex role theories extended the scholarship on gender by recognizing biological differences between the sexes, they gave normative prescriptions for sex roles. People who did not fit those prescriptions often were viewed and/or labeled deviants. This 
structural approach, however, was confronted by data documenting cultural variations in sex "roles" which, in turn, pushed theorization beyond static sex roles toward more fluid understandings of gender relations (Ferree 1999, 2010; Lorber 2004; Risman 2004). Sex role theories were not only criticized for what they tried to explain, but also for what they did not take into account - namely, the constant social interactions that produce and reproduce gender.

In the 1980 s, feminist scholars expanded their critique beyond male/female toward examining family relations and household dynamics. Therefore, in order to understand family relations and household structures, as well as how individuals and families relate to the broader social institutions and structures, feminist scholars introduced the concept of gender. One of the earliest definitions of gender can be found in Analyzing Gender: A Handbook of Social Science Research (1988), edited by Myra Marx Ferree, Judith Lorber and Beth Hess. Ferree et. al. (1988: xviii) argue that gender should not be "... seen as a permanent result of childhood socialization, but as a lifelong work in progress." Better known as "gender theory," the gender approach analyzes how individual behavior and relations are constantly being interacted upon and reproduced, thus giving them "gendered meanings" (Ferree 1990). A fundamental way in which theories based on gender relations differ from the earlier sex role theories is that while sex role theories presuppose the existence of certain behaviors and structures, gender theories document the continual construction of those behaviors and structures as an effect of constant negotiation in daily life (Ferree 1990, 1999; Kimmel 2004; Lorber 1994; McKinnon and Silverman 2005). 
Since the 1980s, following the gender theory approach, gender came to be understood as dynamic processes or what West and Zimmerman (1987) termed as "doing gender." This conceptualization defines gender as a process that is implicated not only in demarcating "males" and "females" within the broader structures of society, but also how these categories of people relate to each other. The next leap in theorizing gender came in the 1990s when feminist scholars argued that gender is not a property of an individual but is an emergent feature of social situations. These scholars argue that gender theorizing until now had been obscuring how gender is about relations and processes involving power (West and Zimmerman 1987; Lorber 1994; Ferree 2010, Lorber et al. 1999). Additionally, gender is one of the most important axes of differentiation that people use not only to distinguish themselves but as the basis for negotiating social status and hierarchies. This characteristic of gender is particularly important to understanding how gender relations were negotiated in colonial Bengal (Chapter Three) and how such relations have continued to be negotiated contemporaneously and transnationally (Chapters Four and Five).

The third wave feminism that started in the late 1980s explicitly drew attention to the axes of identity that inform gender relations and how people relate to each other. Some of the important axes this scholarship identifies are race, age, class and ethnicity. This advancement in gender theorization is more popularly understood as "intersectionality" studies in feminist scholarship (Ferree 2009; hooks 2000; Hernandez and Rheman 2002) and forms another important theoretical foundation of this dissertation. Intersectionality refers to the active interaction of the various relations of inequality such as race, class, sexuality, gender, and age within and across all of the 
institutions of society (Anderson 2005; Ferree 2010).The origins of the intersectionality framework grew out of feminist scholars of color pressing the position that most feminist scholarship in the 1980s concerned only middle-class, educated, white women, and that an inclusive view of women's position should substantively acknowledge the intersections of gender with other significant social identities, most notably race (Knudsen 2004). Such critiques were strong voices in a widely expressed concern that feminist scholarship should more explicitly acknowledge the ways in which social positions and group membership overlap and change the experience of social identity.

The intersectionality framework emphasizes the qualitative differences among different intersectional positions. For example, "the very meaning of manhood may vary when applied to one's own racial group as compared to another group; similarly the meaning of a given racial category may vary for men and women" (Mullings and Schulz 2006:5). As I argue in chapter Three, negotiations of Bengali "manhood" are a bright example of Mullings and Schulz's argument. The intersectionality approach has continued to be emphasized in contemporary gender scholarship as it provides a theoretical platform to discuss gender by simultaneously considering other dimensions of social structure/social identity that constructs gender. Intersectionality is also a useful lens to interrogate the multiplying features that create and define social identities (Shields, 2008). A discussion on intersectionality thus does not only include race, class, and gender, but also age, and sexual orientation to name the most prominent variables (Riley 2004; Shields 2008). 
Critical to the development of intersectionality as a theoretical lens to view gender power relationships is Kimberly Crenshaw's (1991) exploration of the race and gender dimensions of violence against women of color. Crenshaw (1991) argues that the experiences of women of color are frequently the product of intersecting patterns of racism and sexism. The concept of intersectionality has been defined as the oppression that arises out of the combination of various forms of discrimination, which together produce "something unique and distinct" from any one form of discrimination standing alone. Indeed, “...Intersectionality is a conceptualization of the problem that attempts to capture both the structural and dynamic consequences of the interaction between two or more axes of subordination" (Crenshaw, 1991).

Intersectionality is also defined as a theory to analyze how social and cultural categories intertwine (Knudsen 2004). For example, while intersectionality as a theory and as a concept derives from the activist critiques that women of color in the U.S. and U.K. made in the 1970s and 1980s about overly homogeneous political discourse in which "all the women are white and all the blacks are men" (Crenshaw 1991), it is important to consider how the meanings change when stretched to cover other power relations such as inequalities and exclusions. This dissertation illustrates in significant ways how power relations and meanings attached to them change across multiple axes and scales of inequalities and exclusions.

My engagement and application of the intersectionality framework in this dissertation is also informed by another group of scholars who identify similar power relations in their research. Rather than identifying points of intersection, these scholars 
have argued that power dynamics are mutually constituted rather than intersectional (Brennan 2004; Ferree 2009; Mahler and Pessar 2001). Accordingly, dimensions of power relations (such as gender, race, and class) are viewed as dynamic, located in changing, mutually constituted relationships with each other from which they cannot be disentangled. Viewed through this dynamic lens, categories (such as women and Black) and the dimensions along which they are ordered (such as gender and race) are therefore not deemed "false" or "insignificant" even though they are imperfect, variable and highly contested (Ferree 2009).

The intersectional or mutually constitutive lens is important in this dissertation for examining gender relationships across all geographic scales- the nation or the state, the family, and the individual. In fact and arguing for a growing trend of diversity within families in the U.S., Ferree (1999) states that all families "must manage individual intersectionality, because each member has been socially assigned multiple identities (e.g., gender, race, age, and nationality)." Families as institutions are also located in intersections of structural relations of inequality within and across all other institutions (economic, governmental, religious, and civic) at all levels from local to transnational (McCall 2005; Ferree 2010). However, since the negotiation of gender relations across these scales is subject to specific contexts and varies cross-culturally, such negotiations give rise to various gendered geographies that are socially constructed and maintained through power relations specific to cultures, contexts, and societies. Theories of intersectionality would not be needed, at least presumably, if gender roles were structural and static. The intersectionality scholarship is particularly helpful to understanding family relationships as family ties and connections moved beyond the immediate 
boundaries of the household and extended into wider social structures and became part of larger socio-structural processes -- in this case, migration and transnational lifestyle.

\section{Gender in Migration and Transnational Migration Scholarship}

Among the most important of early research on gender and migration were those produced by The Chicago School of Sociology, especially research produced before the 1940s. This early research documented both the experiences of female and male migrants, and of migrant families (Simon 1992). However, these early works were not gendered analyses; they did not take gender as a key organizing principle of human life. Therefore, early research largely looked for and found women in "typically" female activities in the household, as mothers and prostitutes, and as involved in marriage fraud, etc. Such stereotypes were even more frequently in research conducted among migrant women of Asian origin such as Chinese, Japanese, Indians, or Filipino (Hing 2004; Joppke 1999). Although some early attempts were made to include sex as a variable in theorizing migration (such as that by Ernest Ravenstein [1889]), they were very much the exception not the norm.

Overwhelmingly, research at the time viewed men as migrants and women as their dependents, leaving them largely voiceless. In contrast to these earlier studies of migration which were inclusive, but not exhaustive, of male and female migrants, the decades spanning immediately after World War II and into the early 1970s (prior to the feminist movement) overwhelmingly ignored the experiences of female migrants. This could be largely due to the socio-political and economic outcomes following WWII, thus resulting into an inconsistent development of migration studies and theories and the 
strong polarization of such studies towards an analysis of male-only migration (Hing 2004).

Since the 1970s, and as a direct consequence of the war, scholars focused more on studying migration as a consequence of economic situations (such as issues of labor supply and demand) (Hing 2004). Scholarship produced around this time reflects a shared common assumption that as breadwinners in the family, migrants were predominantly men, and these men migrated largely for economic reasons. Thus, although women migrated the fact that migration was and is a gendered phenomenon was not worthy of much mention (Houston et al, 1984; Pedraza 1991). Instead, they ignored, and sometimes remained silent about, the differences in experiences of migrant women vis-à-vis migrant men and documented the experiences of the migrant men's as that of all immigrants.

As examined by more recent scholars, early scholarship therefore constantly portrayed migrant men as the "real migrants" while either assuming that female immigrants were passive beneficiaries of the migrant men or leaving them out of the analysis altogether (Lee 1996; Grieco and Boyd 1998; Hondagneu-Sotelo 1999; Hondagneu-Sotelo and Cranford 1999; Mahler and Pessar 2001, 2006). Nevertheless, it was during the same post-war period that female migration increased as women started migrating independently (Grieco and Boyd 1998; Hing 2004). Given the effects of the war on their marital condition and their increased awareness of opportunities, female migration rose predominantly as a response to labor demands, much in a manner that had been true for the men before (Hondagneu-Sotelo 1999; Lee 1996). Once again, in evident contradiction to the large participation of females in migratory movements, few studies or 
publications were produced taking into consideration the particular experiences of female migrants.

However, a shifting trend in scholarship is found through a review of the sociological research about gender and migration in the late- and post-1970s. We see a move toward understanding how gender fundamentally organizes social relations and structures that influences the causes and consequences of migration (Curran et. al. 2006). The rise of the feminist movement in the early 1970s and the increasing numbers of women joining the formal labor force at the same time contributed to including the study of migratory movements of women into academic discussion. Since then, women migrants became a focal point of discussion in scholarship on how gender operates via migration (Hondagneu-Sotelo 2003; Grieco and Boyd 2003). Not only did this new scholarship study migrant women in relation to their home and host societies, they also examined how immigrant women became either economically independent actors, or migrated as dependents of their family, which in most cases were their husbands. This was a phase when academic scholarship "added women and stirred" to their discussion, overlooking the male migrant almost entirely (Hondagneu- Sotelo 2003).

A little later in the early 1980 s, while many feminist migration researchers documented the experiences of female migrants, some authors developed migration studies using "gender" as the variable "sex," producing male versus female comparisons. As recent scholars note, researchers around that time used quantitative data with "sex" as one of many independent variables for their analyses (Foner 2003; Hondagneu-Sotelo 1999; Hondagneu-Sotelo and Cranford 1999; Mahler and Pessar 2006; Massey 1987). 
Although the reduction of the complex concept of "gender" to the variable "sex" was a far cry from studying the concept of gender, there was a positive effect. Neither males nor females were left out of major studies and thus their experiences could be systematically compared. Therefore, although this research served to improve upon the hitherto male-only studies, there was still the need to develop a more comprehensive study of gender and migration.

The 1980s also marked the inclusion of the female into migration theory; up until this point, once again, most attention was paid to men and men were presumed to move for economic reasons. That stifled theorizing in many ways until feminist scholars argued that migration needed to be understood in broader terms than just individuals. They produced an alternative approach-- the Household Theory, or the New Economics of Migration. The Household Theory brings forth larger units of analysis such as the family and the household. The decision to migrate is thus taken as the result of a socioeconomic analysis that allows the migrants to maximize their expected total income and hierarchical status and also to minimize their potential risks through the diversification of members' income-producing strategies (Massey 1999). The proponents of the Household Theory argue that decisions to migrate are linked to socio-cultural processes developed within the household unit and were not just individual cost-benefit calculations (Georges 1992). The shift in unit of analysis from individual to household necessitated examining women even if they were not the ones migrating. They were still key participants in decision-making processes. 
The decade of the 1990s shifted focus toward understanding migration dynamics by employing more qualitative methods. Research also extended beyond household boundaries and included examining employment dynamics of migration, and role of the state and its relation with migrants (Espiritu 1999; Constable 1997; Hondagneu-Sotelo 1992, Lee 1996; Sassen 1988; Tyner 1999). The Mobility of Labor and Capital by Saskia Sassen (1988) deserves special mention in this regard as one of the pioneering works to identify globalization as feminized and the increasing feminization of migration. A growing collection of studies also demonstrates the wider set of community and civil society associations that are influenced differently by men and women migrants and that also differentially affect men and women migrants' destination experiences (Levitt 2001).

By the mid-1990s, then, research had moved decisively away from "women only" or "men only" and shifted towards studying gender, thus resulting in simultaneously studying men and women migrants and their interactions (Curran et al. 2006). Some of the significant publications around this time argued effectively to include gender and household dynamics in migration research. They continued to challenge "the longstanding assumption that women were part of an equitable set of relationships guiding household decisions about migration" (Curran et. al. 2006: 202). Along with a growing collection of studies analyzing civic and community engagements that were being influenced differently by men and women migrants, this compelled scholars to study gender as manifested through sustaining cross-border kin relationships and transnational lifestyles (Hondagneu- Sotelo 1992; Mahler 1999; Mahler and Pessar 2001, 2006). 
The task of "bringing gender in" to migration studies that was pioneered in the 1970s and strengthened in 1980s came up against an unexpected turn of events when in the 1990s scholars argued for a more transnational than unidirectional approach to migration studies but did not argue explicitly that gender be part of this analysis though they did include race, class, and nation. Other scholars argued for gender's central inclusion in the transnational paradigm (Hondagneu-Sotelo 1994, 2003; Mahler and Pessar 2001; Pessar 1999; Pessar and Mahler 2003). This new phase of "bringing gender in" to migration studies also coincided with the shift in focus to understand migration dynamics by employing qualitative methods in the decade of the 1990s (discussed above). By the mid-1990s, research shifted towards studying gender, thus resulting in simultaneously studying men and women migrants and their interactions (for example, see Boehm and Castellanos 2008; Donato et al. 2006; Hirsch 2003; Hondagneu-Sotelo 1994, 2003; Mahler and Pessar 2001; Pessar 1999; Pessar and Mahler 2003). This trend of emergent research on what I term "gender in motion" is also informed by a transnational feminist lens (see, for example, Alexander and Mohanty 1997; and Grewal and Kaplan 1994). The transnational feminist approach extends the gender and migration scholarship by focusing specifically on colonial and postcolonial processes.

On the whole, and as is evident from Mili and Rahul's experiences that this chapter introduced, living transnationally often provokes reorganization of gendered patterns within the family, giving rise to new gendered geographies of power in family and marriage. Most literature in this regard, however, leaves out much if not most of the "extended" family in its analysis of these reorganizations. This dissertation, conversely, locates the extended family prominently in its analysis because these family members 
continue to be involved in family and spousal relations even when couples migrate overseas This raises critical questions, especially for the couple, of balancing gender norms, ideologies, and relations in family and marriage across two or more sociocultural contexts (home and host society). The inclusion of transnational extended family influences in the dynamics of spousal relations challenges many normative, often unstated; understandings of spousal relations being limited to the dyads of husband-wife., Moreover, these dynamics should be examined with historically contingent, fluid measures.

Given the complexity of the scenario to be analyzed even if for a small set of families living transnationally, what theory tools of analysis are most useful to developing and sharpening a nuanced gendered optic? In this dissertation, I have used two analytical frameworks in examining gender relations amid transnational Bengalis across multiple geographic scales and in various timeframes. My first analytical inspiration comes from Mahler and Pessar's theoretical framework entitled Gendered Geographies of Power. The second analytical framework that informs my "gendered optic" in this dissertation is Boundary Work. I now proceed to discussing in details about these two theoretical frameworks that inspire and inform my "gendered optic".

\section{Theoretical Frameworks}

\section{Gendered Geographies of Power (GGP)}

Gendered Geographies of Power as a theoretical framework was developed by anthropologists Sarah J. Mahler and Patricia Pessar to improve the analysis of gender 
transnationally, particularly with regard to migration (Mahler and Pessar 2001, 2006;

Pessar and Mahler 2003). Quoting Pessar and Mahler (2003:818),

"Gendered geographies of power" is a framework for analyzing people's gendered social agency - corporal and cognitive - given their own initiative as well as their positioning within multiple hierarchies of power operative within and across many terrains... The gendered geographies of power framework is intended to aid case and comparative study research and analysis of gender (and its articulation with other socially constructed identities) across transnational spaces.

Gendered Geographies of Power is composed of three primary concepts (Pessar and Mahler 2003):

(1) Geographic scales - Geographic scales offer a spatially fluid framework to understand that gender operates at many analytical scales simultaneously - spatial and social (such as national, local and body, family, state, etc). In this dissertation, I apply geographic scales to understand how gendered geographies emanate from and are negotiated across various significant scales, particularly the nation and the family, historically, contemporaneously, and transnationally.

(2) Social locations - This refers to the individual's position within the interconnected power hierarchies characterizing relations across the geographic scales. Such interconnected power relations can be created by multiple stratifying factors - history, politics, economics, geography, kinship relations, etc. Social locations are often but not always ascribed at birth; they are also acquired through life circumstances and opportunities, leading to different advantages and disadvantages. This gives social locations their dynamism - they are fluid, changeable and multiple. At any given time each can be plotted along a continuum from most disadvantaged to most privileged. This 
component is helpful to socially locate people by class, race, sexuality, ethnicity, nationality, and age - all of which are important parameters to understand how, in this research, Bengalis have negotiated their social location historically and do so currently. For instance, in colonial Bengal (Chapter Three), Bengali men were privileged vis-à-vis Bengali women (gender) but not vis-à-vis the British (class and ethnicity).

(3) Agency - The third component, agency, is closely related to cultural geographer Doreen Massey's (1994) “power geometry." Massey (1994) argues that the time-space compression of particular conditions of modernity impacts people's geographic and social location, and therefore, in distinct ways, their relations to flows, movements, and interconnections. It does not necessarily involve people's physical movements but more about their networking and interconnectedness and access to, or away from, resources and, therefore, power. Similarly, Pessar and Mahler (2003) also argue that people exercise different types of agency typically depending on their social locations at a given point of this time-space compression. Such exercising of agency is not limited to people who physically migrate, but encompass non-migrants too, and all other actors who take part in the flow and movement thus initiated. Additionally, a person's social locations affect but are not determinant of their agency; rather, they may act in ways that are not typical of people who occupy similar social locations.

Overall, the GGP framework is very useful for the viewing and analyzing gender, power agency in transnational and migration studies. GGP also considers elements and concerns of both agency and structure that allow the possibility of its use within historical and contemporaneous process too. Therefore, I use the GGP framework to examine and 
understand the experiences of Bengali women and men as they negotiate their social location historically and transnationally. The authors of the GGP framework also include in their framework, the role of imagining, or of cognition, that affects individual's social locations and power relations. Therefore, the GGP framework is not only useful in gender, transnationalism, and migration scholarship, it also provides with a methodological lens for comparative research on gender across transnational spaces.

It is important here to note that while I have used the GGP framework in this dissertation to examine dynamics at the macro and meso levels, I have also used it as an adapted framework -- as a micro lens -- to examine dynamics at the micro levels. For example, I have used the original GGP framework en route to examining gender relations at the macro levels of the nation or while analyzing specific time-periods as GGPs. However, my adapted usage of the framework is distinctive from the original framework when I have examined micro level dynamics such as within families and between spouses using the GGP framework. On the whole, my engagement with the GGP framework contributes to the scholarship of intersectionality theory by rendering a scalar analysis. By engaging in analyzing gender dynamics across multiple geographic scales, this dissertation therefore brings GGP closer the scholarship on intersectionality and makes the study of intersectionality more scalar. This is particularly helpful because the analysis examines how gender relations, specifically spousal relations, within the family are sustained across borders, often resulting into conflicting interests and are under constant stress as the actors often transgress gendered boundaries. This also brings me to my second analytical tool, Boundary Work. 


\section{Boundaries and Boundary Work}

Boundaries, like motion, are a constant feature of our world. In her very recent study on how the human brain constructs and comprehends boundaries, Mahler (2013) argues that we are not born knowing the sociocultural categories that organize our group's way of life. We learn these categories and to learn them involves figuring out the boundaries between categories (such as male/female; native/immigrants, etc). Mahler (2013) argues that without any awareness that they are doing this work, infants and young children search for these social regularities or patterns by interacting with others and then proceed to use them to interpret others' actions and to act and think appropriately. We thus grow up silently assuming that what is normal and natural for us is also the same for others (for details, see Mahler 2013). However, when we encounter difference, our minds activate and we respond by doing one or more forms of Boundary Work.

The birth of Boundary Work in scholarship primarily arose out of studies based on race and ethnicity. The concept of Boundary Work is increasingly being used for understanding human behavior in motion - migration, assimilation, acculturation, etc. (for details, see Alba [2005], Wimmer [2008] and Zolberg \& Long [1999]). The emphasis on boundaries has been found to be useful because it is their persistence through praxis, (that is, through the work of setting and maintaining boundaries and even of transgressing) that has ensured the continuation of social divisions. Lamont and Molnar (2002) in their comprehensive overview of scholarly literature in the social sciences emphasizing boundaries have devised a distinction between "symbolic" and "social" boundaries. This 
distinction, Lamont and Molnar argue, encapsulates a thread that runs through the entire literature on boundaries. Symbolic boundaries, they assert, consist in "conceptual distinctions made by social actors to categorize objects, people, practices, and even time and space...Social boundaries are objectified forms of social differences manifested in unequal access to and unequal distribution of resources (material and nonmaterial) and social opportunities" (Lamont and Molnar 2002: 168). Thus symbolic boundaries are the ideas that people have about phenomena that guide the ways in which they go about actually categorizing them. When these conceptual distinctions are widely shared and practiced they translate into rigid, systematic, and carefully patrolled patterns of social exclusion and inclusion.

In my dissertation, I employ the idea of symbolic boundary and Boundary Work primarily as gendered Boundary Work - as people create, navigate, and negotiate their gendered ideas and expectations in family and marriage. As will be discussed in the later chapters, gendered boundaries amid the Bengali population can be found in a deeply rooted history, a colonial legacy, and one, although repackaged, that continues to be seen contemporaneously. The Boundary Work framework in this dissertation helps in understanding the negotiation of power and agency in family and marriage in general and transnationally in my case study. I apply the Boundary Work framework in this dissertation because it aids in uncovering the efforts which people make to construct and maintain boundaries, in order to establish and negotiate their social locations purposefully. 
The GGP and Boundary Work frameworks together form my "gendered optic" in this dissertation. I have applied this optic to my ethnographic data generated from over ten months in India and in the U.S. The results I have found shed light on the gendered geographies of family and marriage amid Bengalis specifically, and, by extension, Indians, and the Boundary Work that they engage in to do so. My field data also reflect how, through ethnography, I have been able to capture the historical progression of a series of interesting strategies that Bengalis implement, through gender, to negotiate their social location.

\section{A Note on using Transnational as a Concept}

Finally, it is important at the outset to clarify what I mean when I refer to my informants as "transnational." In the context of this project, I use the term "transnational" to signify three specific meanings. First, I use the term "transnational" to describe the scope of the lifestyle of my informants. In cultural anthropology until the 1960s, the term "transnational" was often understood as multi-sited experiences of corporate structures that spanned national boundaries (Glick Schiller et al, 1995). By the 1970s, "transnationalism" became more fluid and described practices and institutions that superseded or were unconstrained by the nation-state. However, as scholars argue, migrants have always crossed borders, but ideas of declining hegemony of the nationstate emerged in the migration literature and scholarship turned towards examining continued ties of migrants with their homeland through new ways. This new lens to examine transnational migrants found voice in several books and articles in the early 1990s, including the pioneering works of Glick Schiller and colleagues. These scholars 
suggested that this avenue of scholarship identified "a new process of migration" and that immigrants might be "best understood as transmigrants" (ibid.1995:48). By contrasting migrants' lives that stay vitally connected to people, practices, and institutions of their homeland against the trope of "the uprooted" (Handlin 2002: 5-6), they framed these persistent connections as a trend that had not been sufficiently acknowledged let alone examined in scholarship to that point. Further, Glick Schiller et. al. (1995) suggested that these enduring ties challenged the existing global order dominated by nation-states, instead arguing that social structures need not be bound to political structures, even as they are shaped by them. This vein of scholarship has emphasized the distinction between assimilative tendencies and the structures that support enduring connection to the homeland. Immigrants who participated, whether through travel, commerce, religious affiliation, remittances, or simply interpersonal communication - in activities that crossed national boundaries were seen as a challenge to the nation-state. Given equivalence to a grassroots political movement, immigrant cross-border activity was described as "transnationalism from below" (Smith and Guarnizo 1998; see Mahler 1998: 66-73 for further discussion on this). Advocating for this expanded view of immigrants' lifestyles, Glick Schiller, Basch, Szanton Blanc (1995: 48) explain, "Transnational migration is the process by which immigrants forge and sustain simultaneous multi-stranded social relations that link together their societies of origin and settlement. In identifying a new process of migration, scholars of transnational migration emphasize the ongoing and continuing ways in which current-day immigrants construct and reconstitute their simultaneous embeddedness in more than one society." Following these scholars, I too 
understand "transnational" to be a broader, more comprehensive and nuanced approach, one including migrants' "position, experience, or situation" (Boehm 2012: 6).

Second, I invoke the term "transnational" to denote my use of a method that examines the connections and relationships between different places and cultural contexts, rather than a descriptive approach to describe and analyze commonalities and differences between them (e.g. Radhakrishnan 2011). For example, by adopting the transnational lens, I do not attempt to compare commonalities and differences between cultural practices in Bengal versus those in the United States. Instead, I analyze relationships between people and the places that they live in, including their transnational "social field," that is distinguishing between their ways of being and their ways of belonging in that field (Levitt and Glick Schiller 2004), and the gendered geographies that they produce or reify in them. Transnational social fields, scholars argue, can also be sites of negotiating status amid migrants and their families. For example, Luin Goldring (1998) concluded that the Mexican transmigrants she studied participate in the modification of their social landscape including the ways they are themselves perceived and the image of their ethnic group as well. Goldring attests (1998: 167), "Transnational social fields, and localities of origin in particular, provide a special context in which people can improve their social position and perhaps their power, make claims about their changing status and have it appropriately valorized, and also participate in changing their place of origin so that it becomes more consistent with their changing statuses and expectations." More recently, scholars understand transnational social spaces as being fluid but not amorphous since they do have form, and not restricted to just home and host societies (George 1992; Levitt \& Jaworsky 2007; Mahler 1999; Mahler and Pessar 2006; 
Smith 2005). Moreover, transnational social fields are not limited to migrants only; transnational experiences are shared amongst migrants and non-migrants together because even though the latter do not physically migrate, they do occupy transnational social spaces through the flow and movements of people, money, and "social remittances" (i.e. ideas, norms, practices, and identities) (Levitt 2001; Levitt and Jaworsky 2007). Migrants therefore are constantly creating and maintaining social relations and renegotiating their gender relations and ideologies despite physical or geographic distances (Schiller et al 1992; Georges 1992; Sutton 1992; Mahler 1999, Mahler and Pessar 2006). Although debates around levels of analysis for transnational migration have been ongoing, a majority of the scholars have argued for a broader approach that encompasses social, cultural, religious, and all other formal and informal practices that establish cross-border connections and impact transnational migration (Mahler 1999; Mahler and Pessar 2006; Smith 1993, 2006). For Asian-Indians, like many Latin American migrant groups in the U.S., family is the essential unit that structures their social relations, including those that span national borders and are negotiated in the transnational spaces (Mehrotra and Calasanti 2010; Rangaswamy 2000; Uberoi 1993). Because of this, a family-centered approach to the transnational activities and relationships of Asian-Indian immigrants can be argued as a methodological orientation of this dissertation.

Finally, I choose "transnational" for analytic purposes, as a conscious choice over the term "global." Although "global" is often used in popular media and corporate contexts, in the context of scholarship, the meanings assigned to ideas of the global are often divergent and vague, offering little in the way of academic foundation (Moore 
2004). In some of the most important scholarly engagements related to globalization, the "global" refers to multiple things, most often a realm of interaction that is juxtaposed against the "local" (Castells 1997). When the notions of the "global" are mapped onto empirical contexts, however, it becomes difficult to designate in a rigorous way which practices are produced in the realm of the "local" and which are produced in the "global" (Burawoy et al. 2000; Hart 2002; Radhakrishnan 2011). In scholarly treatments of the term, "global" is often meant not just to transcend national borders, but also to presume such borders to be relatively unimportant (Appadurai 1996: 158 -77; Radhakrishnan 2011). During our interviews, my interviewees have most readily embraced and identified with the power of transcendence in transnational spaces but attaching meaning to the boundaries --regional, national, international, and conceptual. Therefore, in choosing the "transnational" lens, I underscore my interest in this transcendence and one which often produces a cognitive transnational space or a "social field" within which a shared sense of cultural belonging is constructed and reified.

I have intentionally introduced this chapter and my dissertation with a vignette, Mili and Rahul's transnational experiences in family and marriage, because the vignette is an exemplar of the voices and narratives that I have collected for this dissertation. In this chapter, further, I have examined the central concept in this dissertation, gender, and particularly the current engagements with gender in migration and transnational migration scholarship. Finally, I have identified my theoretical lenses or my "gendered optic" which I will be using throughout this dissertation. Having explicated my use of the transnational lens, as location and concept, and as one inflecting gender relations, I now 
turn to my next chapter where I examine the ethnographic research methods that I have conducted for this research. 


\section{CHAPTER II - RESEARCH METHODS}

The primary research methodology guiding this study is Grounded Theory

(Corbin and Strauss 1998). In Grounded Theory, data collection and analysis are meant to occur interchangeably and inform each other throughout the course of the research. More specifically, the principle of "theoretical sampling" (Corbin and Strauss 1998: 73, see below for discussion) dictates that, depending on the theoretical insights that emerge in the course of the analysis, the researcher looks for new data at places, people or events expected to maximize the findings' conceptual variation. Collection stops when further sampling is not expected to widen the range in variation already found in the data. In the case of the present research, events (i.e. festivals, religious ceremonies, and community and private gatherings) and people (i.e. spouses and their family members) were selected at the outset and according to the rationale I explain below. The possibility of sampling theoretically and altering or expanding the data pool remained open throughout the course of data analysis. The data collected proved sufficient, however, to produce useful and saturated conceptual categories, such that further sampling and collection did not become necessary.

Given the study's goal to capture as wide a range as possible of the ways that extended family are important to couples' lives transnationally, and also how people attach meanings of social hierarchy to their social locations, I set out to maximize my sample in terms of people's social attributes, contexts and experiences. In other words, I have collected a multiplicity of views corresponding to people's diverse "social 
location[s]" (Mahler and Pessar 2001: 445) - historically, contemporarily, and transnationally.

The following overarching questions have structured this research:

(1) Given the fact that extended family involvement in spousal relations is normative to Indian-Bengalis, does the extended family continue to factor into IndianBengali migrant couples' negotiations of gender and spousal relations in the United States and, if so, why? And,

2a. Does the fact that their transnational lifestyles exposes Indian-Bengalis to wide contrasts in norms and practices regarding gender and marriage relations provoke a redefinition of these relations while they live abroad, and, if so, how and why?

2b. How do "family" ties figure in this redefinition?

However and in addition, in order to reflect on the above questions effectively, I also included another question which helped me approach the abovementioned main questions more accurately:

3a. How do Indian-Bengalis, both living in the U.S. and in India, conceptualize the "family?"

3b. Who belongs in the "family" and what are their rights and obligations vis-àvis each other and, in particular, toward spouses?

In the pursuit of answers to these questions, I have employed diverse ethnographic methods in this research. Semi-structured, in-depth interviews (discussed 
below) make up the majority of my ethnographic data. In addition to interviews, I have conducted document and archival research, such as analyzing wedding albums and marriage memorabilia. I have also engaged in content analysis of various matrimonial websites, and have analyzed data from my field participant observation. In Table 2.1 (below), I give a synoptic view of my data sources for my respective research questions, and the analysis that I have engaged in for each of the questions. Data collection, particularly the interviews, occurred in Bengali and English and they were analyzed in both languages by myself-someone fluent in both Bengali and English. Whenever I reference quotations from the data rendered in Bengali for this dissertation, then, I have done the translations myself. On occasion when there might be various subtle differences in translation, I provide terms or short quotations in their original Bengali as well as in translation.

Table 2.1: Research Questions, Data Sources, and Data Analysis

\begin{tabular}{|c|c|c|c|c|}
\hline $\begin{array}{l}\text { Research } \\
\text { Questions }\end{array}$ & & Data Sources & & Data Analysis \\
\hline $\begin{array}{l}\text { 1. Given the fact } \\
\text { that extended family } \\
\text { involvement in } \\
\text { spousal } \\
\text { relations is normative } \\
\text { to Indian-Bengalis, } \\
\text { do they factor into } \\
\text { Asian Indian-Bengali } \\
\text { migrant } \\
\text { couples' negotiations } \\
\text { of gender and } \\
\text { spousal relations in } \\
\text { the United States } \\
\text { and, if so, why? }\end{array}$ & 2. & $\begin{array}{l}\text { Field Observation } \\
\text { - Cultural events and } \\
\text { gatherings in South } \\
\text { FL and in Kolkata } \\
\text { - Rituals and } \\
\text { Festivals } \\
\text { - Private gatherings } \\
\text { Interviews - } 42 \text { in total } \\
\text { - } 16 \text { interviews from } \\
\text { spouses ( } 8 \text { couples) } \\
\text { - } 26 \text { interviews from } \\
\text { family members of } \\
\text { couples }\end{array}$ & 2. & $\begin{array}{l}\text { Analytic notes (Corbin and } \\
\text { Strauss 2008) } \\
\qquad \text { Memos } \\
\text { • Themes } \\
\text { • Word Frequencies } \\
\text { Inductive (open) and } \\
\text { deductive coding (Ryan and } \\
\text { Bernard 2003; Corbin and } \\
\text { Strauss 2008) }\end{array}$ \\
\hline
\end{tabular}




\begin{tabular}{|c|c|c|}
\hline $\begin{array}{l}\text { 2a. Does the fact } \\
\text { that their } \\
\text { transnational } \\
\text { lifestyles exposes } \\
\text { Indian-Bengalis to } \\
\text { wide contrasts in } \\
\text { norms and practices } \\
\text { regarding gender and } \\
\text { marriage relations } \\
\text { provoke a } \\
\text { redefinition of these } \\
\text { relations while they } \\
\text { live abroad, and, if } \\
\text { so, how and why? } \\
\text { 2b. How do "family" } \\
\text { ties figure in this } \\
\text { redefinition? }\end{array}$ & $\begin{array}{l}\text { 1. Interviews - } 42 \text { in total } \\
\text { - } 16 \text { interviews from } \\
\text { spouses ( } 8 \\
\text { couples) } \\
\text { - } 26 \text { interviews from } \\
\text { family members of } \\
\text { couples } \\
\text { 2. Field Observation } \\
\text { Events in South FL and } \\
\text { in Kolkata } \\
\text { - Cultural } \\
\text { gatherings } \\
\text { - Rituals and } \\
\text { Festivals } \\
\text { - Private } \\
\text { gatherings }\end{array}$ & 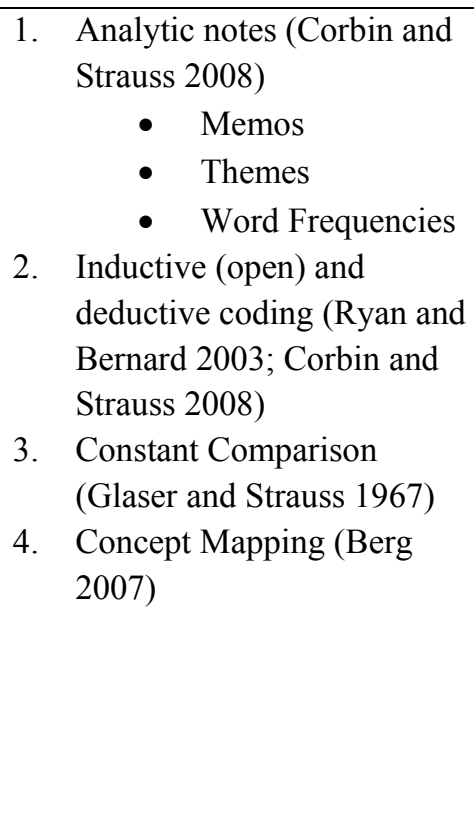 \\
\hline $\begin{array}{l}\text { 3a. How do Indian- } \\
\text { Bengalis, both, those } \\
\text { living in the U.S. and } \\
\text { in India, } \\
\text { conceptualize the } \\
\text { "family?" } \\
\text { 3b.Who belongs in } \\
\text { the "family" and } \\
\text { what are their rights } \\
\text { and obligations vis- } \\
\text { à-vis each other and, } \\
\text { in particular, toward } \\
\text { spouses? }\end{array}$ & $\begin{array}{l}\text { 1. Websites } \\
\text { - Matrimonial } \\
\text { - Other Cultural } \\
\text { Websites } \\
\text { 2. Field Observation } \\
\text { - Cultural events and } \\
\text { gatherings in South } \\
\text { FL and in Kolkata } \\
\text { - Rituals and } \\
\text { Festivals } \\
\text { - Private gatherings } \\
\text { Archival and } \\
\text { documentary research, } \\
\text { such as wedding } \\
\text { albums, memorabilia } \\
\text { examined during pilot } \\
\text { study } \\
\text { 4. Life stories } \\
\text { Interviews - } 42 \text { in total } \\
\text { - } 16 \text { interviews from } \\
\text { spouses (8 couples) } \\
\text { - } 26 \text { interviews from } \\
\text { family members of } \\
\text { couples }\end{array}$ & $\begin{array}{l}\text { 1. Analytic notes (Corbin and } \\
\text { Strauss 2008) } \\
\text { - Memos } \\
\text { - Themes } \\
\text { - Word Frequencies } \\
\text { 2. Inductive (open) and } \\
\text { deductive coding (Ryan and } \\
\text { Bernard 2003; Corbin and } \\
\text { Strauss 2008) } \\
\text { 3. Constant Comparison } \\
\text { (Glaser and Strauss 1967) } \\
\text { 4. Concept Mapping (Berg } \\
\text { 2007) }\end{array}$ \\
\hline
\end{tabular}




\section{"Finding the Voices:" Sampling Strategies}

In this section, I explain the sampling strategies that I have used for this research. I have used multiple snowball sampling to recruit my subjects. Specifically, I have adopted two sampling strategies in this project: (a) Convenience Sample; and (b) Theoretical Sampling. Convenience samples, also known as "availability" samples (Babbie 1998; Mutchnick and Berg 1996), rely on available subjects - those who are close at hand or are otherwise available. Under certain circumstances like in this case where the population parameter is not known and thus random sampling is not possible, convenience sampling can prove to be an excellent means of obtaining valuable and reliable information (Berg 2007). Convenience sampling enabled me to be attentive to expanding heterogeneity. Although not always guaranteed, but convenience sampling, as Handwerker and Wozniac (1997) argue, can maximize the likelihood of capturing the heterogeneity by starting different convenience samples. Following this principle, I collected data from multiple field sites, South Florida (U.S.) and Kolkata (India), to help maximize informants' heterogeneity within them.

The Bengali community in South Florida has deep roots dating back to 1968 . Their reasons for migrating to the U.S., specifically Florida, include either higher education or high-skilled professional employment. In 1990, they formed a cultural association, the Bengali Association of South Florida (BASFL). Over the years, BASFL has been extremely active culturally, religiously, philanthropically, and socially, contributing to various institutions of society. Most Bengalis belonging to this group are 
highly-skilled migrants employed either by the government or in private sectors, and also are one of the most highly educated groups in South Florida.

The other research site - Kolkata or Calcutta - is considered to be the cultural capital of India. Kolkata is a city with a prolonged colonial history and a city that lives simultaneously in its past and present. Founded in the late seventeenth century by the English East India Company during the British colonization period in India, Kolkata (Calcutta as the city was then named to be) was the capital of India until 1911. The city had been in the forefront of the Indian freedom movement in the twentieth century, and has subsequently found innumerable references in historical and modern literature and films. Liberally described as the "Paris of the East," Kolkata is well-known to the rest of India as a city of art, culture, and literature. Noted for its revolutionary history, Kolkata continues to be the hub of culture, education, and the "middle class intelligentsia" (Chapter Two). I have traced the relatives/family members of Bengali spouses in South Florida to Kolkata and have conducted semi-structured interviews with them also.

Data has also been collected from various internet websites. Also, some interviews were conducted through the internet, particularly through Skype voice chat, and emails.

Methodologically, I identify the principles of convenience sampling with the research design proposed by W. Penn Handwerker and Danielle Wozniak (1997). As Handwerker and Wozniac (1997) validated experimentally, convenience samples that reflect the heterogeneity of the population's demographic traits, life experiences and social contexts yield identical findings with random samples. Clarence Gravlee (2005) 
also argued that data sources and informants must be selected to maximize heterogeneity in areas key to the study underway.

Another lead for being attentive to sample heterogeneity in this research can be found in what George E. Marcus (1995) described as "multi-sited ethnography" (Marcus 1995: 95; also see Boehm 2012). In analyzing the benefits that multi-sited ethnography can offer to maximize heterogeneity in research, Marcus (1995: 102) notes,

In projects of multi-sited ethnographic research, de facto comparative dimensions develop instead of a function of the fractured, discontinuous plane of movement and discovery among sites as one maps an object of study and needs to posit logics of relationship, translation, and association among these sites. Thus, in multi-sited ethnography, comparison emerges from putting questions to an emergent object of study whose contours, sites, and relationships are not known beforehand, but are themselves a contribution of making an account that has different, complexly connected real-world sites of investigation. The object of study is ultimately mobile and multiply situated, so any ethnography of such an object will have a comparative dimension that is integral to it, in the form of juxtapositions of phenomena that conventionally have appeared to be (or conceptually have been kept) 'worlds apart.'

Following this principle of establishing a comparative relationship between the actors and cultural practices that they perform in transnational spaces, I conducted multi-sited ethnography, focusing particularly on the two metropolitan hubs discussed above and which are transnationally tied. 


\section{Sample Recruitment Strategy}

Using the multiple snowball recruitment strategy, I located members of the Bengali migrant population in Miami-Dade and Broward counties in South Florida, and requested that recruited participants refer me to those friends and acquaintances who fit the description of the target population. Following Corbin and Strauss' (2008) principle of theoretical sampling, I also recruited informants suited to address questions that emerged from the data as it was being collected. Specific characteristics emerging as salient to conceptualization of spousal relations and extended family, such as changing power relations between spouses or between one spouse and a family member, have prompted me to seek out informants who can speak more directly to these issues, and who were also available for multiple rounds of interviews.

\section{Sample Size}

Evidence gathered during my pilot study in the first phase (discussed below) was valuable for me to understand how informants conceptualized who constituted their extended family members, and therefore determine the sample size. The pilot study also enabled me to conceptualize the "stretch" of data that I needed to gather from multiple family members for this research. Typically, approximately 30-50 interviews are standard for ethnographic fieldwork in order to achieve data saturation (Morse 1994; Bernard 2006). Following this principle, I had anticipated to focus my research on at least a halfdozen couples, interviewing each spouse individually and their extended family to yield the standard number of interviews. However, during my fieldwork, I benefited from strong interest and cooperation from my informants and thus was able to interview more 
couples than I had originally anticipated. I interviewed eight (8) couples in South Florida, and then traced their family and extended family who live in Kolkata and interviewed them. In total, I interviewed forty-two (42) people. In the following table (Table 2.2), I provide an overview of my interview-respondents:

Table 2.2: Interviews distribution by source, location and language

\begin{tabular}{|c|c|c|c|c|c|}
\hline Interviewees & $\begin{array}{l}\text { Number of } \\
\text { Interviews }\end{array}$ & \multicolumn{2}{|c|}{ Location } & \multicolumn{2}{|c|}{ Language } \\
\cline { 3 - 6 } & & U.S. & India & Bengali & English \\
\hline Female & $\begin{array}{l}24(57 \% \\
\text { of total } \\
\text { interviews) }\end{array}$ & 8 & 16 & 9 & 15 \\
\hline Male & $\begin{array}{l}18(43 \% \\
\text { of total } \\
\text { interviews) }\end{array}$ & 8 & 10 & 5 & 13 \\
\hline TOTAL & $\begin{array}{l}42 \text { (100\% } \\
\text { of total } \\
\text { interviews) }\end{array}$ & 16 & 26 & 14 & 28 \\
\hline
\end{tabular}

My interviews were guided by semi-structured, thematic interview protocols (Bernard 2006, discussed below) informed by Research Phase I (below). Following my data analysis in Phase I, I narrowed down the family and extended family members for each couple to include the parents of both spouses and at least three other family members who may or may not be connected to the couple by blood or by marriage. For example, while interviewing couples in South Florida, in over 70\% cases, informants referred to close friends or even their boss or supervisors at work to be their "family." However, while conducting my fieldwork, I realized that getting the full panorama of the family that the informants conceptualized and described, that is interviewing all the 
family and extended family members for every couple, is an utopian idea in my original research design. Therefore, for practical purposes, I interviewed the couples in South Florida first. Then, following their lead to direct me towards their family members, I interviewed their family and extended family members in Kolkata. Also, with extended families, the number of narratives to include could overwhelm a researcher's ability to interview all.

\section{A Note on My Research Population}

In choosing my research project, I have been keenly aware that one of the biggest challenges of researching Indian cultural practices, such as those related to marriage practices, and relationships inflected by them, is the very diversity that defines the country. A variety of languages and cultural practices define this diversity too. Given the nature and purpose of this project described in Chapter One, therefore, the question of whom to interview and why, is of utmost importance. My fluency in Bengali, and my cultural familiarity with this group enabled me to choose the Bengalis as an apt population for the purposes of this dissertation. The Bengalis are a widely acknowledged cultural and linguistic group native to the region of eastern South Asia known as Bengal, which comprises Bangladesh and the Indian state of West Bengal. Historically and contemporaneously, they are one of the widely acknowledged migrant groups to the U.K and the U.S. As I will analyze in my following chapters, the gendered geographies of this cultural group are deeply rooted in its pre-, colonial, and post-colonial histories.

To be clear and concise, in this dissertation, I am studying the lives and experiences of transnational Indian Hindu middle-class urbanized Bengali married 
couples living in the United States and their family members living in India. I am studying them not as a homogenous group (which they are not) but (1) as a group that has been constructed socially, historically, and culturally as if they were homogenous, and (2) within the broader dynamic of transnational extended families (for example, see Gardner 2002). "Middle-class" in this case refers to a rather amorphous socio-economic group covering a fairly large category including some families owning property while some do not. Therefore I group them, but not to homogenize their lived experiences owing to their similar historical, cultural, economic, and religious backgrounds. What is clearly homogeneous in this group, however, is a cultural assumption shared by them attaching a high signifier and status to advanced education, salaried professions, and transnational lifestyles. All three categories-- education, profession, and transnational lifestyles-emerged in my research as important indicators of socio-economic status for the Bengalis. These will be discussed at length in my data chapters.

\section{Choosing Representational Voices and Stories}

A natural corollary that follows sampling from a population and studying them is the representativeness of the data. The obvious question in "telling the story" now becomes: Whose voice(s) and experiences will I choose to narrate the story? Scholars such as Laurel Richardson (1990: 39) caution qualitative researchers in this respect. She warns that, "Deciding how to present voices and lives is a continuous problem for qualitative writers. Because we use the voices and experiences of the people we study, both for their own sake and as evidence of our credibility, we are constantly making writerly decisions about who gets to say what and how often in the text, and who the 
narrator talks about, how and how often." For the past three decades, qualitative scholars have answered the above question (Whose Voice?) in various ways: analyticdescriptions, narrative unfolding, and sociobiography (Warren and Karner 2010).

Following the principles laid out by these scholars, in this dissertation, I adopt the popular approach to writing qualitative research, i.e., analytic-description. With this approach, the main theme and its subthemes are developed from ethnographic, interview, visual, or documentary data. Following this principle, I have analyzed my ethnographic evidence and identified major themes and their subthemes. I have used these data to illustrate the analysis descriptively. I illustrate this data analysis process further below in my data analysis log diagram (Figure 2.6). There are two rhetorical devices that can be used in the analytic-descriptive approach to representing the data: (i) the typology or the continuum, a kindred idea of what anthropologist Clifford Geertz (1988: 78) described as "I-witnessing"; and (ii) placing the people studied at the center of the analysis (Warren and Karner 2010). Given the nature, scope and purposes of this dissertation, I have adopted the second device in my analytic-descriptions throughout this dissertation. This device, i.e., placing the people studied at the center of the discussion, can again have two components: (a) individual sociobiographies, or (b) the collective story (Richardson 1990, 2007; Warren and Karner 2010). Following the principles of individual sociobiographies, I have presented each person's or couple's story wherever it is most applicable in my chapters, and have then analyzed separately. That is, I use the data that most closely and clearly reflects the pattern under discussion. Next, following every individual sociobiography, I have connected each of the stories within a coherent social context, one that can become a collective story. The collective story uses an analytic 
chronology. That is, the common elements to each individual's story are used to frame the collaborative or joint accounting. I accomplish this task by first narrating the individual sociobiography and then linking it to the larger collective by substantiating via percentage it represents to the whole how often that theme or narrative arose in the interviews and in my analysis. The weaving of individual voices together to tell a collective story, scholars argue, can be a powerful mode of representation (see for example Duneier 2000; Venkatesh 2008).

\section{On Anonymity}

While I do use the real names of my research settings and sites, I do not reveal the names of my interviewees and informants. Instead, I refer to people whom I have interviewed by pseudonyms and sometimes have changed their identifying details such as their workplace or their residential neighborhood upon their request to ensure their anonymity. Almost all interviews have been recorded, barring a few which I conducted impromptu as the situation allowed me to do so. Unrecorded interviews include those that I conducted while giving a ride to someone, or during an extended chat in front of a local supermarket, or at some events and invited gatherings. 


\section{Research Phases}

I have conducted this research in multiple phases, with each phase engaging one or more of the ethnographic methods. Phase I consisted of conducting research using the Internet, and gathering preliminary evidence from a pilot study. Phase II was the formal evidence acquisition phase and continued for over ten (10) months. This phase comprised conducting intensive, in-depth interviews in India and in the U.S. Participant observation formed another important source of evidence during this phase.

\section{Research Phase - I}

\section{The Internet}

The first phase of data collection and analysis utilized the Internet. I collected data from eight Bengali cultural and matrimonial websites about "family" involvement in arranging marriages. These websites included Shaadi.com, Bharatmatrimony.Com, Shaadisapna.com, Matrimonialsindia.com, Jeevansaathi.com, Lifepartnerindia.Com, Vivaah.Com, and Simplymarry.com. I have accessed these websites between June and August 2011 and have collected data from them. Typically, advertisements for prospective brides or grooms from one of these websites will read as follows: 


\section{Table 2.3: Examples from Matrimonial websites}

\begin{tabular}{|c|c|}
\hline Grooms seeking prospective Brides & Brides seeking prospective grooms \\
\hline $\begin{array}{l}\text { "I am a nice cultured guy, who has } \\
\text { moderate value and consider family very } \\
\text { important. I am fun loving and friendly by } \\
\text { nature. I have done B.Tech in Electronics } \\
\text { \& Comm. Engg. and currently working for } \\
\text { a reputed MNC as Tech. Lead. I have an } \\
\text { elder brother who is working as } \\
\text { SPM(Civil Engg.) in an MNC in } \\
\text { Seychelles. My father is retired O.N.G.C. } \\
\text { Chief Engineer and my mother is a } \\
\text { homemaker." } \\
\text { Looking for: "Looking for a nice girl who } \\
\text { is willing to share her life with me, is } \\
\text { honest, confident, cheerful, loving and } \\
\text { supportive. Who has moderate values and } \\
\text { consider family to be important. Who } \\
\text { understands the importance of friends and } \\
\text { values a good laugh \& fun." }\end{array}$ & $\begin{array}{l}\text { Profile written by parents } \\
\text { "She is our only child. Though she has been } \\
\text { brought up in a cosmopolitan city, she } \\
\text { believes in simplicity and is well versed with } \\
\text { our culture and traditions. She has been an } \\
\text { excellent student throughout her academic } \\
\text { life. Her hobbies include listening to music, } \\
\text { singing, watching TV and making Rangoli. } \\
\text { She is homely and likes spending time with } \\
\text { family and friends." } \\
\text { Looking for: "We are looking for someone } \\
\text { who would be understanding, caring and } \\
\text { broad minded." }\end{array}$ \\
\hline $\begin{array}{l}\text { Profile written by parents } \\
\text { "Few words about my son } \\
\text { Hi, my son is a highly ambitious person } \\
\text { with loads of with positive attitude. He is } \\
\text { hard working, but not impatient. People } \\
\text { also say that he is broad-minded, which I } \\
\text { think means, being liberal in thinking. He } \\
\text { is handsome, smart, earning good. } \\
\text { Romantic, loves music like crazy and } \\
\text { photography. And his pets. } \\
\text { He is a total dream for any girl. I am not } \\
\text { saying so because I am his mom, but he is } \\
\text { a total man which any girl would love to } \\
\text { spend her life with." } \\
\text { Looking for: "We are looking for nice girl } \\
\text { with charming personality, an } \\
\text { educationally sound background, caring } \\
\text { and good looking. Our only son's wife }\end{array}$ & $\begin{array}{l}\text { Profile written by parents } \\
\text { "We are searching for a suitable alliance for } \\
\text { our daughter. She is fair with normal physic. } \\
\text { She has done a 2-year computer- course. She } \\
\text { got job through SSC Examination, this year. } \\
\text { among my two daughters she is elder. The } \\
\text { younger one is in BA (English) 2nd Year. } \\
\text { She values our culture and family } \\
\text { relationships." } \\
\text { Looking for: "Well qualified, kind hearted, } \\
\text { should have feeling for her, elders, and } \\
\text { others, understanding, down to the earth." }\end{array}$ \\
\hline
\end{tabular}




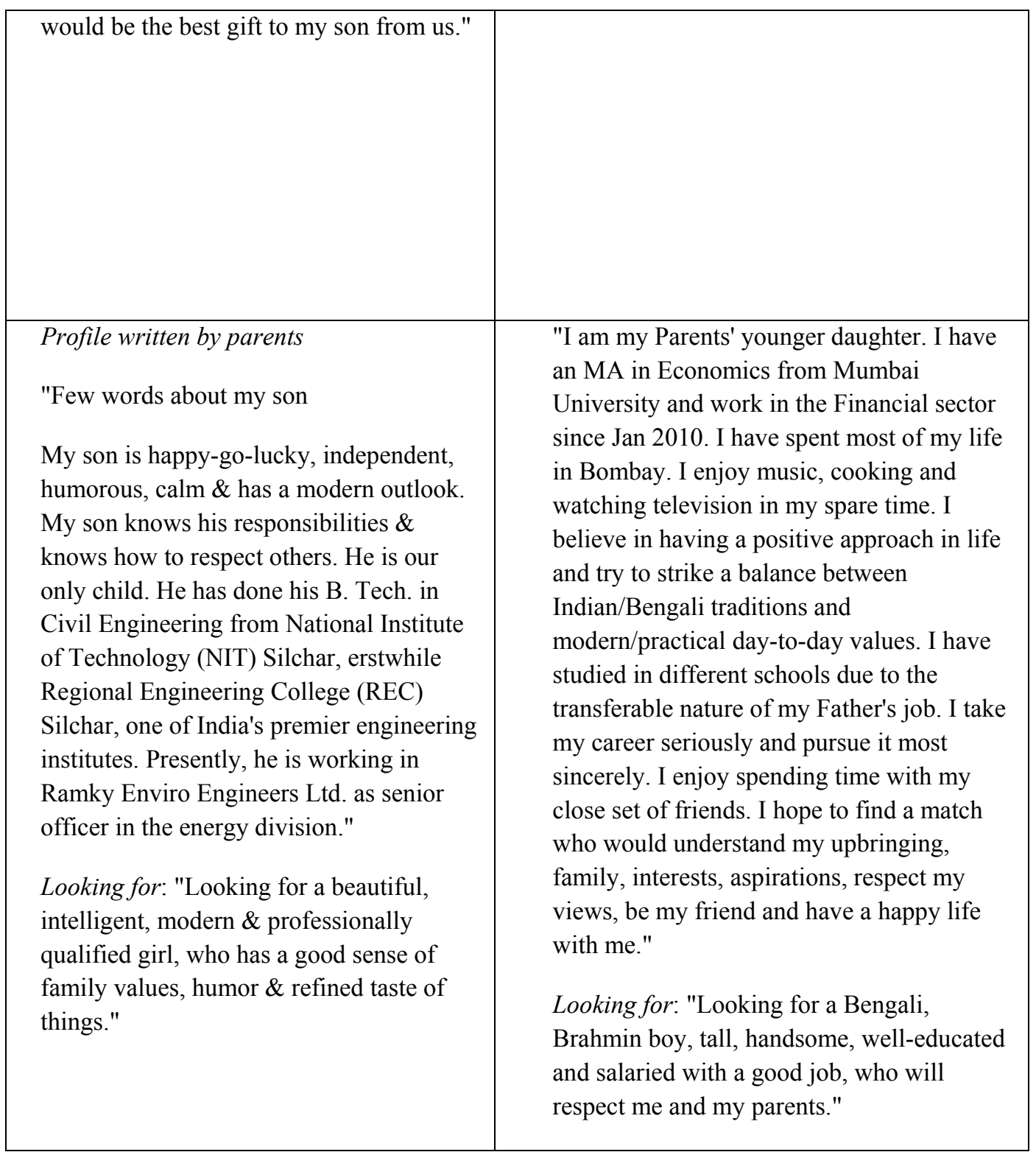

Having collected data from the matrimonial sites during my first phase of

research, I analyzed the data gathered using the qualitative data analysis software

MaxQDA. I conducted an iterative process of maintaining memos, theme-hunting, and

finally coding the data in this software (all stages discussed in details further below).

Upon analyzing the data gathered from the matrimonial websites, I used a visual 
analytical tool, the Code Relations Browser, from MaxQDA. The Code Relation Browser (Figure 2.1 below) is an effective visual tool which shows which codes have been assigned to which text, and how often has this been done. The larger the cluster, the greater the number of codes that has been assigned to this text. From this particular section, it is evident that people attach the highest meaning to family status and values while seeking a prospective partner. Not surprisingly then, the next step was to investigate what happens to this family involvement after the search for a partner is over and the wedding ceremony is complete.

\section{Figure 2.1: Code Relations Browser}

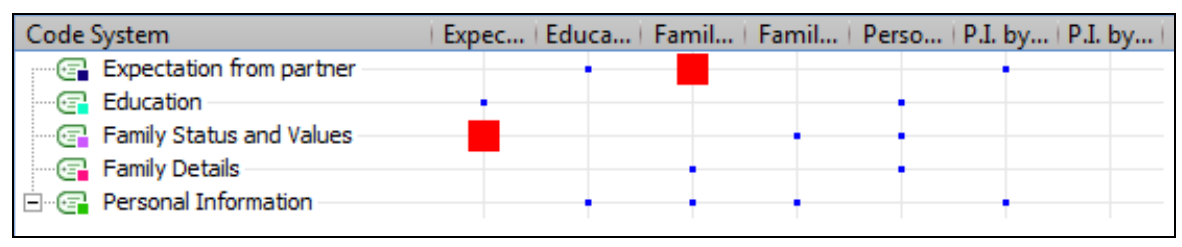

Following Krippendorff and Bock (2009), I have also conducted content analysis to analyze the above data and additional data from blogs, cultural websites, and NGO websites in which people portray and discuss the research population's family relationships, marriage and spousal relations.

\section{Pilot Research}

Following my preliminary research using the Internet, I continued to collect evidence during my pilot research in India, primarily in Kolkata, in the summer of 2010. During my pilot research, I conducted several semi-structured interviews and also archival research in the Asiatic Society library, Kolkata. This provided me with an opportunity to hone my interview strategy and interview question set (discussed below 
under Phase II). In particular, the pilot research helped in making my interview protocols more appropriate to the rapidly changing nature of the family in India. I also conducted some interviews using Skype voice chats and emails. The pilot research was helpful; I realized that structured interviews cannot shed light on the topics that I am studying here. For example, whenever I had asked informants "Who or what is family to you?" in almost all instances, they asked me in return: "You mean now or then?" The rapid sociocultural changes in India that were already ongoing during my pilot research created the backdrop to my informants' reactions, something which I analyze in following chapters. Therefore, when I went back to the field for formal evidence acquisition later, I reframed my question to How do they conceptualize the family? To be clear, even then their responses did not exclude the changing Indian social fabric. But my open-ended questions did leave more scope and opportunity for them to elucidate how and why they thought "family" as an institution is changing for them, or not. Similar to my analysis of data from the matrimonial websites, I used the analysis techniques of theme and pattern identification with the data gathered during my pilot study. Using the same software, MaxQDA, I could identify patterns in what people say, the terms they use and the debates they engage within en route to using this information to fashion appropriate research protocols for my Research Phase II. The two most significant themes that arose during my pilot research and the ones that I carefully included in my final interview protocols are a constant reference to family status and values, and education of the spouses. 


\section{Figure 2.2: Cognitive Map produced using Maxmaps}

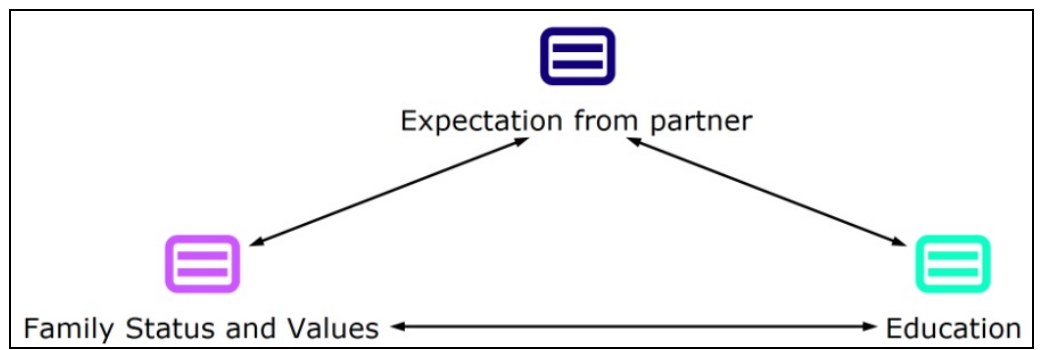

In the above figure (Figure 2), I produced a conceptual map using MaxQDA's visual tools, to depict the two most significant themes that arose during the pilot research. In my interview protocol that I used during my formal evidence acquisition (Phase II, below), I had carefully included these two dimensions, i.e., family status and values, and education, although taking ample caution that I do not lead the interviewees in a structured manner to respond along these dimensions only.

\section{Research Phase - II: Data Collection}

Having accomplished identifying the significant themes operative in Bengalis' family and spousal life, I started Phase II of my research in the summer of 2011. This phase primarily included conducting intensive, semi-structured interviews with Bengali couples living in the U.S. and willing to be studied and their family members living in India. I interviewed the couples between July - December 2011, and then travelled to India to interview their family members from January 2012 - April 2012. This phase also included some participant observation of the couples in their natural settings such as their homes and at private and public events. 


\section{Semi-Structured Interviews}

As I have indicated above, semi-structured interviews formed the majority of the ethnographic data collected in this study. Interviews were designed to provide the opportunity to inquire into people's perspectives and not just to analyze their stated perspectives. Thus, the design called for finding a small number of people who would represent the range of voices identified during my pilot research, and whose views I would be able to contextualize and examine more exhaustively. Scholars note that variability in cultural meaning results from differences in persons' social contexts and life experiences (Handwerker and Wozniak 1997). Studies that aim to capture this variability, therefore, require informants whose life experiences and social contexts reflect the differences that may influence the meanings under study (ibid.). In this case, I utilized several snowball samples that varied with regard to years as migrant in the U.S., educational accomplishments, income, and years of marriage.

The interviewing schedule, provided in Appendix A to this dissertation, was developed following the analysis of the data retrieved from the Internet and the pilot research, which were the first data analyzed. Before I started my fieldwork, I imagined that given the sensitivity of the research, informants might not always be willing to divulge sensitive information on marriage and spousal relations. Therefore, to overcome this data collection challenge, my interview schedule was carefully designed to include a technique typically referred to as "scenarios" in qualitative research (Caulkins et al. 2000). Scenarios are designed such that instead of asking interviewees for their opinions directly, they are often asked to choose a perspective on a related, often fictitious, 
situation at hand. This enables interviewees to respond more flexibly without having to be concerned about their privacy. That is, they would select the perspective which most closely reflected their own and then I could inquire about why they chose that perspective. I developed the scenarios used by drawing upon popular novels, movies, advertisements, and historical events, etc. Such scenarios were structured so that they could function as excellent ice-breakers and also encourage informants to relate them to personal experiences. However, when I started to interview my respondents, I did not have to take refuge in the scenarios at all. Almost all of my informants were very interested and enthusiastic to talk about their own experiences. My positionality as a Bengali woman, I firmly believe, also facilitated this process; respondents were eager to share their experiences with me because, I believe, they could identify with me. This also aided their comfort level for divulging sensitive, personal information. I am grateful to them for opening their hearts to my questions and answering them with their rich and interesting stories.

The interviews had a somewhat gendered outcome: I could interview more women ( $57 \%$ of total respondents) than men ( $43 \%$ of total respondents). Also, interactions with women came out to be lengthier, more personal and candid. This is not to say that men were not interested in telling their own stories. Conversely, they were also eager and on occasion were more candid than the women. But there were cultural barriers to my access, barriers structured by gender. For Bengalis, much like many cultural groups in India, gender segregation - especially at social events and gatherings is quite normative but also affects cross-gender interactions in the home. That is, there are gendered boundaries for interacting with people and they inflected my research 
experiences. For example, at a particular Bengali festival organized by the Bengali cultural association that I attended, women could be observed to perform certain actions such as organizing the event and helping with their culinary expertise, while men could be observed in actions related to managing finances for the event. Given cultural practices of gender segregation, it is not surprising that I enjoyed easier access to women. My positionality as a married Bengali woman impacted whom I could interview, when, where or for how long. In general, my interactions with the women were less limited than with the men.

\section{Participant Observation}

In addition to conducting semi-structured interviews, I attended and observed a number of private and public Bengali gatherings over a span of 12-14 months. These gatherings ranged from rituals, festivals, birthday celebrations, and private social gatherings in South Florida and in Kolkata. Interactions during these events allowed me to learn more about the cultural practices, particularly gendered practices, of Bengalis in their natural settings. By participating in these events, I was able to continuously interact with and be a part of the ordinary everyday lives my informants, a hallmark of participant observation (Corbetta 2003; Bernard 2006). I used detailed field notes to describe and interpret my interactions with the people and places I engaged with in South Florida and in Kolkata.

\section{Research Phase II: Data Analysis}

As discussed so far, data collection and sampling for this study benefited from and combine the insights of various approaches to qualitative research. Analytically, 
however, and as I have indicated at the onset, I have followed the steps from Grounded Theory (Corbin and Strauss 1998), i.e. theory "derived from data systematically gathered and analyzed through the research process" (ibid. 12). As discussed above, this analytical method seeks out, through a protracted process of minute interaction with the research material, the key patterns in the data, turns them into conceptual abstractions which in qualitative data analysis are referred to as "codes." Codes then are applied systematically to the data, attaching these labels to whole documents, phrases, photos, etc. More than one code can be applied to these subsets of the whole data because many data relate to more than one concept. Coding the same items by different codes links the codes as well (refer to Figures 2.1 and 2.2 above which exemplify these relations). Coding, then, organizes the data so that it can be retrieved efficiently by each concept or sub concept, analyzing related material together. Additionally, coding facilitates comparisons such as contrasting how husbands versus their wives responded to particular ideas, scenarios, questions, etc. Figure 2.3 (below) is a graphical representation of this iterative analytical process.

This inductive analytical process also corresponds to the key principle of the Grounded Theory. According to the pioneer grounded theorists I follow, Juliet Corbin and Anselm Strauss (ibid.), this principle is that, unless she aims to expand on existing theory, the researcher does not begin with a preconceived theory in mind. Rather, she selects a broad area of study and allows theory to emerge from the data; in other words, she builds, rather than tests theory. In my case, the idea that the extended family continues to be an important part of spousal relations, had been encountered twice- once in the literature and later during my first research phase. In this case, then, I began my 
research with a minimum of preliminary ideas, but with a methodology that aided me to expand my research as new ideas emerged. The theoretical base that informed these conceptualizations was expanded during my interactions with my informants. When I had set out to discover themes and codes in the data, I had not started with any preconceived categories of codes that I attempted my data to fit in. Instead, I developed a coding scheme as it emerged from my data during the analysis.

\section{Figure 2.3: My Data Collection and Analysis Log}

\section{(Adapted from Strauss and Corbin 1990)}

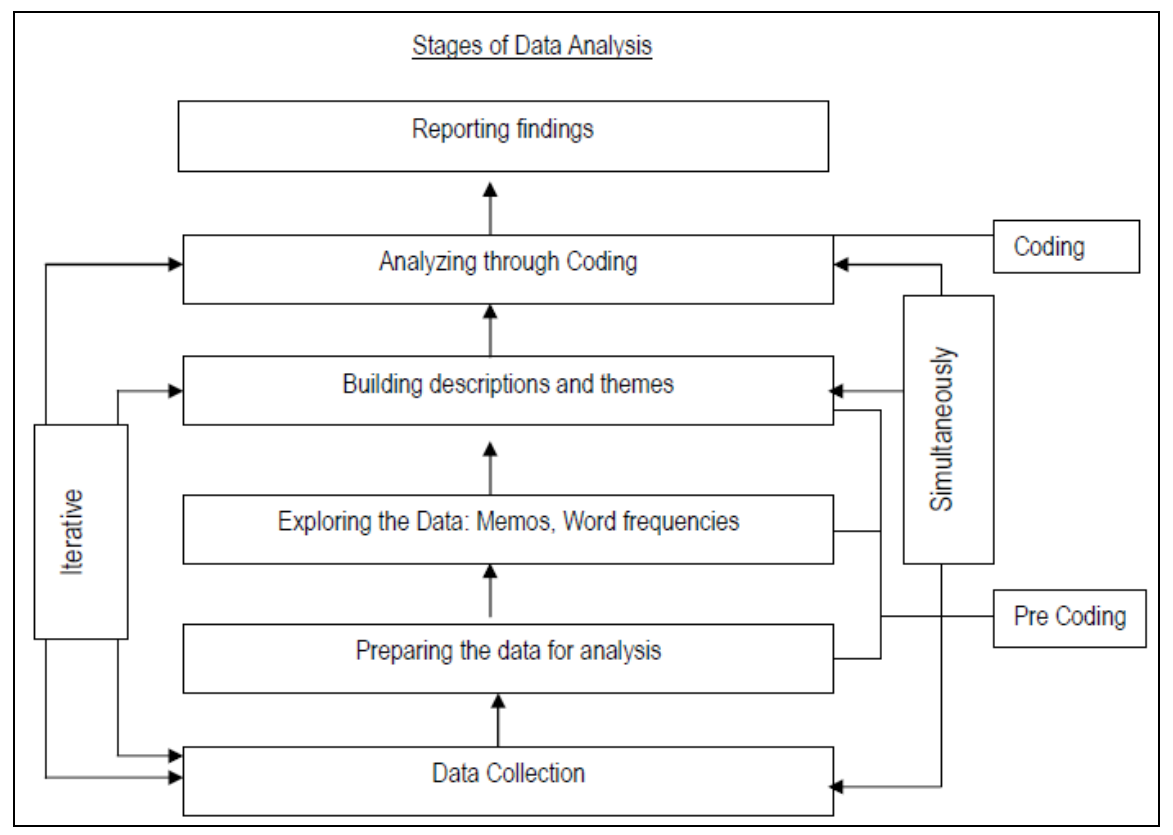

Data from field notes and interview transcripts were entered into the software program MaxQDA, for analysis. Transcripts of all the interviews were imported into the program making different text groups of data - couples, family members, wife, husband, etc. Socio-demographic data such as age, gender, and employment/occupation were recorded using the Attributes option of the program as a way to create a comprehensive 
database of the demographic descriptors of the subjects interviewed and to facilitate the quantification of relevant variables for further exploration and reporting. The complete table of attributes contains information on each person's gender, age, marital status (for family members), education, occupation, number of children, home and car ownership, etc.

Once all the transcripts were imported, I engaged in a process of pre-coding, or open coding. This stage typically consists of three important steps which I have performed to analyze the data:

(i) Memo-writing: Memoing or memo-writing is the initial stage that I conducted to identify analytic categories within the data. Memos are reflective notes made by the researcher that help in future stages of analysis. In other words, I conducted memowriting to note and analyze either or all of the following cases: a) a snapshot of that particular interview that will benefit analysis; b) any special features/characteristic about that particular data that I wanted to highlight; c) linking the concepts and literature with that particular data (or linking that data with some other similar data). It is perhaps the last function that renders memoing its comparative function. I engaged in this step based on the basic conceptual elements of the project (i.e., perceptions of who is family and who is not, relationships based on expectancy and dependency, spousal relations, motivations and decision-making, expectations and experiences) in addition to key questions contained in the interview protocols (family stories, marriage and spousal experiences with regard to family members, migration history, etc). The memo-writing stage therefore demonstrates a process in detecting conceptual patterns in the data at the 
very early stages of the data analysis. Memoing, also known as "open coding," was essential to understanding the data and to begin specific identification of patterns and themes en route to creating initial codes. "Open coding" (ibid. 101) refers to the analytical process of gradually classifying similar phenomena under higher-order, abstract categories that often will be turned into codes and applied systematically to the data. Examples of the early stages of detecting such patterns and representing them as conceptual abstractions are therefore available in the "memos" (ibid. 110).

(ii) Theme identification: The next analytical step was taking memoed ideas and deciding which ones merited more systematic work. This is the step toward identifying themes, precursors to codes. Broadly defined, themes are abstract constructs that link expressions in datasets, literature, and even images and sounds. Identifying themes within a dataset is one of the most fundamental tasks of qualitative research. Ryan and Bernard (2003) identify at least four aspects/stages of theme identification: a) discovering themes and subthemes; b) winnowing themes to an important few in order to analyze and manage them better; c) hierarchically arranging themes thus identified; and d) linking themes to theoretical models. The literature on theme identification offers some strategies to identify or "discover" themes that I closely followed to find themes in my data: 1) When similar phenomena are repeated multiple times in the data; 2) indigenous typologies or categories (local terms used in describing a phenomenon); 3) Metaphors and analogies; 4) transitions; 5) similarities and differences (also known as "constant comparison method"); 5) linguistic connectors; and 6) theory-based themes. However, although theme identification strategies are almost similar throughout the literature, themes are often used as synonym with “concepts", “categories”, "labels', “expressions” etc (Ryan 
and Bernard 2003). Strauss and Corbin (1990) link themes and expressions as "conceptual labels" which are placed on discrete happenings, events, and other instances of phenomena.

(ii) Word frequencies and key words in contexts (KWIC): In these techniques, my analysis was more guided by words and terms used by the informants in definite contexts, rather than analyzing larger segments of text via a set of themes or categories (Ryan and Weisner, 1998). For example, the word frequencies technique helped in analyzing how often informants used the words "expectations" and "dependency" to describe their family relations. I found this method to be useful in discovering patterns in any particular part of the text body (field notes, answers to open-ended questions, etc). This method helped me analyze the importance of any particular word measured by the number of times it has been used by the informant. Ryan and Weisner (1998) call this "word salience." Then, based on word frequencies, I also conducted Key Word In Context (KWIC) searches which helped me to look at how informants were talking about particular topics and issues.

\section{Coding as Analysis:}

Coding, or the process of applying conceptual patterns systematically to raw data, is a set of processes that Corbin and Strauss term "conceptual ordering" (ibid. 15). A bulk of the analysis through coding depends on the identification of themes and patterns within the data (Coffee and Atkinson, 1996). According to Coffee and Atkinson, coding is "...condensing the bulk of the data sets into analyzable units by creating categories with and from the data" (1996:26). However, it may be emphasized that coding is a 
process of data analysis, not the analysis itself. Similar to themes, coding helps in linking concepts or instances within the data. Seidel and Kelle (1995) sum this linking function of coding in their following words: "codes represent the decisive link between the original 'raw data,' that is, the textual material such as interview transcripts or field notes, on the one hand and the researcher's theoretical concepts on the other" (1995:52). Codes may also denote the words of participants or incidents as concepts derived from observation or video.

In coding, data are compared to uncover their patterns and also the variation in their patterns. Data are thus organized systematically by based on the conceptual scheme (codes) produced from memoing and theme identification. As I explained in the earlier discussion of Grounded Theory and also in my data analysis log above (Figure 2.3), the analytical process it dictates is inherently comparative, because asks researchers to detect and show the range of variation in the concepts that emerge in the course of the analysis. To this end, when the researcher detects a pattern in the data and represents it as an abstract theoretical concept, she examines and defines it in terms of what Corbin and Strauss (ibid.) call a concept's properties; in other words the characteristics along which a category may exhibit variation. This method of coding on the basis of concepts and how they may vary along certain properties is termed "theoretical" (ibid. 88). In other words, the researcher examines data on the basis of existing concepts and their properties in order to detect sameness and variation and thus expand the categories' conceptual range. For example, a central pattern that emerged in the data in this project is a discussion on continued family involvement in spousal lifestyle, a pattern that I represent as "family involvement in spousal relations." People's responses involving family involvement are 
not all the same but, rather, include a range such as whether family involvement in spousal relations continued historically, whether it continues now, how and how often it does happen, etc. The responses thus exhibit a variation along the properties of "family involvement in spousal relations." When these differences are repeated they become "properties" of themes and these get translated into sub-codes. Data that was originally coded for "family involvement in spousal relations" then would be re-coded for the subcodes and this would facilitate more fine-grained analysis.

As evident in Fig 2.3 above, pre-coding or open coding, and coding or theoretical coding do not take place in a linear order. The coding process becomes theoretical as soon as the researcher discovers a conceptual category and the properties along which it exhibits variation in her data. Yet coding also remains open in the sense that the researcher is always on the lookout for potential new categories or new properties of categories already detected. In this process, the conceptual scheme and its corresponding analytical labels (codes) may be revised one or more times, depending on the insights the researcher gradually gains in the course of the analysis. Analysis stops when categories are "saturated" (ibid. 136), i.e. when no new information seems to emerge in the data, or when new information does not seem to add much to the purposes of the research.

In the following section, I describe my conceptual categories and their properties as I have used them in the data analysis for this dissertation. With each conceptual category, or macrocode, I provide the subcodes and the criteria that I have used to either include or exclude texts to be coded under them. Further, with each macrocode, I provide 
a code tree from MaxQDA depicting that particular macro code with its sub-codes and sub sub-codes.

In the following tables and figures below, I provide a synoptic view of my conceptual categories and their properties. For each conceptual category that I have stated below, I use my macrocode and the primary category and the sub codes as the sub categories. I describe each category and also state how and why I coded the interviews with those conceptual categories. 


\section{Table 2.5: Conceptual Category "MARRIAGE" and its properties}

\begin{tabular}{|c|c|c|c|c|}
\hline MACRO CODE & SUBCODES & DESCRIPTION & INCLUSION CRITERIA & EXCLUSION CRITERIA \\
\hline \multirow{9}{*}{ MARRIAGE } & What is Marriage? & $\begin{array}{l}\text { Description of respondents' understanding } \\
\text { of marriage }\end{array}$ & $\begin{array}{l}\text { descriptive answers, includes } \\
\text { imagination work in marriage }\end{array}$ & $\begin{array}{l}\text { responses that do not } \\
\text { explicitly relate to marriage }\end{array}$ \\
\hline & $\begin{array}{c}\text { Matrimonial } \\
\text { Advertisements }\end{array}$ & $\begin{array}{l}\text { responses on matrimonial advertisemenst, } \\
\text { including personal experiences narrated by } \\
\text { the respondents }\end{array}$ & $\begin{array}{l}\text { experiences and opinions on } \\
\text { the role of matrimonial } \\
\text { adevrtisements in Bengali } \\
\text { marriages }\end{array}$ & $\begin{array}{l}\text { responses that do not state } \\
\text { matrimonial advertisements } \\
\text { explicitly }\end{array}$ \\
\hline & $\begin{array}{l}\text { Gendered } \\
\text { responses from } \\
\text { Bengali men }\end{array}$ & $\begin{array}{l}\text { Responses primarily from the husbands } \\
\text { and some of the family members on } \\
\text { marriage and their perceptions on marriage }\end{array}$ & Responses from male only & responses from females \\
\hline & $\begin{array}{l}\text { Gendered } \\
\text { responses from } \\
\text { Bengali women }\end{array}$ & $\begin{array}{l}\text { Responses primarily from the wives and } \\
\text { some of the family members on marriage } \\
\text { and their perceptions on marriage }\end{array}$ & responses from females & responses from males \\
\hline & $\begin{array}{c}\text { How was marriage } \\
\text { arranged }\end{array}$ & $\begin{array}{l}\text { descriptions on how marriage was arranged } \\
\text { by the family and extended family }\end{array}$ & $\begin{array}{l}\text { includes all marriages, even } \\
\text { ones where respondents } \\
\text { chose their spouses }\end{array}$ & $\begin{array}{l}\text { responses on post-marital } \\
\text { dynamics }\end{array}$ \\
\hline & $\begin{array}{l}\text { Changes after } \\
\text { marriage }\end{array}$ & $\begin{array}{l}\text { Primarily how spouses described their } \\
\text { experiences after marriage. Predominantly } \\
\text { responses from the wives }\end{array}$ & $\begin{array}{l}\text { dynamics of marriage after the } \\
\text { wedding rituals, also when } \\
\text { compared to women's maiden } \\
\text { life }\end{array}$ & wedding rituals \\
\hline & Marriage "rules" & $\begin{array}{l}\text { Responses on how couples behave and } \\
\text { interact with the family and in society after } \\
\text { marriage }\end{array}$ & $\begin{array}{l}\text { Responses from couples and } \\
\text { family only referring to } \\
\text { practices after the couple's } \\
\text { marriage }\end{array}$ & pre-marital dynamics \\
\hline & $\begin{array}{l}\text { Typical Bengali } \\
\text { Marriage }\end{array}$ & $\begin{array}{l}\text { When couples and families described the } \\
\text { idealized Bengali marriage scenarios }\end{array}$ & Only idealizations & $\begin{array}{l}\text { Couple's marriage if not } \\
\text { identified with the ideal }\end{array}$ \\
\hline & $\begin{array}{l}\text { Family } \\
\text { involvement in } \\
\text { marriage }\end{array}$ & $\begin{array}{l}\text { Respondents views on how and why family } \\
\text { was involved in the couple's marriage }\end{array}$ & $\begin{array}{l}\text { All reactions from couples and } \\
\text { families on family's } \\
\text { involvement in arranging } \\
\text { marriages }\end{array}$ & pre-marital dynamics \\
\hline
\end{tabular}

\section{Figure 2.5: Code system of MARRIAGE}

Whatem




\section{SPOUSAL RELATIONS}

\section{Table 2.6: Conceptual Category "SPOUSAL RELATIONS" and its properties}

\begin{tabular}{|c|c|c|c|c|}
\hline MACRO CODE & SUBCODES & DESCRIPTION & INCLUSION CRITERIA & EXCLUSION CRITERIA \\
\hline \multirow{5}{*}{$\begin{array}{l}\text { SPOUSAL } \\
\text { RELATIONS }\end{array}$} & $\begin{array}{l}\text { What couples said } \\
\text { about their life in } \\
\text { the U.S. }\end{array}$ & $\begin{array}{l}\text { Descriptions by spouses on their life in the } \\
\text { U.S., particularly their spousal lifestyle }\end{array}$ & Responses from couples only & $\begin{array}{l}\text { Responses from family and } \\
\text { extended family }\end{array}$ \\
\hline & $\begin{array}{l}\text { What family } \\
\text { members said } \\
\text { about couples' } \\
\text { lifestyle in the U.S. }\end{array}$ & $\begin{array}{l}\text { Descriptions by family and extended family } \\
\text { on how they think couples live in the U.S. }\end{array}$ & $\begin{array}{l}\text { Responses from family and } \\
\text { extended family }\end{array}$ & Responses from couples \\
\hline & $\begin{array}{l}\text { What couples said } \\
\text { about family } \\
\text { involvement in } \\
\text { their spousal life }\end{array}$ & $\begin{array}{l}\text { Couples' refelctions on how they think } \\
\text { their family and extended family are } \\
\text { involved in their spousal dynamics }\end{array}$ & Responses from couples only & $\begin{array}{l}\text { Responses from family and } \\
\text { extended family }\end{array}$ \\
\hline & $\begin{array}{l}\text { What families said } \\
\text { about their } \\
\text { involvement in } \\
\text { couples' spousal } \\
\text { life }\end{array}$ & $\begin{array}{l}\text { Family and Extended family's reflection on } \\
\text { how they think they are involved in the } \\
\text { couples' spousal relations }\end{array}$ & $\begin{array}{l}\text { Responses from family and } \\
\text { extended family }\end{array}$ & Responses from couples \\
\hline & $\begin{array}{l}\text { Typical Bengali } \\
\text { spousal relations }\end{array}$ & $\begin{array}{l}\text { Descriptions from respondents on how } \\
\text { they perceive typical Bengali spousal } \\
\text { relations }\end{array}$ & $\begin{array}{l}\text { Typical or ideal cases } \\
\text { decribed, may include } \\
\text { respondents' own spousal } \\
\text { relations if akin to the ideal }\end{array}$ & $\begin{array}{l}\text { When respondents did not } \\
\text { identify their spousal } \\
\text { relations as typical }\end{array}$ \\
\hline
\end{tabular}

\section{VALUES AND IDEOLOGIES}

\section{Table 2.7: Conceptual Category "VALUES AND IDEOLOGIES" and its properties}

\begin{tabular}{|l|l|l|l|l|}
\hline MACRO CODE & SUBCODES & \multicolumn{1}{|c|}{ DESCRIPTION } & \multicolumn{1}{|c|}{ INCLUSION CRITERIA } \\
\hline Informants describing the ideology of \\
VALUES AND
\end{tabular}




\section{MIGRATION}

\section{Table 2.8: Conceptual Category "MIGRATION" and its properties}

\begin{tabular}{|l|l|l|l|l|}
\hline MACRO CODE & \multicolumn{1}{|c|}{ SUBCODES } & \multicolumn{1}{|c|}{ DESCRIPTION } & \multicolumn{1}{|c|}{ INCLUSION CRITERIA } \\
\hline & Migration Story & $\begin{array}{l}\text { Respondents' descriptions on the general } \\
\text { events when couples migrated }\end{array}$ & $\begin{array}{l}\text { General descriptions, not } \\
\text { specific cases of family } \\
\text { involvement }\end{array}$ & $\begin{array}{l}\text { Any specific cases relating to } \\
\text { the other sub codes }\end{array}$ \\
\hline $\begin{array}{l}\text { Family bonds upon } \\
\text { migration - what } \\
\text { couples said }\end{array}$ & $\begin{array}{l}\text { Couples' descriptions and reflections on } \\
\text { how they imagine their family ties to be } \\
\text { after migrating }\end{array}$ & Responses from couples only & $\begin{array}{l}\text { Responses from family and } \\
\text { extended family }\end{array}$ \\
$\begin{array}{ll}\text { Family bonds upon } \\
\text { migration - what } \\
\text { family members } \\
\text { said }\end{array}$ & $\begin{array}{l}\text { Families' descriptions and reflections on } \\
\text { how they imagine their ties with the } \\
\text { couple to be after migrating }\end{array}$ & $\begin{array}{l}\text { Responses from family and } \\
\text { extended family only }\end{array}$ & Responses from couples \\
\hline $\begin{array}{l}\text { Any other changes } \\
\text { for the couple }\end{array}$ & $\begin{array}{l}\text { Any changes that did not fit the above } \\
\text { three sub codes }\end{array}$ & From all respondents & $\begin{array}{l}\text { Any responses that have } \\
\text { already been coded as any of } \\
\text { the above sub codes }\end{array}$ \\
\hline $\begin{array}{l}\text { Any other changes } \\
\text { for the family }\end{array}$ & $\begin{array}{l}\text { Any changes that did not fit the above } \\
\text { three sub codes }\end{array}$ & From all respondents & $\begin{array}{l}\text { Any responses that have } \\
\text { already been coded as any of } \\
\text { the above sub codes }\end{array}$ \\
\hline
\end{tabular}

Figure 2.6: Code systems of SPOUSAL RELATIONS, VALUES AND

\section{IDEOLOGIES, and MIGRATION}

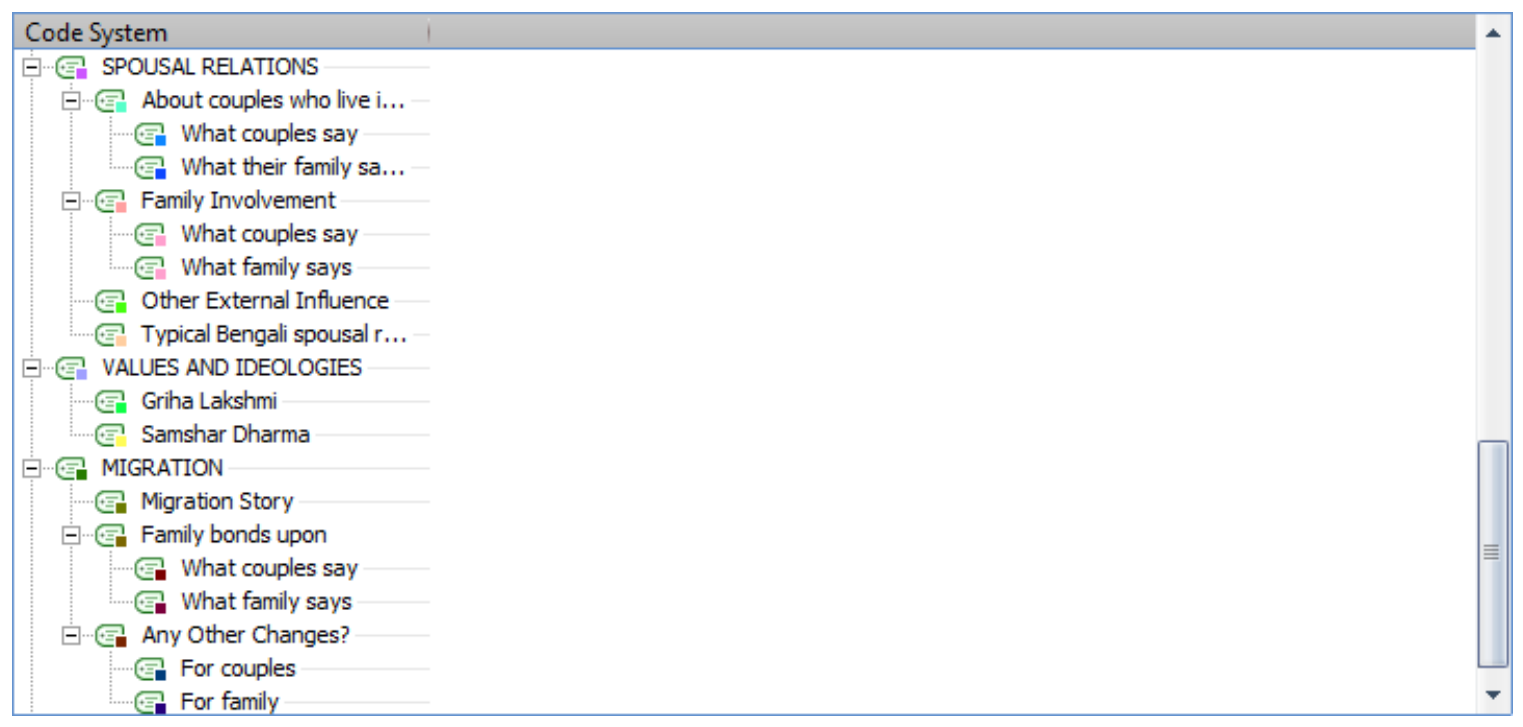


Figure 2.7: Code Relation Browser showing Relationship between Family and Family involvement in spousal relationship

\begin{tabular}{|c|c|c|c|c|c|c|c|}
\hline Code System & FAMILY & Structure & Change in Structure & Cognition & Change in Cognition & Extended Family & Beyond Kin \\
\hline Family Involvement & $\bullet$ & $\bullet$ & $\bullet$ & 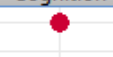 & $\bullet$ & $?$ & $\bullet$ \\
\hline
\end{tabular}

Through icons where size represents quantity, the code relation browser shows the significance of the codes Family and Family Involvement. In the above figure, the highest number of coded sections is (1) Family Involvement in spousal relations as conceptualized by both couples and their families, and (2) Extended Family's involvement in spousal relations. Family in general continues to be a significant factor in couples' spousal relationship, as the browser shows.

Figure 2.8: Code Relation Browser showing relationship between Family and Extended family in terms of structure and cognition (conceptualization)

\begin{tabular}{|c|c|c|c|c|c|c|c|}
\hline Code System & FAMILY & Structure & Change in Str... & Cognition & Change in $\mathrm{Co} \ldots$ & Extended Family & Beyond Kin \\
\hline Structure & $\bullet$ & & $\bullet$ & $\bullet$ & $\bullet$ & $\bullet$ & + \\
\hline Change in Structure & + & $\bullet$ & & - & - & : & i \\
\hline Cognition & 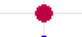 & $\bullet$ & $\bullet$ & & $\bullet$ & $\bullet$ & $\bullet$ \\
\hline Change in Cognition & $\bullet$ & $\bullet$ & $\bullet$ & $\bullet$ & & + & $\dot{t}$ \\
\hline$-\mathrm{G}$ Extended Family & $\bullet$ & $\bullet$ & $\bullet$ & $\bullet$ & + & 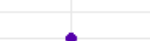 & - \\
\hline ㅋ.ㅂ Beyond Kin & - & + & + & $\bullet$ & + & $\bullet$ & \\
\hline
\end{tabular}

The above code relation browser shows the relationship between how informants conceptualize their family and extended family in comparison to the structure of their family (comparable to household structures). In the figure, the highest coded section is where respondents explored their conceptualization of family and extended family. Significant in this figure is also how often the extended family has been conceptualized by the informants. 
Figure 2.9: Code Relation Browser showing relationship between MIGRATION and VALUES AND IDEOLOGIES

\begin{tabular}{|c|c|c|}
\hline Code System & VALUES ... Griha Lakshmi & Samshar Dharma \\
\hline MIGRATION & $\cdot$ & $\cdot$ \\
\hline Migration Story & - & - \\
\hline Family bonds upon & घ & - \\
\hline What couples say & - & e \\
\hline What family says & - & - \\
\hline$\square$ Any Other Changes? & - & \\
\hline F For couples & & \\
\hline For family & - & \\
\hline
\end{tabular}

Figure 9 shows the relationship between migration and values and ideologies for the respondents. Family bonds upon migration show up as significant for both couples and their families. Specifically, gendered values and ideologies such as grihalakshmi and dharma are found to be important as interviewees continued to emphasize on them. I discuss about both ideologies in my coming chapters.

In the following section, I give a brief overview of the eight couples who I have interviewed for this dissertation. To reiterate, I have used pseudonyms for all respondents in this research.

\section{Portrait of the Eight Couples I Interviewed}

In this section, I provide a holistic portrait of all the eight couples whom I interviewed for this research. In doing so, I will provide analytic descriptions of each of the couples first, and then state which of their extended family members I also interviewed. I list the couples in the order in which they were interviewed. 
Table 2.9: Overview of the couples

\begin{tabular}{|l|l|l|l|l|}
\hline Wife & Husband & $\begin{array}{l}\text { Was the } \\
\text { marriage } \\
\text { arranged by } \\
\text { the family? }\end{array}$ & $\begin{array}{l}\text { Any } \\
\text { children? }\end{array}$ & $\begin{array}{l}\text { Migrated } \\
\text { to the } \\
\text { U.S. in }\end{array}$ \\
\hline Mili & Rahul & No & $\begin{array}{l}\text { Yes, two } \\
\text { daughters }\end{array}$ & 2003 \\
\hline Smita & Sanjeev & Yes & No & 2000 \\
\hline Lali & Sanjoy & No & Yes, a son & 2008 \\
\hline Priti & Rajiv & Yes & $\begin{array}{l}\text { Yes, a } \\
\text { daughter }\end{array}$ & 2006 \\
\hline Aditi & Ashoke & No & No & 2006 \\
\hline Meghna & Neel & No & $\begin{array}{l}\text { Yes, a } \\
\text { daughter } \\
\text { and a son }\end{array}$ & 2003 \\
\hline Arpita & Sameer & Yes & Yes & No \\
\hline Rita & Shishir & Yes, a & 2005 \\
\hline
\end{tabular}

\section{Mili and Rahul}

Mili and Rahul, 38 and 41 years respectively, were born and raised in Kolkata,

India. Both of them were raised in a joint family structure of household, as they and their families told me. Mili completed her under graduation degree from a reputed college in Kolkata, while Rahul took training in computer applications and completed his Masters in Computer Application (MCA). In their interviews, Mili and Rahul have referred to their understanding of "family" with respect to their childhood family structure and their 
current understanding of the family. The couple married almost twelve years ago. Theirs was not a typical arranged marriage by Bengali standard. The couple migrated to the U.S. in 2003, first to Los Angeles, CA, and then to Miami, FL. Rahul's economic opportunity was their primary motivation to migrate. Mili was a dependent spouse until recently. She has joined a local graduate school where she is pursuing her advanced educational degree. The couple has two daughters, three and nine years old respectively. I have interviewed Rahul's mother Ruma, Mili's mother, Meena, and Mili's younger sister, Piya. All three of them currently live in Kolkata.

\section{Smita and Sanjeev}

Smita and Sanjeev, 43 and 45 years respectively, were born and raised in Kolkata, although Sanjeev spent a significant part of his childhood in Rourkela, a city located in the northwestern border of the Indian state of Orissa. Sanjeev also spent a significant part of his formative years in Venezuela were his father was working with an industrial firm. Smita finished her Masters degree in English Literature from a top-ranked university in Kolkata, while Sanjeev, after finishing schooling in Venezuela, went back to India to earn a degree in computer software. Smita and Sanjeev's marriage was a traditionally arranged marriage by Bengali standard. The couple migrated to the U.S. in 2000, because Sanjeev's employer's contract required him to join office in their U.S. location. Smita migrated with Sanjeev as a dependent spouse, but soon she was able to find a job that suited her expertise. The couple chose not to have any children. I interviewed Smita's father Anish, Sanjeev's paternal cousin-brother Sampad, and Sampad's wife, Sakhi. 


\section{Lali and Sanjoy}

Lali and Sanjoy, 36 and 39 respectively, were born and raised in Kolkata. They were both brought up in joint family household in the city. Lali earned a Masters in Library Science in Kolkata while Sanjoy earned his degree in computer engineering. The couple met through a close friend and after a few courtships decided that they wanted to get married. The couple did not characterize their marriage as a typical Bengali arranged marriage. Lali and Sanjoy migrated to the U.S. in 2008, Sanjoy on a H1B category work visa and Lali on a H4 type visa (dependent of the H4 category). Visa restrictions and lack of support from the family are primary factors why Lali continues to be a dependent spouse. However, recently Sanjoy's employer has promised him that he will file for their permanent residency, and a successful application will lift away the work visa restriction from Lali. The couple has a three-year-old son. I have interviewed Lali's sister Neela, Lali's friend Rimli, Sanjoy's sister Sreeja, and Sanjoy's uncle, Mukul, all of whom currently live in Kolkata.

\section{Priti and Rajiv}

Priti is 32 years-old and was born and raised in Guwahati, a northeastern Indian town, and Rajiv, 36 years-old, was born and raised in the Indian capital city of New Delhi. Both of them lived with their parents before marriage - a "nuclear household setup" as they described in their interviews, while keeping in touch with their families in India and globally. Priti and Rajiv's marriage was a typical arranged marriage. In fact, it was the best classic example in my interview pool. Priti is a journalist by profession although she resigned from her work soon after she married Rajiv. The couple migrated 
to the U.S. in 2006. Rajiv now works as a financial analyst in South Florida, while Priti is bound by her dependent visa status to remain at home. They have a baby daughter. I have interviewed Priti's mother Nandini, Priti's maternal aunt Shipra, and Rajiv's uncle Pranab.

\section{Aditi and Ashoke}

Aditi, 33 years-old, was born and raised in Kolkata, while Ashoke, 37 years-old, in Jamshedpur, a town in the northwestern part of West Bengal. Aditi lived in a big joint family setup with grandparents, uncles, aunts, and cousins, while Ashoke lived with his parents while being in touch with the rest of their family in India. The couple met at their university in Banaras, India, where Aditi was pursuing her Masters in Chemistry and Ashoke a Masters in Engineering. After a few years of courtship while at the university, the couple decided to get married after graduating. Ashoke completed his Masters in Computer Application (MCA) and joined a firm that sent him to the U.S. Aditi followed Ashoke as his dependent spouse to migrate. The couple migrated to the U.S. in 2006. I have interviewed Aditi's mother Chitra, Aditi's cousin sister Sneha, and Ashoke's father Arun.

\section{Meghna and Neel}

Meghna and Neel, 36 and 38 respectively, were born and raised in Kolkata. They both grew up in big family setups as they described in their interviews. Meghna and Neel earned their degrees in Computer Engineering in 2005 from a well-recognized university in the U.S where they met. After some courtship, the couple married soon after their graduation. Both of them work in the same IT firm in South Florida. Meghna and Neel have two children, a daughter who is five years-old and a son who is three. I have 
interviewed Neel's mother, Nupur, Neel's father Ashish, and Meghna's cousin sister Twisha, all of whom live in Kolkata.

\section{Arpita and Sameer}

Arpita and Sameer, 34 and 37 years-old respectively, were born and raised in Kolkata. Both of them lived in big family setups. Their marriage was traditionally arranged by their respective families. Arpita completed her bachelor degree in Education while Sameer chose the conventional professional avenue to become a software engineer. The couple migrated to the U.S. in 2009, soon after they married. I have interviewed Arpita's father Shekhar, Arpita's mother Lata, Sameer's mother Sucheta, Sameer's father Nitin.

\section{Rita and Shishir}

Rita and Shishir, 35 and 38 years-old respectively, were born and raised in Kolkata and they spent their formative years in joint family setups in the city. Rita finished her Masters degree from a well-known university in Kolkata, while Shishir completed his bachelor degree in computer engineering from a local college. Their marriage was arranged by their family. The couple migrated to the U.S. in 2005, Shishir on a H1B category visa and Rita on a H4. The couple has filed for their permanent residency which is in process. They have a three year- old daughter. I could interview Rita's father Subeer, Shishir's father Arup, and Shishir's sister Anju.

The portrait of the eight couples, while providing background to understanding the couples, is not enough to understand the dynamics within these families. Therefore, in 
my following section, I unpack three key concepts that are constant throughout this dissertation: family, extended family, and spousal relations.

\section{Range of Voices}

As stated in my previous chapter and in this one too, a research objective which guided data collection and analysis was to uncover the range of voices on "family," "extended family," and "spousal relations," especially across transnational spaces. I sought to problematize who belongs to the family, how the boundaries of family and extended family are recognized and categorized, and how respondents conceptualize their spousal relations with respect to their extended family, especially across transnational spaces.

Couples and their family members voiced their opinions and emphasized their conceptualizations on these in their interviews. Based on their responses, family relations can be conceptualized as inclusive of people related by blood and marriage but also people not related in these quintessential ways but who are treated as family. Close friends and neighbors frequently are included in family. Similarly, respondents have voiced their opinion on how they conceptualize spousal relations especially with respect to the family and extended family, comparing historical norms and practices to the contemporary ones. In the following data chapters, I offer a more nuanced analysis of this data. However, what has remained consistent in my respondents' views is that the family and extended family continue to be an integral part of spousal relations even in transnational spaces. 


\section{Conceptual Plan of the Dissertation}

The overall plan of this dissertation, as stated earlier, is to examine the gendered geographies of Hindu middle-class transnational Bengali migrants. What is the role of Hindu religious practices in informing gendered practices amid transnational Bengalis? By delimiting my case to Hindu transnational Bengalis, I attempt to tease out the complex interconnections between ideology and praxis: the interconnections between Hindu ideologies of dharma and grihalakshmi, and their manifestations in everyday gendered practices across transnational spaces. These practices, as briefly mentioned above, are not a sporadic outcome of any socio-cultural process, but can be explained through a series of strategies having a prolonged history. This history is also a story of this group's negotiation of their social locations vis-à-vis larger populations, first during the colonial era and now in a global era. Discussion in the data chapters that follow is structured to reflect my more nuanced analysis of this history of their gender and status negotiations. In each chapter I examine how people articulate their gendered geographies of family and marriage in their everyday transnational lives. In Chapter Three, I analyze the historical gendered geographies of Bengali gender relations in family and marriage and examine the Hindu religious ideologies that inform these institutions. In Chapter Four, I compare how their historical GGPs are reflected in more contemporary practices when couples live in the U.S. and their family members continue to live in India yet all of these actors negotiate their GGPs across transnational spaces. In Chapter Five, I examine specifically the gendered imaginings associated with their transnational GGP negotiation. 


\section{CHAPTER III - GENDERED GEOGRAPHIES IN NINETEENTH CENTURY}

\section{BENGAL}

As I was conducting my interviews in South Florida and in Kolkata, my informants consistently referred to some important historical moments pertaining to nineteenth century Bengal that they understood as having shaped contemporary Bengali gender relations in family and marriage. "If you want to understand how these [contemporary] relationships in family and in marriage evolved, you will have to look back at a history that we find consistently operating in our everyday lives even now," Priti told me on an autumn evening as we were sitting in the living room of their twobedroom apartment in South Florida. Priti is 32 and married. She was born and raised in Guwahati, a northeastern Indian town, and migrated with her husband Rajiv to the U.S. six years ago. Rajiv is 36 years-old, was born and raised in the Indian capital city of New Delhi. Both Priti and Rajiv lived with their parents before marriage in what they term a "nuclear household setup." I examine these household compounds later in this chapter and in subsequent ones for they are very important to understand. They allow couples to keep in touch with their families in India while they live outside or even in different areas of India or an Indian city. Priti and Rajiv's marriage was a typical arranged marriage. In fact, it was the best classic example in my interview pool. Rajiv now works as a financial analyst in South Florida, while Priti is bound by her dependent visa status to remain at home. They have a baby daughter. I have interviewed Priti's mother Nandini, Priti's maternal aunt Shipra, and Rajiv's uncle Pranab. 
A journalist by profession, Priti resigned from her job with a popular national newspaper in India a few weeks after the couple got married in India. When I asked her the reason for her resignation, Priti referred to a "change" that contributed to her decision for resignation. "What kind of change?" I inquired. She explained, "The change has not been much about decision making. I have always been my own decision-maker. But the main change was that, before marriage, I did not have to think, you know. Before marriage I could choose the things I wanted to do, the people I wanted to be friends with. But all of those changed after marriage. So it was a different life altogether." The "change" that Priti explained is tied to a history of Bengali gender norms and expectations especially around family and marriage which is the focus of this chapter. It is this history, I came to understand but did not originally expect to find, that contributes to the understanding of relations between Bengali men and women, and the gender relationships that they craft. "What kind of gender norms and expectations in marriage are you referring to?" I asked hoping for more details. "It [her marriage with Rajiv] was a totally arranged marriage," Priti responded. "So that comes with a call for adjustments - with your partner, with the new place [at her in-laws'], and most importantly, with yourself! And you have to set in your own identity in that new place. It is like transplantation. For me, that [marriage] is still the biggest move in my life. As far as decision-making is concerned, I never stopped making my own decisions, even through the transition stage." Priti laid down in clear terms the gendered expectations from her as the newly married bride and daughter-in-law: she had to cater to the needs and wishes of her husband, and take care of his parents and the rest of his family. Priti "adjusted" to this gendered set of norms at her in-laws because it was culturally expected. However, 
migration presented her and her husband with a different gendered geography of power especially with regard to her spousal life. "When I came to the U.S. with my husband," Priti narrated, "every day I see him leaving for work, while I am all by myself at home. Even though it was my decision to migrate with him, now I understand what being a dependent is all about." The primary motivation for Priti and Rajiv's migration was Rajiv's pursuit for a better "salaried profession," an important boundary work that arose during my fieldwork and which I examine in details below. Rajiv now works as a financial analyst with a reputed MNC in South Florida while Priti, like most dependent spouses in my interviewee pool, is restricted by her visa status and cannot be gainfully employed in the U.S. Evidently, like Mili whom I have voiced in Chapter One, Priti's life has also passed through various phases, the two most important phases being marriage and migration, and each of the phases has altered her life's gendered geographies of power.

Almost ten thousand miles away from Priti in South Florida, I heard a similar story about change from historical gendered geographies in family and in marriage from Sameer's mother Sucheta in Kolkata. As we were chatting on a spring afternoon at Sucheta's home in Kolkata over several cups of tea, Sucheta reminisced, "We grew up with the kind of values that were given to us by our elders, or the kind of picture that we saw in our time. We lived in a joint family and shared very close bonds with our grandparents, aunts, uncles, and cousins." Sucheta reminisced at length about her childhood days. Her marriage with Nitin was arranged by their families in Kolkata. Since then, the couple has continued to live in Kolkata where they raised their two sons, Sameer and Sudip. Nitin is a gynecologist based in Kolkata, while Sucheta works for a 
non-profit organization, helping orphans and poor children. Sameer married Aditi and the couple now lives in South Florida where I was able to interview both of them. Sudip, the younger brother, lives in Detroit where he works in a research laboratory. Arpita and Sameer, now 34 and 37 years-old respectively, were born and raised in Kolkata. Both of them lived in big family "setups" as they had mentioned in their interviews. Their marriage was traditionally arranged by their respective families. Arpita completed her bachelor degree in Education while Sameer chose the conventional professional avenue to become a software engineer. The couple migrated to the U.S. in 2009, soon after they married. In addition to interviewing Sameer's parents, Sucheta and Nitin, I have also interviewed Arpita's parents Lata and Shekhar.

During her interview Sucheta, like Priti, informed me about the history of Bengali gender relations thinking this background necessary to my interest in contemporary Bengali gender relations. "The gendered arrangements that we see around us today are not very different from how they used to be during our grandparents' generation," Sucheta explained. But she continued by drawing more nuanced comparison about past and present gendered arrangements: "Households have become smaller now, but gendered expectations and their practices have not changed much. They are not identical to what they used to be, but they are very similar to what they used to be." Sucheta looked back to her childhood days to reminisce about these "gendered arrangements," particularly within the home, the intimate scale of interactions. "My grandfather never engaged in any household related work. In fact, he never took any interest in it," she reflected. "But it was not a very big deal, at least for my grandmother. The household was her domain." Sucheta carefully picked out the gendered spheres that had operated 
historically, akin to how Rahul had described his mother Ruma's early married life in Chapter One. "But there is also one more thing," Sucheta continued, now underscoring a concept central to understanding much of Bengali gender relations. "Our grandfathers were a part of the 'bhadralok' culture [Bengali middle-class "respectable" men, discussed below], and that meant that they should never have to engage in any household work of any type. Professionally, they were careful to be employed either in governmental services (the pulse of the society was still beating according to the colonial administrative arrangements), or become doctors, engineers, or lawyers. Those were the only 'prestigious' professions, they imagined. No other profession could fit into the bhadralok's category. If anyone had a business of any sort, they would frown upon that person. They still do." Sucheta explained the categorical boundaries that the bhadraloks negotiated within and across maximizing their social locations given the limitations that they could not cross. It is this negotiation of their gendered and social location in their family and society which I examine below.

As anticipated earlier in this chapter, en route to discussions on social hierarchies in this chapter, I will examine critical questions around gender operating at various geographic scales such as the nation, the family and in marriage. There will be shift of geographic scales in Bengalis preoccupation with status negotiation. The colonial scale in the nineteenth century shifts to becoming a national scale after the end of the colonial rule, and later with forces of globalization, into international and eventually transnational scales. However and importantly, in each case, there emerges the story of the Bengalis' negotiation and assertion of higher social location. In each case the strategies used by Bengalis are gendered. Categories constructed via boundary work in each of these 
geographic scales contribute to our understanding of the gendered strategies of negotiating higher social status.

But before delving into understanding the dynamics of the bhadralok, Sucheta's account of this category of Bengali men made me curious about what the status of the women in the society was at that time. When I inquired, she smirked saying, "Women were important as long as they contained themselves within predetermined boundaries set up for them by their men." Sucheta's response opened up a centrally significant yet contested area that preoccupied Bengal historically, and continues to inform Bengali gender discourses, norms and practices at present: the women's question. "You know, women were very important to the family, because they were the ones who took care of the family and held the family together. I have heard that my grandmother, when she was only twenty years old, spearheaded a paribar [Bengalis use this term to refer to family or household interchangeably] of more than fifteen people, tending to each person's needs and demands. Of course, they had their cooks and chauffeurs and servants who did much of the heavy household chores, but to organize and lead the household daily was my grandmother's work. Ironically, in spite of her accomplishing a good education with complete support from the family, she was not allowed to be gainfully employed. The family was completely against her joining the formal labor force."

The gendered geographies of power in marriage and family relations that Priti, Sucheta, and over eighty percent of my respondents like them described in their interviews did not appear suddenly out of nowhere. In fact, these gendered geographies of power are well-informed by a history of Bengali gender relations that my informants 
constantly referred to and which I aim to explain in this chapter. Referring back to the history that she talked about earlier, Priti continued, "Historically, if you look at nineteenth century Bengal, a lot of the gender relations that we live now were constructed and manipulated around then, around the Bengal Renaissance, and of course, by the British." In fact, both the colonial rule and the Bengal Renaissance, as Priti notes, created important social and gender hierarchies in the society and within the intimacy of the home which almost all of my interviewees related their responses to.

In this chapter, then, I examine three key gendered events in nineteenth-century Bengal in order to offer a background to my interviewees' responses: 1) the birth of the Bengali bhadralok class (Bengali men belonging to the middle class); 2) the women's question in nineteenth century Bengal; and 3) the shifting GGPs in Bengali marriage and the family from this late colonial period. To be clear, this is not a chapter on nineteenth century Bengal; instead, I examine in this chapter only the above-mentioned historical dynamics that my interviewees referenced as important to how they live their lives today. That is, I did not anticipate incorporating these events' history into my discussion of contemporary gender relations among Bengali transnational migrants but they arose in my data collection and during data analysis I realized their critical importance to my study. I then proceeded to analyze how these gendered dynamics operate within and across multiple socio-geographic scales simultaneously: supra-nationally, nationally, within a group (Bengalis), and within the intimate geographic scale of the home. As I document in this chapter, the gendered construction of the Bengali bhadralok is a classic example of gendered geographies of power and gendered boundary work instrumented at the supranational level by British colonial authorities. The women's question, on the other 
hand, is intimately related to the Bengal Renaissance. Together these reconfigured Bengali gendered geographies of power within the group as it negotiated its social status vis-à-vis other groups during late colonialism and the emergence of India as a nation. These strategies, in turn, inflected the domestic, intimate scale which some generations later would turn supra-national again as families would transnationalize with international migration. In the following sections I tease apart these entwined gendered scales for heuristic purposes.

\section{At the Geographic Scale of the Nation: The Prolonged Shadow of the Bengal Renaissance}

Almost every scholar of nineteenth-century Bengal is aware of the resonance of the multilayered term "renaissance" that is often used to describe the period between the early nineteenth century and the early twentieth century in Bengal. Much as with the term given to the European Renaissance, the Bengal Renaissance involves the revival of art and literature. A large body of scholarship examines this period's cultural and social characteristics and events, far too many to engage thoroughly here but see, for example, A. Gupta, ed., Studies in the Bengal Renaissance (1958); J.K. Majumdar, Raja Ram Mohan Roy and the Progressive Movements in India: A Selection from Records (1941); B.B. Majumdar, History of Political Thought from Rammohun to Dayananda (1934); Susobhan Sarkar, On the Bengal Renaissance (1985); and R.C. Majumdar, Renascent Bengal (1972), among others.

An implication of the Bengal Renaissance and one that is particularly important for understanding the gender dynamics central to my dissertation is a series of attitudinal 
changes in social perspectives during the Renaissance (Bhattacharya 2005). Cultural reforms and practices were a huge preoccupation of the attitudinal changes during the Bengal Renaissance. The most important attitudinal reform around this time was a shared social belief of transitioning from the medieval to the "modern." This idea of "modernity" was best marked with, as Sucheta pointed out, "a literary and cultural revolution. A burst in culture, literature, novels, and theatres, and of course, educating the women in the family." Although at first glance the last part of her statement may seem strange given her list but it is a key point because, at its core, this particular sense of modernity found expression in thinking around family and marriage (Majumdar 2009). Educating women was particularly important as will be explained below. Scholars argue that this transition (from medieval to modern, see below) was best expressed in marriage practices and the family in Bengal, which soon became sites of confluence as well as a tussle over multiple visions (ibid.). "Now, of course," continued Sucheta, "when women are educated, the social structure has to be ready to face the consequences. Educated women will want to have a career, be employed, and have their own earnings. However, society decided to fashion the educated woman differently. How? By educating her yet confining her within the domestic sphere."

Where did these Bengali ideas about modernity come from? Almost all cultural reforms, practices, and norms during this time were directed by the reformists towards one common factor: colonial rule. The comparative frame contrasted India with Europe (Bhattacharya 2005). The comparison took many forms (ibid.). Comparisons between the West and the East, and preoccupation with achieving cultural excellence, took place during the Bengal Renaissance and produced some clearly formulated gender dynamics 
that would re-fashion family and marriage in nineteenth-century Bengal. My informants have consistently traced back to those dynamics in their responses to their family and marriage relations in contemporary times.

\section{A Gendered Idea of Modernity}

One central idea that goes hand in glove with the Bengal Renaissance is that the Renaissance was also the harbinger of modernity specifically in Bengal and, by extension, in India. Scholars have argued, and argued quite rightly, that modernity can never be homogenous and takes on, in fact, multiple meanings in different historical spaces (Bhattacharya 2005; Majumdar 2009). In the particular context of Bengal at the time of the Renaissance, Bengali modernity can be understood best by emphasizing two points. First, while the aspiration to modernity was of enormous significance since the Renaissance, the more important dimension is the power involved with the idea of modernity. In other words, modernity, in this respect, can also be understood as a category of power relations. These power relations often became gendered power relations - they had worked for the Bengalis in imagining and desiring modernity that has crafted their gender relations. These power relations, albeit in different forms, continue in Bengalis' contemporary practices as my field data attest. The shifting power relations are informed by the shifting perception of modernity. For example, since the Bengal Renaissance, "modernization" of Bengali society, and to a very large extent, Indian society as a whole, has been the central occupation of social reform projects initiated by both colonial authorities and Indian people (ibid.). The idea of modernity was not limited to the public sphere but extended its tentacles also to the intimate sphere, the home 
(discussed further below). In recent times, as evidenced during my field work, the perception of modernity has shifted again to one attaching a high signifier to achieving a transnational lifestyle. Bengalis in particular adopt a transnational lifestyle as the latest stage of their "modernization."

Second, the projects of modernity that started during the Bengal Renaissance were not limited to the public sphere (politics, economy, education); they also stretched into the intimate sphere, the home, as well (Majumdar 2009). Many of the social reforms during the Bengal renaissance were particularly aimed at the "improvement" of the domestic sphere. These social domestic reforms included new legislation regulating marriage, allowing widows to remarry and the establishment of the fields of inquiry and teaching such as "home science" (ibid.). These reforms were meant to bring modern principles of management to the home. The home, then, was inextricably related to the nation, and the scientific, rational and modern management of the home was thus linked to a scientific, rational and modern nation (for example, see Sarkar 2001). With this history in the backdrop, it is not surprising that contemporary "modern" practices within the intimate sphere, as this dissertation examines, are of great significance for the Bengali middle class. For some time they have tied their identity and status to modernity. However, as the dissertation also examines, while contemporary ideas of modernity and how it can be achieved shift, they nonetheless remain gendered.

Why is it important to examine these specific historic gendered eras? In addition to the fact that they have continued informing contemporary gender relations, these gendered eras are part of how Bengalis as a whole people socially locate themselves vis- 
à-vis larger social scales (viz. colonialism, nationalism, and transnationalism). "Bengalis, in general," reflected Mili, "are very concerned with what everyone else will think and say about their actions. As a result, Bengalis almost always are trying to negotiate a high status in the society -- whether it is a power dynamic between the daughter-in-law and the mother-in-law, or between the neighbors, or between friends. Bengalis, as a population, are always conscious about their position in society, and they make sure that they occupy a high position. One way that they do so is by commanding their cultural ethos that has been handed down the generations since the nineteenth century." As my data will show below and in coming chapters, it is not just that Bengalis' geographic and social scales have shifted over time, but that Bengalis have continuously and strategically enhanced their social positioning within and across these scales as the scales shift and shift again.

During the Bengal Renaissance of the nineteenth century, then and to summarize, Bengalis have consistently negotiated their social locations across various geographic scales -- vis-à-vis the colonial rulers, vis-à-vis other regional and cultural groups in the Indian subcontinent, and even within their own group. These negotiations to attain higher social locations, I argue, continued after the end of the colonial rule, and in fact, are still readily observable in their contemporary transnational practices. Gender still figures prominently as an essential element of Bengali strategy in this negotiation. Categories constructed via boundary work in each of these geographic scales contribute to our understanding of the gendered strategies to claim and assert higher social status. This is precisely the point that Priti, Sucheta, and Mili, like many others in my interviewee pool, emphasized in their interviews. Therefore I now proceed to explain them below 
beginning with the case of the cultural construction of the Bengali man by the colonialists in nineteenth century Bengal.

\section{At the Geographic Scale of Bengalis as an ethno-linguistic group: (1) Bengali Men through a Gendered Kaleidoscope; (2) the Women's Question in Bengal; and (3) Righteous Ideologies and Practices}

In their arguments on social hierarchies in Bengal, social scientists have argued that the Bengali middle class, or the bhadralok class that this dissertation studies, was and still is far from being a consistent and coherent class (Bhattacharya 2005; Bhaviskar and Ray 2011; Majumdar 2009). However, the vertical realities of class that were operative in society then and influenced this middle class were heavily informed by their mobility. They desired mobility and felt held in check by their caste. Colonial Bengal produced a disproportionally large urban bourgeoisie, the bhadralok class, primarily drawing from the three upper castes in society - Brahmins, Kayasthas, and Vaidyas. However, and unlike the Marxian bourgeoisie class, in Bengal, a large section of this urban class was propertyless, and pre-eminently engaged in governmental and other bureaucratic employment. They were salaried (Bhattachrya 2005). To be sure, and to recall from my previous chapter, these are exactly the two indicators that I have followed in determining the urban middle class that I have studied for this dissertation. In fact, occupation was one major category fortified by boundary work done by the bhadralok class, as Sucheta's interview revealed above. They bhadraloks would only do certain occupations and not others - absolutely no domestic labors for example. In their edited work Elite and Everyman: The Cultural Politics of the Indian Middle Class (2011), sociologists Amita 
Baviskar and Raka Ray argue that the Bengali middle class in the late nineteenth century articulated its class identity through a conscious distancing from the "other" which was defined as "the social lower classes" (Banerjee 2004: 3 as cited in Baviskar and Ray 2011: 249). It is this dimension of the Bengali middle class, the bhadralok class, and how they related to the larger society, the colonizers, and finally, with their women, that I will examine in this section through a gendered kaleidoscope and within a boundary work framework.

\section{Who are the Bhadraloks?}

From around the mid-nineteenth century, Bengali rural and urban society differed in many fundamental respects, yet Bengalis shared at least one feature: they occupied a local elite status. In each city, town, and village there was one group of Bengali men who claimed and were accorded recognition by the British colonial authorities as superior in social status to the mass of their fellows. These were the bhadralok, literally the “respectable people," the "gentle men” (Baviskar and Roy 2011; Bhattacharya 2005).

The bhadralok in Bengal became increasingly important when the British expanded their trading activities in Bengal (The English East Indian Company) in the early nineteenth century. This increased the colonial demand for loyal locals who could handle many administrative tasks. Given that the Bengal Presidency was the first and the most important anchor of the colonial administration in India, the local population was an ideal source of this labor and the British started recruiting them. The bhadraloks were quick to grasp these opportunities and maneuvered themselves into these positions. By being an important workforce recruited by the British, bhadraloks soon became the 
middlemen between the colonial rulers and other "ethnic" groups in colonial India. To be clear, every regional or cultural group in India had its own gendered geographies of power vis-à-vis the colonial rulers, and these gendered geographies of power shifted depending on the region. However, the favoring of the bhadraloks by the British colonial authorities created a kind of middle-class both at the colonial/national and at the local levels. The bhadraloks would have to work hard to harden the boundaries between themselves and the lower status peoples below them as well as between Bengalis and other ethnic groups in India. I now turn to this in greater detail first at the local level and later at the national level.

The bhadraloks distinguished themselves from the rest of local society in terms of behavior, deportment, speech, dress, style of housing, eating habits, occupations, and associations (ibid.). That is, they were the elite and needed to keep themselves noticeably distinct from the "everyman," the common men, and also different from the colonial rulers (Baviskar and Roy 2011). To bring in the boundary work framework here, the bhadraloks worked hard to draw bright boundaries between themselves and those occupying lower social statuses. They wanted everyone to know they could not sink to those groups' levels. Still, the bhadraloks were, themselves, cut off by a bright boundary to the top by the British colonials.

The bhadraloks categorically separated themselves from others beneath them, Bengalis and other Indians, primarily via the categorical distinctions of occupation and manual labor. The basic and most rigidly maintained distinction between bhadra and abhadra, the respectable people from all others, was the bhadraloks' complete abstention 
from manual labor and their belief in the inferiority of manual occupations (Bhattacharya 2005; Baviskar and Roy 2011). The material conditions of life of the bhadraloks, however, were often not that good, particularly when compared to their aspirations (Bhattacharya 2005). This strain in maintaining a lifestyle they could barely afford in order to separate themselves from the "lower groups" formed a central theme of many cultural artifacts of this period. For example, in The Sentinels of Culture: Class, Education, and the Colonial Intellectual in Bengal (2005), historian Tithi Bhattachrya, examines the cultural construction of the bhadralok via a popular work of fiction. In the popular farce Kerani Charit [The Character of a Clerk] (1885), Bhattacharya explores the protagonist Nanda who owns some land in his native village but refuses to live there himself. He intends to be employed in a salaried profession, as he thinks that, following Goswami (1974), "there is a certain status to a chakri [salaried profession] that is essential to be a part of civilized society, irrespective of how much property one has in the village" (Bhattacharya 2005: 98).

Scholars such as Bhattacharya (2005) argue that while the bhadralok aspired to be truly bourgeoisie, they are better characterized as the "petty bourgeoisie," because they owned little to no property or capital. The real bourgeoisie were the local colonial rulers (Bhattacharya 2005). She effectively describes why she termed them the "petty bourgeoisie":

The term petty bourgeoisie is extremely confusing [particularly because, in a previous chapter, the author described the petty bourgeoisie in relation to the Marxist sense of the term]. Marx refers to the 'lower middle class' as one 
comprising the small manufacturer, the shopkeeper, the artisan, and the peasant, who may assist the working class in its struggle against the bourgeoisie, but only to prevent itself from sinking into the ranks of the proletariat. They are the owners of small capital, economically trailing behind the big bourgeoisie and politically between the worker and the capital. Their class position demands they be reactionary, even though at particular historical junctures they may play a revolutionary role against the bourgeoisie. [Their] main enemies are mass education and female education (2005: 60).

So how does a group of people excluded by boundary work from achieving the higher social status in a hierarchy ensure their middle status? They draw as bright a line as possible between themselves and those beneath them. This is classic boundary work. But their hold on middle-class status was tenuous at best, always threatened. Given these threats, they turned to another criterion which they would use to emphasize not only their distinctiveness from the lower classes but also their civilized distinctiveness. This criterion, education, was classically colonial so that it could endear the bhadralok to the British. Thus, from around the 1850s, education, particularly English education, became the primary improvement strategy for this petty bourgeoisie (see for example, Bhattacharya 2005; Joshi 1991; Loomba 1998; Viswanathan 1990). Education, along with salaried jobs, became a social imperative for the bhadralok and to insure their access to it the Bengalis started their own private educational institutions.

This section emphasizes men's social status negotiations as they were the primary agents, but it is important to note - and will be developed further below — that they chose 
to modernize not only by educating males but females as well. A significant aspect of education around this time for the bhadralok was associating education with knowledge, and knowledge, in turn, with private property (Bhattacharya 2005). The advantage that the petty bourgeoisie, the bhadralok, saw in education was that it could be owned much as landed property but without the negative aspects of landed (or other wealth) ownership. For example, family and extended family could not cheat someone out of it because education could not be distributed in materialistic terms. It could be used to get access to material wealth but could neither be stolen nor lessened in quantity. Education, therefore, came to be known as the supreme form of wealth among Bengalis at this time (Bhattacharya 2005). The association of the bhadralok with education and intellectual labor and property, as I will discuss further down in this chapter, became generalized to a common sense by the end of the nineteenth century.

However, the bhadralok's use of education and their association of education with private property was marked by a unique gendered geography of power. As far as education concerned their women, the bhadralok followed the colonial state's view on women's education which favored a "womanly tendency" in their course structures for female schools. The education report of 1919 (Bhattacharya 2005) emphasized that the character of education given to girls ignores their needs and the kind of life that they will lead in the future. That is, the course curriculum omitted what ought to be the essential elements in their training period, namely, the teaching of domestic duties and the implantation of the best Hindu ideals of womanhood (for details, see Report of the Commission Appointed by the Government of India to Inquire into the Condition and Prospects of the University of Calcutta, Vol.2, Part 1, 1919: 5-35). Not surprisingly, a 
separate system of education for their women found full support by the bhadralok. This separate system of education for women emphasized the virtues of stridharma [dharma of the female or the wife] - clearly defined in terms of obedience, duties, and companionship to men (Bhattacharya 2005). In a later section in this chapter, I examine this aspect of the bhadraloks' gendered geographies of power in relation to their women.

At the scale of the home, the bhadralok again performed much gendered boundary work. Referring to a discussion on gendered division of labor or, rather, the lack of thereof in spousal relations, Mili's mother, Meena, related this history to the contemporary Bengali bhadralok: "A Bengali [middle class] man, in general, will not even make a cup of tea for himself. Why? Because he is the bhadralok. He thinks that he will be degrading himself if he does so. He always needs someone to make him that cup of tea. And sadly, no one really makes an attempt to make him realize that he should make his cup of tea! In fact, often you will find that someone will say 'Arre, [Hey!], make a cup of tea for him.' So that has always been the norm! But that is not applicable to the wife. No one asks about her. When she comes home after work, tired, if she wants to have a cup of tea, she makes one for herself. Why do you still have this gender imbalance? Because it is the way that he has been brought up. The social learning process that he is being a part of. The things that he sees around, he tries to replicate them, and he thinks that it is all right to do that! It still exists today in Kolkata. That is for sure."

The stigma against men performing physical labor long characterized the bhadralok category in Bengal. Earlier scholars such as Mary Douglas (1966), and recent scholars such as Leonore Davidoff (1995) and Baviskar and Ray (2011) have argued 
what makes domestic labor distinctive is that they use it for class constitution and delimiting class boundaries. This is exactly how the bhadralok used it for their boundary work. The core activities of domestic work, such as cooking, cleaning, and childcare, involve "converting the raw into the cooked, dirt into cleanliness, and disorder into order" (Baviskar and Ray 2011: 250, borrowing heavily from Douglas and Levi-Strauss). The ability to maintain these boundaries, to keep themselves above manual labor, is for the bhadralok a sign of power and privilege. That is, to be middle-class and male in Bengal, such as the bhadralok, is to remove oneself further from such labor-oriented work (Bhattacharya 2005; Baviskar and Ray 2011). By carefully conveying their habits, practices, and choices, this class of Bengali men therefore practiced boundary work to separate themselves from their "inferiors." Not surprisingly, then, the term bhadralok has been used frequently as a synonym for high social status among Indians since the late nineteenth century.

Summarizing then, the bhadralok emerged as a combination of a landed class (such as Nanda in Kerani Charit above) and the petty-bourgeoisie class (Bhattacharya 2005). They formed themselves into a distinctive but tenuous middle-class in Bengal. They could exercise most control over the bottom boundary to their social status and they had to work continuously to keep this boundary from being transgressed.

An additional stressor for the bhadralok was the fact that they, themselves, were far from homogenous. In fact they were quite heterogeneous in terms of their caste composition. As mentioned above, most bhadraloks were drawn from the upper three castes of Bengali Hindu society- Brahmins, Vaidya, and Kayasthya. However, the 
boundary work which typically would keep the castes separated had to be transgressed for a variety of cultural, political and ideological reasons especially during the Renaissance. How to transgress caste boundaries to a certain point-- but not too far-was part of the difficult boundary work the bhadralok had to do. Sumit Sarkar's (2002) work on the kerani (clerk) forms an important marker for this argument. While Sarkar points towards the existence of differing economic subcategories within the category of the bhadralok while other scholars have extended Sarkar's argument to show why and how these divisions were socially maintained (see for example, Bhattacharya 2005 and Baviskar and Ray 2011). Thus, scholars draw upon material explanations to explain how the bhadralok appeared to be homogenous and thereby were able to propagate a unified cultural ideology during the Renaissance even though they truly suffered from internal stratifications. Keeping this difficult balancing act even was essential to the ability of the bhadralok class to claim higher social status. In so doing they negotiated not only their local status but also, increasingly, enhanced their social location on the national stage visà-vis other regional groups of the India (Bhattacharya 2005).

One key example of how the bhadraloks occupied middle and gendered terrain in India at this time is the construction of the Bengali babu, a particular category of the Bengali bhadralok class. Why is it important to understand the cultural construction of the effeminate Bengali babu? Scholars argue that the class of Bengali babu was a colonial construct, a category of men who were Indian phenotypically but British culturally and deemed effeminate in terms of gender and sexuality (Majumdar 2009; Sinha 1995). The Bengali babu, thus, was constructed so that he would not threaten the highest social status of the white colonial (British) man yet he could participate in colonial male activities. 
Most importantly, as a categorically defined (that is bounded) effeminate gentleman, he was culturally unsuitable as a potential mate for a white female colonial. He played the perfect GGP middleman. In short, the dynamics of British colonialism required a "native" yet loyal middleman group who would also not threaten the colonists' own masculinity. The Bengali babu fulfilled this role and thus aided Bengali bhadraloks in general to institutionalize their advantages. One of the major ways they institutionalized their social location was through culture as the "sentinels of Indian culture" and through education. They became the learned and cultured class.

With their bottom boundary hardened and brightened, the Bengali bhadraloks could focus on how to improve their upper boundary. This, of course, was the colonists' nightmare and the British colonial men found a trump card they would use to fortify their own lower boundary: gender. There is significant historiography on how the British were able to reduce the bhadraloks' "manliness" (Sinha 1995). How? The epitome of British men's manliness during the colonial era was evident in two social domains from which the bhadraloks would be categorically excluded: sports and chivalry toward their women. By promoting the Bengali babu as effeminate, bookish, and over-serious he was not the sportsman British women were conditioned to desire and, as a class of man characterized as lustful and lacking in self-discipline, he did not qualify as chivalrous either (Bhattacharya 2005; Sinha 1995).

During our interview, Smita indirectly referenced the Bengali babu with her comment, "The Bengali men are typically known to be 'softies,' right?" "They are not known as the macho types, like they will not kill people," she continued. "So that trait 
translates into relationships too. They are softies, so they will be vacillating." Smita is married, in her early forties, and is a professional business analyst for Hewlett Packard (HP) in South Florida. Sitting in the guest room of her single-family townhome on a crisp autumn Sunday afternoon in denims and a tee-shirt, Smita is the image of a selfassured professional. She and her husband Sanjeev were married in India and then migrated to the U.S. for better opportunities. Sanjeev is a software engineer who is also associated with HP but in a much senior position. Smita's matter-of-fact assertion that Bengali men are "softies" is tied to this history of colonial rule.

Not mentioned in Smita's interview was the fact that the Bengali babu faced a very complex gendered task himself. To maintain his enhanced social position vis-à-vis colonial men, he needed to allow his persona to be characterized as "effeminate" so that he would not be perceived as a sexual threat. However, he also needed to not be so effeminate as to be powerless vis-à-vis Bengali women of his social class. He also needed to show his learned status, his modernity, and therefore he could not completely dominate his mate either. As the nineteenth century was coming to a close, the middleclass in Britain as in the U.S. and other "advanced" countries favored higher levels of education for girls as well as boys and women were beginning to work in careers such as nurses and secretaries. If "western" women enjoyed greater freedoms, how could the Bengali babu achieve similar status while not quite threatening those above him? The answer lies in another gender dynamic that gripped nineteenth-century Bengal: the women's question. 


\section{The Women's Question}

What is the women's question that preoccupied nineteenth-century Bengal, and why does the women's question continue to be important today? Mili summed up the women's question when I asked her the above question: "Earlier, what used to happen is, when a girl got married, she had to stick to that marriage no matter what happened. And there were boundaries within which she had to live her married life. And when the girl was married, she was out of her family; she wasn't a responsibility any more. She belongs to her in-laws. And that is why, when the husband died, the girl had to jump into the pyre and be the sati. That was to signify that her world comes to an end with the demise of her husband. Her husband was supposed to be the whole world for her. So in that case, she neither could come back to her family nor to her in laws. She wasn't a responsibility anymore." Like Smita and Mili, many of my informants have raised the issues around the women's question in Bengal and which I will examine below.

Scholars argue that the women's question during this time focused on the centrality of the figure of the Bengali woman within a culture defined by indigenous cultural elite, the Bengali middle-class man, the bhadralok. Postcolonial theorist Partha Chatterjee notes (1989: 623),

What we must note is that the so-called women's question in the agenda of Indian social reform in the early 19 th century was not so much about the specific condition of women within a determinate set of social relations as it was about the political encounter between a colonial state and the supposed 'tradition' of a conquered people - a tradition that, as Lata Mani $(1986,1987)$ has recently shown 
in her study of the abolition of satidaha [widow burning], was itself produced by colonialist discourse. It was colonialist discourse that, by assuming the hegemony of Brahmanical religious texts, the complete submission of all Hindus to the dictates of those texts, and the necessary basis of practices such as widow burning in the sanctions of the texts, defined the tradition that was to be criticized and reformed. We will now see how Indian nationalism, in demarcating a political position opposed to colonial rule, took up the women's question as a problem already constituted for it: namely, a problem of Indian tradition (Chatterjee1989: $623)$.

A rich literature, including the above reflection on the women's question by Partha Chatterjee, documents the "problem of Indian tradition" concerning the women's question during this era and reveals an interesting gendered geography of power. That is, the debates and discussions were not about the women. Rather and despite the moniker given them, they were about the men and their patriarchal negotiations. A classic case and one examined carefully by postcolonial scholars such as Lata Mani is the nineteenth century debates over sati. Sati refers to "the good woman". Later, the idea was extended to refer to widows who jumped onto the funeral pyre and join her husband in cremation (Harlan and Courtright 1995). In her hallmark work, Contentious Traditions: The Debate on Sati in Colonial India (1998), Mani deftly argues that the importance of sati lies not in the practice of widow immolation but rather in how sati preoccupied British colonial officials, the Bengali bhadrolok community, Brahmin pundits, and the missionaries in the eighteenth and the nineteenth centuries. For example, often the ideological battles among the different classes overlapped on the broad issues, like the scriptural sanction of sati. 
However, the irony of the discourse is that the actual performers of the practice, the widows, were marginalized in the debate. Neither the pamphlets nor the petitions nor the newspapers of the time addressed the widow's suffering. The women were either glorified as heroines facing the flames or were pitied as helpless victims. They were thus, according to Mani, neither the subjects nor the objects of the discourse. They were just the terrain on which the debate was carried out.

If the debates over sati were not about the women and their suffering, what were they about? During this era, Mani argues, the bhadrolok used sati for their own purposes. They either strove to control widowed females' sexuality through sati (pro-sati lobby) or ascetic widowhood (anti-sati lobby). While the British categorized the bhadralok as "effeminate" and thus bounded them from access to their women, the bhadralok nonetheless did gendered boundary work to strengthen their social location at the top of the hierarchy open to Indians (Bhattacharya 2005; Engels 2002; Mani 1998; Ray 2000; Sangari and Vaid 1997; Sinha 1997). Sati, and controlling the dynamics of sati, became one important channel through which the bhadralok could harden the boundary beneath them. Sati, then, was a way to handle a group of people, women, who could potentially damage the bhadrolok's carefully balanced social location (Mani 1998). If the widows were to live, they might be a temptation for the bhadrolok themselves or for others. Either case would threaten the bhadrolok's dominance among Indians as they would be accused of not being in control. To have the women "voluntarily" end their lives for their husbands solved this problem. However, this solution had an obvious drawback. Sati appeared uncivilized to many, particularly those like the British who viewed themselves as the epitome of civilization. Ascetic widowhood (the position of the anti-sati lobby) 
could "solve" that problem. Another sticky issue for the bhadralok was how to educate their women so Bengalis would be seen as cultured but not to educate them too much as to threaten the bhadralok's control over them. This delicate negotiation continues to today and in my interviews emerge through the word commonly used to describe Bengali women-"feisty."

When speaking about Bengali women and comparing them to Bengali men, Smita claimed, "Bengali women were and are always a little feisty. More than the rest of Indian culture." She further asserted, "And among all of Indian women, probably Bengali women are the most feisty. They [Bengali women] are 'softies' in some aspects but, you know, they are like a strong breed. So naturally they are a lot more focused on career and they are always doing something." Smita's reflection is directly informed by her own lifestory. Originally a graduate in English Literature from a top-ranked university in India, Smita followed her husband Sanjeev to the U.S. after their marriage, thus fulfilling societal expectations. However, she did not want to remain imprisoned as a dependent wife in the new place. She continued looking for opportunities where she could fit in with her expertise and benefited from Sanjeev's full support in her efforts to do so. Coincidentally, Sanjeev's employer, HP, required people to work in their business sector, and they approached Smita. Without any delay, Smita grasped this opportunity and has been working with HP for the last twelve years. Many years after she had started her job as a business analyst, Smita also earned a Masters in Information Systems from a local business school to align her expertise with her job profile. Smita is thus a personification of Bengali women as a "strong breed." 
However, in spite of being portrayed as a "strong breed" and "feisty" the truth is more complex. Historically, Bengali women of the bhadralok class had roles appropriate to their men's needs. Sometimes they needed to be more supportive than feisty, more weak than strong. They needed to modulate their assertiveness/submissiveness quotient in accord with what their bhadralok partners needed in negotiating the social locations for their whole class. And to do so meant additional boundary work separating the bhadraloks vis-à-vis the rest of the population. The need was solved through the invention of the "respectable" female partner - the bhadramahila [bhadra = respectable/civilized; mahila $=$ woman/lady] (Bhattacharya 2005).

Much has been written in newspapers, magazines, and novels about the category of the respectable bhadramahila. The bhadramahila was to the home what the bhadralok was to the public sphere - a civilized, educated, cultured presence that was clearly not British but also clearly a superior Indian. The bhadramahila played a critical role in the bhadraloks' boundary work. Therefore she was both was highly valued and in need of male protection from the corrupting forces of the greater society. The solution? Have her exercise her talents but within the confines of the home and family. She became the maximum domestic cultural expression of the middle-class and served as a model to other social classes and castes (Bhaviskar and Ray 2011; Sangari 2001).

In fact, Kumkum Sangari (2001: 307) argues that there has been an "astonishing consensus" around gendered domestic labor, domesticity, and the domestic sphere in general. On the one side of a clear gendered boundary were the bhadramahila and on the other side were "unprotected" women. "Unprotected" was the signifier for women who 
could not afford to stay sequestered in their homes and thus were exposed to the public. These were women who by just moving around in public (for work, trade, etc.) were deemed unprotected and thus incapable of achieving bhadramahila status. This same boundary between the "respectable" bhadramahila and the "unprotected" women of the street has continued over the decades and still prevails (Baviskar and Ray 2011). As I explain later and as anticipated in the comments from Arpita now, this old boundary line has had to shift in order to accommodate another criterion for enhancing social status. "In our culture [Bengal], women, that is the bhadramahila," Arpita told me, "should work outside the home only if that become an economic necessity. Under normal circumstances, women should be maintained first by their fathers and then after marriage by their husbands. It is their [father's and husband's] dharma, their righteous duty."

So to summarize, the nineteenth century in India saw the emergence and solidification of a gendered geography of power marked by significant yet continuously contested boundaries. Vis-à-vis the Indian social hierarchy the bhadralok occupied a high social location but they had to stay inferior to British men and not threaten British women. Consequently, the bhadralok needed the right type of female partner, one who would appear modern but not be too assertive else risking the carefully the men's crafted middle-ground position. At the same time, however, the bhadraloks also wanted their women to be of high status, in order to lift the entire group's social location in the Indian social hierarchy. This is why the "women-question" occupied a great deal of discussion in Bengal. 
Before leaving the discussion of the women's question during the period of nationalist struggles, it is important to return to the topic of educating women. Why was there a need to educate Bengali women at this time? One reason can be found within the colonial gendered geographies operative then. Whenever a colonial power is superseded, its systems of social stratification and their corresponding forms of boundary work do not necessarily disappear altogether. Some "lines that divide" do while others persist and are appropriated (or re-appropriated) to do boundary work again, just with different groups. Such is the case with education in the late colonial period. If Bengalis strove to not only overthrow the British but also to locate themselves highly upon the expected postcolonial social hierarchy, what role would education of Bengali women play? For a response, I first turn to the spontaneous comments of Aditi during our interview.

A married woman in her early thirties, Aditi commented that "I think the seeds of the 'need' to educate women were sown by great men like Vidyasagar, Rammohan Roy, and Vivekananda [men who were pioneers during the Bengal Renaissance] to name a few. Their efforts were directed towards the betterment of women who, at that time [in nineteenth century Bengal] were treated as comparable to domestic animals. Not only for women in the lower sections of the society, but even in rich families. It was almost blasphemy if women spoke their minds or said something intelligent! It was a threat to the so-called 'men's world.'" Aditi reminisced stories that she has heard from her mother and grandmother. The Indian nationalist movement at the turn of the nineteenth century required that middle- and upper-class Bengali women be educated in order to become more modern and thus suitable for their educated husbands. Yet this education could not position them too highly so as to challenge the authority of their menfolk. The balance 
found was education oriented toward preserving feminine qualities and/or feminine occupations (not unlike females' education in Europe or in the U.S. at the same time) (Chatterjee 1986, 1997; Walsh 2004). Masculine control over women and, in particular, their sexuality became issues of increasing concern in this balance to educate women but not so much as to foster too much consciousness of "modernity" and its accompanying freedoms for women (Chatterjee 1986).

In short, Bengalis wished to modernize and to view themselves as modern leaders but men still felt anxiety over how modern they would let their women become and this played out in gatekeeping of their bodies. For instance, one of the three Brahmo Samaj founders, Kesabchandra Sen, returned from a trip to England in 1871 and committed to the idea of educating girls but keeping them separate from boys. His idea of girls' education was one that would focus on their "unique biologically determined" feminine nature. Sen argued that girls need not learn "manly" subjects such as geometry or the sciences but, instead, should study the domestic skills that would secure happiness in their futures as wives and mothers (Borthwick 1984:86- 87). Sen's position was opposed by members within his own group who continued to fund a girls' school that provided equal education for all children. This school was then merged with the oldest women's secular school in Calcutta, the Bethune School, to provide women educational opportunities at primary and secondary levels as well as at the university level. However and in spite of this, the gendered boundary work to separate and keep separate "manly" and "womanly" subjects in education took hold (Walsh 2005). Clearly, their agenda called for balancing the needs of modernization with those of patriarchy leading to a 
modicum of education for women, but by no means so much that they might disturb the existing patriarchal order (Chatterjee 1993).

Education segregated by gender was the primary form of boundary work in schools but this was not the only negotiation of social status at the time. Rather, there was another layer of boundary work which Aditi raised in her interview. "Now, if we look at a few aristocratic families like the Tagores to start with," Aditi claimed, "we see women's education was considered a very important part of female upbringing. The daughters and wives of that family were extremely talented and they expressed those talents freely and played very important roles in reforming the society and creating new ideas in the field of Bengali cuisine, fashion, and education, to name a few. Now, they were an 'aristocratic' family. Education was their right and privilege. Whereas when it came to the middle-class Bengalis, girls considered themselves lucky enough if they received an elementary grade education and were married off at the ripe age of sixteen or eighteen!" Clearly, Aditi's response relates to an additional axis of boundary work within this gendered geography of power: what typically is characterized as "class." Aditi concludes, "Educating the girl child became a social norm in Bengal [at that time] and since then this has continued pretty much like being on auto-pilot. However, how much of that education she actually decides to use or gets to use in her future was not and still is not an important factor in the society." Aditi's last remark is directly related to her own experiences. A graduate in chemistry from one of the leading universities in India, Aditi is now only a dependent spouse living in South Florida where her husband, Ashoke, works with American Express. Spousal visa restrictions and lack of support from her 
husband and in-laws have kept her away from pursuing her academic and professional goals.

The women-question was critical in most controversial debates over social reform in the early and mid-nineteenth-century Bengal. And most of the current literary works on the era examine gender as it defined Indian nationalism during the colonial and postcolonial years (Chatterjee 1993; Sinha 1995). However, though this period witnessed significant reforms in practices involving women, the women-question, as Chatterjee (1993) notes, suddenly disappeared from raising any public passion within a few decades following the Bengal renaissance. While there may be other explanations for this sudden disappearance of the women's question, Chatterjee (1993:117) argues that “The reason [of the relative unimportance of the women's question in the last decades of the nineteenth century] lies in nationalism's success in situating the 'women's question' in an inner domain of sovereignty, far removed from the arena of political contest with the colonial state. The inner domain of national culture was constituted in the light of the discovery of 'tradition'."

This "discovery of tradition" is closely linked to the intimate geographic scale of the home. If, as argued above, women's social locations were contested by colonizing and colonized men, would women be pawns in the more intimate space of the home? In contrast to the higher scale of the nation, at the social scale of the home Bengali women aligned with their male counterparts particularly with regard to anti-imperialist nationalist struggles (Blunt 2006; Desai, 2002, Sinha 1995; Thapar-Bjorkert 1997). Indeed, it is within the domestic scale that women were empowered and empowered themselves into 
the "strong breed" needed for successfully battling the colonizers. In so doing, women were not playing roles of traditionalists holding back the new nation, but, rather, "as agents of national progress and esteem" (Thapar-Bjorkert 1997:496). "Not only were the public/private boundaries blurred, the domestic arena became an important site for the steady politicisation of women's consciousness" (ibid: 494).

The home became a gendered site but not one reproducing "traditional" patriarchies. Rather, homes became the preparation grounds for nationalist struggles in which gendered divisions - boundaries accentuated by male negotiation of colonizer/colonized social status—relaxed while nationalist boundaries—Bengali men and women uniting to fight against the British--strengthened (Desai 2006; Legg 2003). Exploring the imaginative and material contours of the home for middle-class Bengalis, postcolonial theorists Dipesh Chakrabarty $(2000)$ and Partha Chatterjee $(1989,1993)$ the importance of domestic space and social relations in forging nationalist politics. Chatterjee, for example, argues that middle-class Bengali homes, the place of women within them, and anxieties about the modernization of women and domesticity, were all vitally important in shaping the symbolic domain of anti-colonial nationalism. Both the home and the nation thus became contested sites, imagined in ways "that resisted rather than repeated westernization" (Desai 2002, 2006).

The women's question is important to understanding Bengali gender relations within and across multiple geographic scales - from the domestic to the colonial so far. This dissertation will also address its influence transnationally. Before I can move to that fundamental objective, however, it is necessary to bring into the analysis the philosophies 
upon which the women's question in Bengal rest: the philosophies of dharma and grihalakshmi and the strict sense of boundary work involving femininity and masculinity for Hindu Bengalis.

\section{Hindu Bengalis' righteous duties and practices informing group and family relations}

As I will examine below, for Hindu Bengalis dharma forms the ideological foundation for gender relations within and across multiple scales - the family, in marriage, and even nationally and transnationally. So what is dharma? There is no exact English translation of dharma. However, in An Introduction to Hinduism, Gavin Flood effectively sums it up this way:

The term 'dharma' is untranslatable in that it has no direct semantic equivalents in any western languages which convey the resonance of associations expressed by the term. It has been variously translated as 'duty', 'religion', 'law', 'justice', 'ethics', 'religious merit', 'principle', and 'right'. More particularly dharma is the performance of Vedic ritual by the Brahmans. It is the ritualistic order of Vedic sacrifice, which refers especially to the performance of the solemn rites enjoined on all Brahmans, to the domestic rituals, and to obligations appropriate to one's family and social group. Dharma is an all-encompassing ideology which embraces both ritual and moral behavior, whose neglect would have bad social and personal consequences (1996:52-53). 
Dharma is an obligation as declared in the philosophical texts of the Vedas, to perform ritual action (karma / kartavya) "which brings to itself no reward" (Flood 1996: 53) other than that if it is not obeyed, it will result in sin or retribution, or adharma.

One central idea embedded within dharma is the concept of life-stages or ashramas. The meaning of ashramas - originally limited to refer to hermitage - was extended to refer to permanent possibilities or lifestyle choices that every person must pass through (Flood 1996; Kishwar 1990, 1994). There are four such stages which occur in one's life in succession: the celibate student (brahmacarya), the householder / family man (ghrihacarya), the hermit or forest dweller (vanaprastha), and the renouncer (samnyasa). The celibate student stage of life (brahmacarya) is the first stage, extending to when the student goes to his teacher (guru) to learn the Veda. Once the student completes this stage, he returns from his teacher's place (gurukula) - with a developed mind - and is ready to start his second life-stage: ghrihacarya, or the married life. It is particularly this second ashrama (ghrihacarya) that is key to understanding marriage and spousal relations. The third life-stage - vanaprastha - is a generational move upward when he is expected to become a grandfather. The final phase or samnyasa is when he is expected to shun all material attachments and seek final liberation (mokshya). By specifying the various life-stages that a person should pass through in a consecutive manner, dharma provides a classic example of boundary work punctuated by periodic transgressions across a person's lifespan. The four stages or ashramas have definite boundaries to maintain while living in that stage. Thus, the ashrama is a known bounded stage of life in which boundary work is done by each person to himself or herself to 
conform to broader social and religious norms. To conform to these stages in life is to fulfill one's dharma.

By specifying the various life-stages that a person should pass through in a consecutive manner, dharma provides a classic example of boundary work punctuated by periodic transgressions across a person's lifespan. Upon completion of those expectations at the specific stage, s/he may transgress the boundary but only to access the next ashrama and conform to it. Ashramas, thus, are quintessential life stages between which people go through via rites of passage. For example, by finishing their respective education and getting married thereafter, both Smita and Sanjeev have conformed to the initial stages or ashramas fulfilling social expectations. As soon as they were married they were expected to transition into their next stage, that of grihacarya or family life. This also means that social expectations are involved with the couple having a baby and thus welcoming parenthood. Smita and Sanjeev transgressed this social norm by choosing not to have any children. Thus, even though the couple transitioned into grihacarya or family life, to their family and to the larger society, they did not adhere to the norms of that stage and, hence, did not fulfill their dharma.

The key point to understand with dharma and the ashramas is that there is a set life cycle for Hindus marked by stages that everyone is expected to achieve in life. There are boundaries between stages and there are also ways to pass from one stage to another. This does not mean that the boundaries become blurred because they are expected to be transgressed at ritual times. That is, this is a categorical system with transitions built in. While one is in a particular stage, $\mathrm{s} / \mathrm{he}$ is expected to be in that stage until ready for the 
next. Then s/he can move to the next. This is classic example of the anthropological concept rite of passage.

Not surprisingly, dharma is not the same for males and females. This is where the GGP framework becomes important because dharma is mutually constituted with gender and other axes of identification. This can be better understood by examining the spousal relations guided by dharma. Scholarship on family and spousal relations asserts that the subordination of personal goals is not necessarily reciprocal among spouses in India (Uberoi 2006). Traditionally, as several female Indian scholars have noted, Indian husbands do not emphasize self-sacrifice or meeting the needs of their wives. They are able to retain their status and authority even if they neglect or abuse their spouses (Neff 2001). Indian women, on the other hand, are instructed socially from an early age to be pativratya, to "worship" their husbands and that this will help make them "respectable women" (Dhruvarajan 1990; Neff 2001). Therefore, as a pativratya married adult, Indian women are obligated to perform their various kitchen duties, clean, labor and care for their husbands, family members and children, but tend to receive significantly less health care and education than males (ibid.). Dharma does prescribe some rules for the husbands, such as to provide economic and material support for his family and to make important family decisions (ibid). On the whole, therefore, dharma functions to create gendered boundaries between spousal roles.

There is a very interesting time when dharma, in the history of the gendered geography of power in colonial Bengal, merits special mention. It occurs during the nineteenth century Bengal renaissance and anti-colonial movements. During this time 
many Bengali housewives from middle and upper middle-class families whose access beyond their private spheres was restricted during normal times, joined their husbands in the national movement. What would be sufficient reason for them to emerge into public when that would put their good reputations (and thus those of their husbands) at risk? They participated not because of their demand to be a part of the public sphere or to join the Indian national movement. Rather, they did so because of their urgency to abide by their dharma to support their husbands (Mukhia 2002). Yet they still remained obedient wives. In this case, not only was the gendered concept of dharma maintained by these women but they also maintained it across a different social scale than previouslysupporting their husbands in the broader public, national arena and not just in the domestic domain. As soon as the anti-colonial struggle was accomplished, then, the same Bengali men who had advocated for educating women as part of a greater movement to modernize their people would expect the women to retreat back into the domestic realm and into sex-segregated schools. And fulfilling dharma was the perfect foil for this strategy. This case shows how dharma is at once a boundary maintenance system yet flexible enough to permit periodic boundary shifting when negotiating other axes of differentiation come into play. Indeed, dharma understood as the fulfillment of one's duty within specified life stages is a very flexible form of boundary work in that it can be adapted to different time periods and by different leaders for their purposes yet still produce what all good boundary work tends to produce: social power relations.

Among Bengalis, another unequal gender power dynamic is manifested when viewed through the lens of another important philosophy: grihalakshmi. Griha meaning home has been imagined in scholarship to be a sacred and secure space. Ley (1981) 
describes the home as "both a thing and an idea" (Holloway and Hubbard 2001:68). This imagination of the home evokes an image of safety and protection, “... with familiar and protective boundaries...a haven in a heartless world" (McDowell 1997). Scholars like Domosh (1998) find that homes are seen as being a bounded, physical entity, which provides a private exclusive space where the residents are free to express their emotions, desires and rest their fears. Yet feminist scholars like Domosh and Seager (2001), Sunder Rajan (2004) and Rao (1996) recognize the home as a site of conflict, control, rebellion and resistance. In short, the home is often ideologically a haven but in reality a locus of great contestation, particularly between spouses.

The conceptual grounding of contestations within the griha -- the home -- is also intertwined with a critical understanding of how patriarchal relations can be and often are based on an a priori subordinate position of women in a gender hierarchy especially within the home. In her recent article the feminist sociologist Vrushali Patil writes, "the presumption of women as sexual-political subjects prior to and external to social relationships is an ongoing problem that distorts extant gender realities" (2013:850). Patil's writing is heavily informed by Chandra Mohanty's (1988) longstanding argument that the position of women in a gender hierarchy is assumed even before their entrance into any social relationships such as in marriage. While the term "patriarchy" has been critiqued by some scholars to be a Western construct (e.g., Oye wu’mi 1997), patriarchal arrangements are at the heart of the problematic construction of women as sexualpolitical subjects across time and space. The a priori subordinated position of women in a gender hierarchy is central to the understanding of the ideology of the grihalakshmi. 


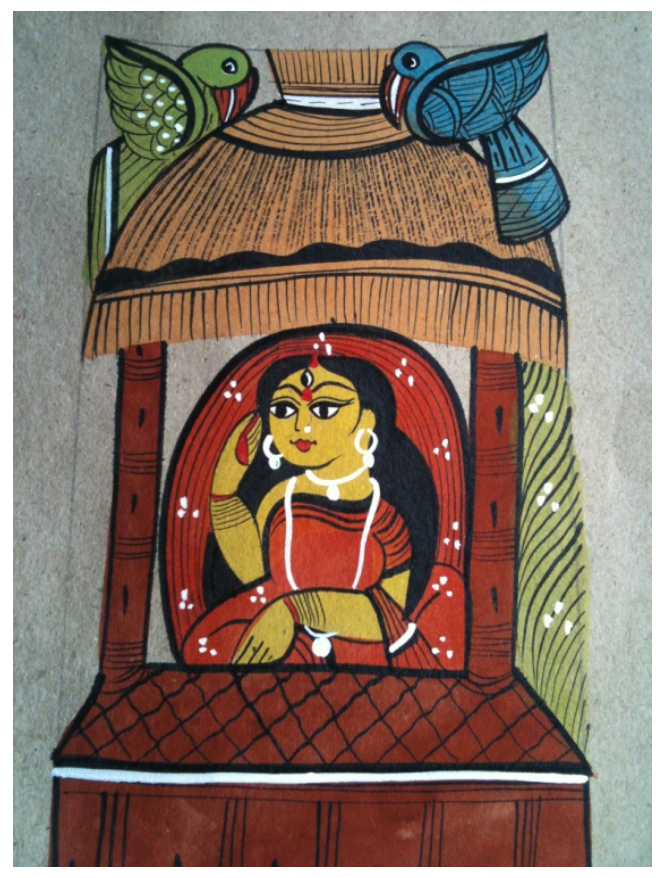

Figure 3.1: Folk art depicting a married Bengali woman as Grihalakshmi by a local artist in Kolkata. Author's Personal Collection.

So how does this relate to grihalakshmi? Keeping the above theoretical orientation of the home in context, the ideology of grihalakshmi has continued to inform Bengali gender relations within the intimate sphere of marriage, family, and home, and has done so for a very long time (Bhaviskar and Ray 2011; Majumdar 2009; Sangari 2001). "If you want to talk about grihalakshmi, we have to go very back in history," Arpita told me during our interview.

A woman in her mid-thirties, Arpita explained this ideology to me as we sat in her living room in Miami one afternoon, sipping coffee. She and Sameer were married four years ago in India. Theirs was a typical arranged marriage. Their families met first and only after the marriage date was set did Arpita and Sameer meet. Soon after their marriage, Arpita gave up her job as a teacher in a junior school in India to followed Sameer to the U.S. as the latter wanted to migrate for work reasons. Arpita explained in 
depth her perspective on grihalakshmi and in so doing provided another example of how my interviewees continuously made direct links between their contemporary lives and the historiography of Bengal from some two centuries ago. "We have to understand the pillars on which Bengali society was formed at the turn of the nineteenth century," she argued. "The root concept is that [Indian society] is a patriarchal society. So the idea of grihalakshmi, although it is about women, was fashioned according to the benefits and needs of men. Men structured this idea that if women had [grihalakshmi] qualities, they were good, they were grihalakshmi. But these were all to the men's benefit. And then from there, this idea continued to be a learning concept. And most people followed this learning process to raise their daughters specially. That if you have all these qualities, you'll be a Lakshmi." Arpita identified clearly how this ideology seems to be about women but actually serves the interests of men by turning women into obedient wives. As argued earlier in this chapter, men's social status rested at least in part on the pillar of his wife's virtues, of her belonging to the bhadramahila class. "But the funny thing is," Arpita continued, "in Hindu mythology, we do not know what Lakshmi's character was. All we know is, she is the goddess of wealth and prosperity. So the whole thing is a social construction. And it was all constructed to benefit men. And that has been followed down the generations [in the ways] to raise daughters. One daughter has been raised in such a way that she also raises her daughter the same way. Only then [following the grihalakshmi ideology] will you be a good mother. The story does not end if you become a Lakshmi. You have to give birth to and raise your daughter such that she also becomes a Lakshmi. Only then will your Maatri dharma or motherhood be fulfilled. So strong has been this social learning. And this has been handed down over the generations. And girls 
from a very young age have been taught to think and prepare themselves for a specific cause, place, and space in society. What is that? That one day when they will get married, they have to become a grihalakshmi." In this parlance, the continuation of the grihalakshmi ideology by the Bengalis especially Bengali migrants who I studied for my dissertation is reminiscent of Robert Anthony Orsi's (1985) work on Italian migrants in the US inventing virtuous Italy based on childhood memories so that the next generations are raised with no exceptions.

Arpita's statement on grihalakshmi is a typical exemplar of many of my female respondents' reflections on the ideology and is significant in several ways. Arpita, like the other female respondents, argues that although this ideology serves men, it is women who do the day in and day out gendered boundary work of grihalakshmi. It is also women who transfer the ideology to their daughters and in so doing continue to subject them to this gendered boundary work. Therefore that women subject themselves and their daughters to patriarchy. That is, they play a more profound role in their own subjugation than that which emanates from fulfilling dharma. Kumkum Sangari (2001: 292) recognizes the centrality of household in the everyday production and reproduction of social and gendered inequality particularly related to manual labor and grihalakshmi: "Since the household is a space for the daily production and recreation of social inequality not only on gender but also on class and caste lines, the cross-cutting class relations inside the households would themselves severely mediate the ideological translations of labor." While the boundary work concerning dharma is shared by men as well as women, my data suggest that women do a disproportionate share of the gendered boundary work by being the grihalakshmi. Additionally, dharma and grihalakshmi in 
nineteenth century Bengal meant that women were largely geographically circumscribed to the home - the intimate sphere. And, as discussed above, this was one of the reasons why widows presented a potential problem to male dominance.

Scholars of South Asia have elucidated the ways in which the ideology of dharma has initiated debates over domesticity (therefore over the ideology of grihalakshmi). As I have argued above, these debates arose simultaneously with the creation of a middle class in the late nineteenth century and a class construction that is quite visible even today. Indeed, Tanika Sarkar (2001) shows that the debates around the forms that domestic life should take were publicly played out in colonial India. But scholars also note the limited scholarly work done until now on how the Bengali middle-class, particularly the bhadralok, articulated its class identity through a boundary work distancing the "inferior" (Bhaviskar and Ray 2011). However one common theme that these scholars note is that the home, household and family, slowly but surely, came to be widely recognized for their role in the production and reproduction of gender inequality. In the following, concluding section of this chapter, then, I examine the intimate gendered geographies of power as they operated and took shape in family and spousal relations, and within the home.

\section{At the geographic scale of intimacy: Family, Marriage and the Home}

Thus far, I have examined Bengali gender relations structurally and historically but not in terms of gender dynamics within the intimate scale. I now engage in examining their gendered negotiations at the intimate geographic scale - the home. However, in order for the reader to understand the gendered geographies that were operative within 
Bengal's social milieu especially in family and marriage, it is important to first understand how the intimate scale functioned on a national level - that is, providing a pan Indian picture as backdrop to this discussion.

The earliest phase of the study of family in India described and examined the family in terms of its structure: the joint family (Gore 1965, 1968; Ross 1961). The joint family structure that this scholarship examined comprised a couple, their unmarried children as well as their married sons and their families. This scholarship looks at the joint family as "a multiplicity of genealogically related units (akin to the nuclear family model) living under one roof and sharing in resources, rituals, and property" (D'Cruz and Bharat, 2001: 168). Rita's father Subeer, who, like all male respondents in this research represents the bhadralok class, captures this arrangement well in his response to my question on how was the nature of the family historically. Subeer responded, "Previously, parents - the elderly parents I am talking about - had three or four sons, or two sons and two daughters. The sons always lived with the parents in a big house, and the daughters were married off and kept visiting the parents. Nephews and nieces, everyone used to live together. We celebrated festivals together, bought new clothes together, and all these things were very much part and parcel of daily life. For years and years. Houses were big; there were facilities for everyone to stay together." Subeer and his wife raised their daughter Rita, now 35 years-old, in Kolkata where she spent her formative years in a joint family in the city. Rita finished her Masters degree from a well-known university in Kolkata, while her husband Shishir, now 38-years old, completed his bachelor degree in computer engineering from a local college in Kolkata. Rita and Shishir's marriage was arranged by their family. The couple migrated to the U.S. in 2005, Shishir on a H1B 
category visa and Rita on a H4. The couple has filed for their permanent residency which is in process. They now have a three year-old daughter.

Subeer's reflection on the historical gendered geographies of power that operated within the large family units is far from unique. My respondents have referred at various points in their interviews to this historical characteristic of large joint families. For example, Priti's mother Nandini responded to my same question on family historically in her following words: "Father, Mother, siblings ... in India, very important is the extended family, immediate relatives. Even relatives' neighbors become your family. And that is how we have grown up. So when I was growing up, my school days and college days....when I was with my parents, before my marriage...I can relate to this...because it used to be a very happy family...going to school...come back and then you will always fine some Pishi [father's sister], some Maashi [mother's sister], some people were always there and the afternoon session was going on. Snacks being served. Then the family over the weekend, in winter, getting the car and going off to Diamond Harbor [popular tourist destination in the outskirts of Kolkata]. And in that, never alone! Mashis, Pishis, and even next-door neighbors - they were very much part of the family. If some special dish was being cooked in the Mashi's or Pishi's house, it was brought over to ours, and vice-versa. And so with the neighbors. Very Happy. Very happy. Uncomplicated life. Very simple living. Very good values given to education. And... strict things about eating time, how much can you venture out with friends, can you go alone or not. In school days, friends' dad used to pick up and drop off. The parents would know all our friends, where we went, with whom we went. And all day long, Mashi, Pishis, Mama [mother's brother], Kaka [father's younger brother], Jetha [father's elder brother], and more of extended 
families. All weekends full of cooking and eating mangsho-bhaat [lamb curry and rice, symbolic of prosperity and happy times]. Happy scenario."

The above quotations paint a very vibrant portrait of large groups of people cohabitating and sharing meals, etc. But they also raise and important social science question: Who qualifies as extended family? Families are social constructs and so it is key to figure out the boundaries to the concepts of family in general and extended family in particular. When I asked Mili's husband Rahul to explain who forms an extended family, he responded, "Depends on the relationship and the kind of bonding you have had with that person. Maybe not your real uncle like your father's younger or elder brother, or father's maybe very good friend from college, they become like your uncle more than your blood-uncle. And there are many such instances. Many other families, not every family though, such as .... couple and then their immediate family become closer than the real relatives are. And it all again depends on one family to the other. Some family may have six or seven brothers and sisters, they are all very close...in some families- two three have moved away and they don't have time to bond, some one or two family members they are very close to... again as I said, they are father's friend, or mother's...Mashi's in-laws family and that kind of a thing, ... and they become almost like family. They may not have any blood relationship, but they become almost like family. It happens. It still happens. But whether it will happen from now till in the future, I do not know."

Rahul's phrase "It depends..." captures the complexity of trying to pinpoint family among Bengalis and Indians more generally. Historically the systematic study of 
the family in India, has, by and large, been a study of family patterns (Bharat 1994), rather than of family dynamics (Uberoi 1998). Important works in this regard include the works of M.N. Srinivas (1942) and M.N. Banerjee (1944-45) (see Bharat \& Desai 1995 for a comprehensive bibliography). However, earlier scholarly conceptualization of the joint family failed to capture the dynamism (as opposed to structure) of the joint family, living under the control of one "patriarch." This literature therefore was overwhelmingly silent in addressing the dynamics between various family members such as between family and extended family members

Existing scholarship has documented to some extent the relations in the joint family and thus captured some of the early gendered geographies of power that operated within joint families. Scholarship reveals that familial and fraternal bonds were encouraged. Problems in the fraternal relationship could arise because age differences give rise to status differences in the family that, in turn, could precipitate rivalry and conflict (D'Cruz and Bharat, 2001). These were thwarted by the principle of deference to age. In sibling relationships, particularly between brother and sister, the brother was deemed to be the protector and the sister was a source of affection and emotional support but clearly inferior to her brother in terms of family social status. The strength of this sibling relationship was aided by the absence of rivalry and by the brother's potential to be a strong support in times of adversity during the sister's adult married or unmarried life. The brother also played an important role for the sister's children as a source of affection, economic support, shelter and ritual significance (ibid). 
One important gendered geography of power that can be understood from this scholarship is by following how conjugal relationships operated in the joint family. Conjugal relationships were peripheral in the family for the maintenance of the family. This was so, because if conjugal relations were allowed to develop, it was assumed that they could set the atmosphere for the creation of an undesired nuclear family. In order to overcome the undesired, the joint family was structured and institutionalized according to several principles: (a) the segregation of the sexes, which is manifested in a sexual division of roles as well as in a separate social life for both men and women, the rules of which are internalized through gender role socialization; (b) the disapproval of the romantic complex prior to marriage through arranged alliances orchestrated by the family, the absence of courtship and the discouragement of overt manifestations of emotional behavior between the couple (D'Cruz and Bharat, 2001). Deviations from these were highly condemned, with the spousal relation being one of respect from the wife's side and indifference/kindness from the husband's; and (c) the ability of all the adults in the house, especially the males, to regard all the children as their own and not favor any one child/any one group of children (ibid.). Despite these mechanisms, physical and emotional intimacy between the spouses and a strong mother-child bond did develop and coexisted with joint family sentiments. When they conflicted, they often led to a division of the joint family.

Earlier scholars also examined authority and leadership patterns in earlier forms of the joint family and how they were decided along gender and age lines. In terms of gender, the joint family followed the terms of a typical patriarchal society -- where men are the breadwinners and inheritors assuming greater power than women and this persists 
even where wives are wage earners as well. Smita described this arrangement in her following words: "I think it [gender relations in family] used to be very one sided. It used to be a very male chauvinistic society before... and I've seen it I think in my own house and I've seen it everywhere...if anyone has to compromise, it has to be the woman." In this earlier form, while women were subordinate to men, their status in the family was also influenced by the fact that they were "unrelated strangers." They would enter "the family as individuals who must fit in with the family where the men are related, live in the same house and already belong to it" (D'Cruz and Bharat, 2001). So this was a different gendered geography of power at the intimate scale that women, when married, had to negotiate. How? Each woman entering the home via her marital ties was socialized by the women already in the home, typically the mother-in-law. The new bride's interactions with the men, including her husband, were minimal due to gender segregation in the family and male superiority. Consequently, companionship among spouses was actively discouraged in such a joint family. Companionship is egalitarian so it makes sense that such a patriarchal and hierarchical family structure would spurn spousal companionship. The spouses might grow too powerful as a unit and thwart the larger family, its needs and its power asymmetry. To prevent such a threat, women were not only segregated from men, they were kept structurally at a significantly lower social status overall. And who was the principal architect of their lowly status? The highest of the lowest gendered strata (the patriarch's wife) enforced the gendered boundary work against her daughters-in-law.

With this backdrop, I will now narrow the lens specifically to Bengal. The centrality of the imagined joint family structure in Bengal towards the end of the 
nineteenth century / early twentieth century was more a matter of active contestation rather than an accomplished fact (Majumdar 2009: 12 -14). A close examination of the nature of marriage and spousal relationships around this time sheds light on the relationships between people in the family and in marriage. In Marriage and Modernity: Family Values in Colonial Bengal, historian Rochona Majumdar (2009: 13) argues, "The centrality of the couple was often recognized but at the same time subordinated to the larger ideal of the joint family. There were conflicts, of course, between these ideas of the individual or couple and the family. These struggles gave rise to certain changes in the marriage form". This was a gendered geography of power that was not quite identical to the one operative at the national scale and yet it was similar to the national model because the joint family was at the center and the couple was still peripheral.

Among the Bengali bhadralok class and as detailed earlier in this chapter, gender relations at the intimate scale of the family began to shift from the end of the colonial rule primarily with the move to educate females. There was a shift in patriarchal practices too. Popular in scholarship as the "new patriarchy," this arrangement saw the maximum shift in social location for the daughter-in-law of the family (Majumdar 2009). The daughterin-law was now brought from the lowest position within the family, the "doormat" position as used to be historically, to the second highest, the highest being her husband the son of the family. The gendered geographies of power between the couple, and between the couple and the extended family therefore changed. The formal image of the bourgeoisie couple form, or the dyadic couple form, was "firmly set in and circumscribed by the context and the ideal of the reconstituted joint family, in which the couple lived with the groom's parents and other relatives, sharing the same home and eating out of the 
same kitchen. A perfect marriage was one that performed this compromise" (Majumdar 2009: 127).

Also built into this new ideal of the family was the ideology of a new patriarchal order, different from the one that operated until the mid-nineteenth century and still operates in many regions of South Asia. This was the representation of the couple in marriage as a dyadic couple (Majumdar 2009). To be sure, all married couples are dyads. However, until the new patriarchal arrangements, in Bengal at least, the couple form was not recognized as a separate entity, a dyadic entity. The couple, after marriage, was absorbed into the larger family, with members having their own roles and responsibilities towards the others following their dharma. There was little to no space, at least officially, for the "couple." The couple is a more modern idea. This shift in gendered geography of the spouses, scholars argue, is a blend between the Victorian model of companionate marriage indigenizing forces that bound the couple not to a nuclear family but back to the joint family (Majumdar 2009). To build houses that could accommodate large numbers of people — children and their spouses and grandchildren along with other relatives — was a marker of Bengali high social status. The dyadic couple form became another boundary work strategy via which Bengalis continue to assert their high social location within the larger society. How? The Bengalis portrayed their dyadic couple form as a statement of "modernity," envisioning a revision in their marriage and family practices (Majumdar 2009). However, and quite akin to the other gendered strategies found operative in nineteenth-century Bengal, much of the GGP shift within the Bengali family and spousal relations, scholars argue, has been finally to counter patriarchal agendas. For example, postcolonial theorist Dipesh Chakrabarty $(1993,2002)$ argues in his discussion of 
colonial Bengali society that the emphasis on family and a specific kind of education for girls and women conducive to the maintenance of the family were ultimately about the ideals of modern Bengali patriarchy. Chakrabarty's argument on historical Bengal can be traced to their contemporary practices, even transnationally as my next chapters will examine.

The fact that the women came into their husband's family from diverse family backgrounds generated new gendered geographies of power in their family and spousal life. They were expected to conform to gendered ideologies and practices in the family in order to survive, though such practices appealed as distasteful and stressful to them. This could work as a strain on the family, threatening its stability if the conjugal bond is strong, thereby demonstrating the relevance of minimizing it. Mechanisms to reduce this strain included a further division of work among the women - one made explicit via the complex of arranging marriages. Gratification for women came from motherhood, especially from the birth of sons, who ensured them high status in the family. Daughters were not valued as much since it was assumed that they could not elevate the women's status in the family and in the larger society. Daughters also enhanced economic burden as dependents and eventually had to leave their natal home. Seniority played a pertinent part in determining the authority among the adult males, with the oldest male -- the patriarch -- being the most powerful. He might share some authority with the oldest female in order that the household may be effectively managed by her. Undoubtedly, as the eldest son matured, the head of the family might delegate some authority to him which helped him prepare for his future role as head. It was not uncommon to find 
women exerting authority covertly through their husbands (D'Cruz and Bharat, 2001; Majumdar 2009).

\section{Chapter conclusion}

In sum, historical empirical works on the earlier form of the joint family established the belief that the joint family structure was the norm in independent India although later empirical works on the preindustrial, urbanization period questioned this notion (Goode 1963; Shah 1968, 1996). For Bengalis, in addition there was another dimension why, in spite of recognizing the nuclear couple form as important, the joint family form and extended family ties continued to be important. As I will examine in the next chapter, large and joint families continued to symbolize high status in Bengali society at large. 
CHAPTER IV - GENDERED GEGRAPHIES OF MARRIAGE AND THE FAMILY IN BENGAL AFTER INDIAN INDEPENDENCE

In the previous chapter I examined three key gendered events in nineteenthcentury Bengal in order to offer a background to my interviewees' responses: 1) the birth of the Bengali bhadralok class (Bengali men belonging to the middle class); 2) the women's question in nineteenth century Bengal; and 3) the shifting GGPs in Bengali marriage and the family from this late colonial period. To be clear, the previous chapter did not examine all of Bengali history in the nineteenth century; instead, I examined only the above-mentioned historical dynamics that my interviewees referenced as important to how they live their lives today.

In this chapter, I turn my attention to the early post-colonial period in Bengal (from the 1950s until the late 1990s) to examine Bengalis' family and marriage dynamics. Like in the previous chapter, in this chapter I will examine this time period in Bengali history from the perspective of different geographic scales -- supra-national and national, as a group, and within the intimate scale. Using the GGP and Boundary Work frameworks, I will examine Bengalis' marriage and family dynamics at the supranational, national and the intimate scales, and their negotiation of social status at the geographic scale of the group.

\section{Marriage and the family at the supra-national and the national geographic scales:}

\section{Nationalizing the joint family}

One of the most important negotiations in marriage and the family immediately after British rule ended in 1947 can be understood by examining the independent nation's 
continued preoccupation with the family. How? The political transition during the end of the colonial rule in India involved a struggle for power pitting the president of the newly formed republic, Dr. Rajendra Prasad against the Prime Minister, Jawaharlal Nehru (Majumdar 2009). This was followed by the resignation of India's first law minister, Dr. B.R. Ambedkar just prior to the first general elections in the country. At the center of these political convulsions was the Hindu Code bill of 1955-56, a set of three laws which redrew the social boundaries of marriage, family, and property matters in India in the first years following independence. Bringing negotiations in Bengali marriage from a regional to a national geographic scale, Majumdar (2009: 208) analyzes the Hindu Code Bill:

As we analyze the debates on the Hindu Code we will also be moving from the immediate arena of the Bengali marriage market to the national stage. This is because with the passage of the laws that made up the Code, and the Special Marriage Act just the year before, in 1954, marriage was, in a manner of speaking, nationalized. In other words, for the first time we have some notion of an Indian Hindu marriage with some regional and customary variations. This also makes clear that by legislating for a uniform code that would govern the personal laws of all Hindus, the sovereign Indian nation-state was at the same time creating legal norms guiding the relationship of the individual to his or her family, for these laws dealt with critical topics such as Hindu women's right to divorce and questions of minority, of adoption, and of what constituted a legal Hindu marriage. 
Why was there a need to create national norms regarding marriage and the family? One fundamental reason lay in another crucial political shift around the mid1900s and one which was voiced consistently during my interviews: the Partition of Bengal. In fact, Bengal was partitioned twice (first in 1905 and next in 1947) and the necessity to legislate a "Hindu marriage" or an "Indian marriage" was largely due to the political dynamics associated with the second partition of Bengal. Partha Chatterjee (1999:112) compares the first partition of Bengal (in 1905) with the second partition (in 1947, the year of Indian independence). The first partition, Chatterjee argues, was exclusively a colonial administrative decision partitioning Bengal into two administrative provinces based on cultural demography. This was an example of the colonial strategy of divide and rule -- a classic case of boundary work. In contradiction to the first partition, the second partition was marked by mass nationalist agitation (popularly known as the Swadeshi movement) in India, "demanding the repeal of the partition on the grounds that the people of Bengal were culturally one and indivisible" (ibid. 112). The second partition had at least two interrelated critical political and social implications. First, the partition executed a project which heretofore had been imagined only. This project realized the existence of two nations: one based on linguistic nationalism, Bangladesh and the other, based on religious nationalism, India. As a result, the socio-political history of this political era found at its center significant migration of Hindu-Bengalis from the newly created nation of Bangladesh into the Hindu state of West Bengal in India.

The resulting migration ushered in with it new ideologies and complex boundaries of marriage and family relations. When I asked Mili's younger sister Piya how the ideologies around family and marriage changed over those years in response to the huge 
population shifts, Piya explained: "The thing is, if you say 'idea' of family, then the idea has remained more or less the same. But what has changed is the structure of family that is understood in society. One big issue is the problem of space. And--these are all interrelated - as the population grew, so did the pressure on space increase. Thirty years back, this was not a problem. Second, Kolkata is also home to a large number of migrants (mostly from Bangladesh) which adds to the population. So, say there is an apartment of $1000 \mathrm{sq} \mathrm{ft}$. Parents and their two sons live there. But when the two sons marry, that 1000 sq $\mathrm{ft}$ is not enough for six people. So, the sons move out after marriage, and it's easier to get an apartment than build a house." To anticipate the swift, sharp rise in population, a demand began for high-rise architecture that could not accommodate the traditional extended or stem family as a joint family living under one physical roof.

The rapid rise in migrant population was coupled with another important reason which sparked the immediate need to nationalize the joint family in India around the mid1900s. A powerful section of independent India's new leadership regarded the domain of the family -- that is matters concerning marriage, kinship and property --as an area of "backwardness" which needed to be reformed (Majumdar 2009). Central to the idea of the joint family was the practice of arranged marriage as negotiated by families which transferred the married daughter permanently to a different kin network. Arranged marriages and the joint ownership of property were seen as inimical to the projects of modernizations nationally. To change the principles of the family, one necessarily had to tackle the questions of matrimony. Hence, the newly formed nation resorted to the greatest liberal instrument, the law, to reform this important area of social life. 
The reformation in family and marriage and the various structural and political shifts in the mid-1900s impacted people's living arrangements across the geographic scale of the nation and within the intimate scale. People started negotiating family relationships across households and even when the roof became only symbolic and not physically covering the whole family -- that is, new systems of family "settings" or "setups" (discussed further below) started to emerge in the changing Indian social fabric.

\section{Idealizing the joint family nationally}

With the changes in the Indian polity, economy, society, education system, value system and legal system following the end of British rule (Kapadia 1966), and with the joint family being considered the norm prior to these changes, alterations in the family structure were expected. Several empirical studies that were undertaken after India gained independence in 1947 have, broadly speaking, produced three sets of data. The first set of data (Conklin 1976; Kapadia 1959; Lal 1990; Ramu 1988; Roy 1974; Vatuk 1982) is more representative for the young, urban, and educated section of the population. But some scholars such as Ross $(1955,1961)$ and Kaldate (1961) argued that industrialization and urbanization had led to geographic and social mobility, and anticipated that all of those forces would eventually break down the idealization of the joint family. A third set of data indicates the persistence of the joint family despite industrialization and urbanization. These studies reveal that household size was found to be relatively uniform across the country, with the average size increasing for both urban and rural areas and most couples following joint family norms as best as possible (Conklin 1976; Gulati 1995; Ishwaran 1982; Shah 1968, 1996). Kapadia (1956) found the incidence of joint 
households to be as high as nuclear ones in urban and rural areas with urban households having a bigger size than the rural ones. Gulati (1995) and Shah $(1968,1996)$, on the other hand, found rural household size to be larger than the urban.

However, one central limitation of these studies is that they focused on the structure of the family (that is joint or nuclear) and not on how the members within the family functioned. To be clear, the studies examined in important ways the forms and structures of families such as joint and nuclear. But these studies did not examine how the relationships between the various members in those families were changing. That is, these studies did not account for the changing relationships in family and marriage as a result of changes in the social, political, and economic fabric of India immediately after independence.

An alternate point of view on how relationships within families changed was also upheld. Several researchers illustrate that in the face of industrialization, urbanization, land division, migration, education, mobility, education and employment of women, structural change occurred but the functional jointness of family continued (e.g. Agarwala 1955; Ames 1969; Desai, 1955 1964; Gore 1965; Ishwaran 1982; Kapadia 1956; Khatri 1975; Kurian 1976; Lakshminarayana 1982; Ramu 1972; Singer 1968; and Singh 1988). This is shown to be true of urban and rural areas and of various caste, income, occupation and religious groups in different parts of the country. Empirical evidence demonstrates that change in the socio-structural fabric did not imply a total breakdown of the joint family system. Change and continuity are not mutually exclusive, but simultaneous -- a contradiction made possible by functional adaptation processes 
which maintain and modify the joint family in the industrial urban setting (Singer 1968). Change is thus limited (Gore 1968), with functional jointness being a necessity for survival in the absence of social security (Ishwaran 1982; Oommen 1982). These findings concluded that while the joint family was changing, it was not moving to a conjugal nuclear system, but towards a development that Khatri (1975) termed as the "adaptive extended family."

Recent scholars such as Patricia Uberoi (2006) have argued there have been significant developments toward the end of the 1900s with reference to changing household structures in India largely as a result of changing lifestyles. Uberoi (2006) argues on a national scale how the social reality of "freedom" and "destiny" of the "modern Indian woman" contradicts the moral economy of Indian family life as projected in the contemporary popular media. Particularly salient in her argument is the constant negotiation between the expression of female desire and culturally normative expectations of feminine deportment. Uberoi (2006) also emphasizes another aspect that is one of the central arguments in this discussion: the notion that the "nuclear family" triumphing over the "traditional joint family" that is ongoing in Indian popular discourse, is only a social myth. Uberoi $(1993: 8,2006)$ argues that the changing household structures (often limited to couples and their children, if any) are a product of changing class status in contemporary India, "with as yet unexplored implications for understanding the question of class formation in contemporary India". In her hallmark work Family, Kinship, and Marriage in India, Uberoi (1993: 1-2) argues: 
The reluctance to address the subject of the Indian family stems not from the unimportance and marginality of the field [of family studies], but rather from its importance and sensitivity. It is as though critical interrogation of the family might constitute an intrusion into that private domain where the nation's most cherished cultural values are nurtured and reproduced, as though the very fabric of the society would be undone if the family were in anyway questioned or reshaped. In fact, the family and its values are very much at the center of fundamentalist religious discourses, in this region as elsewhere.

While current scholarship on Indian families is limited in its engagement with changing family dynamics (that is, how various family members relate to each other), this scholarship indicates that boundaries of family were redrawn in the face of massive social and political changes after India was independent from the British rule. Much of the redrawing of the boundaries in family and marriage was done via legislations such as the Hindu Code Bill. I examine the boundaries and their transgressions in family and marriage relations using the analytical framework of boundary work. My evidence expands existing scholarship and directs towards the reconfiguration of the family boundaries to allow for the extended family to reside way beyond the geographic ideal -that is, to include those living in the same city, same country, and even family members living abroad as well. This is a family dynamic that is imagined by my informants and by Bengalis at large who continue to idealize the joint family in the face of massive sociopolitical changes. My informants have called this dynamic the family "setting" or a family "setup." 
What is a family "setup"?

One key conceptualization of the changing boundaries of family that emerged from my data is the idea of a family "setup" or a setting, a multifaceted term that gets to the heart of family relationships and their continuity and change amid the Bengalis. What is a family "setup?" "A family setup refers to an arrangement, a temporary or a permanent one, in which various family members enter into a mutually happy and convenient arrangement," clarified Piya. I was not exactly sure about what Piya meant by a "convenient arrangement that is not permanent," and so I asked her for further clarification. "Well, let's start with the kind of family I grew up in," she responded. "I have grown up in a nuclear family by conventional understanding. Meaning, that I lived in a house with my parents, my sister, and myself. I did not have any grandparents (neither parents' parents were alive when I was born), but I have always been close to my uncle, aunt, cousins. Although they lived elsewhere in the same city, but never for a single day had we thought that we are different families. So to my understanding, my family is my parents, sister, uncles, aunts, and cousins, but we live in separate units such as setups which do not interfere in our living as a family." Piya's reflections are directly related to her own life. Having been born and raised in a nuclear family "setup," both Mili and Piya have always remained strong relations with the other members of their family -- uncles, aunts, and cousins. Piya married soon after Mili and Rahul married, and now she lives with her husband and in-laws as a joint family in Kolkata.

In my interview with Aditi, the "setup" arrangement was central to the discussion too. "If you look at the idea of nuclear family, the idea did not start after the turn of the 
millennium (2000). Nuclear family started 30 or 40 years back, when we were born. But to me, they were not nuclear 'families,' they were nuclear 'setups.' We grew up in a nuclear family setup. So the concept [of a setup] arrived at the time of my parents, if not before." Aditi continued to reflect on how family setups evolved over the decades and how that often complicated family dynamics. "Now, when our parents are becoming parents- in-law, they are trying to make the nuclear setups a joint venture. Why? Because they feel that they are not secured without their sons or daughters from being around them. They are now trying to recreate the concept of the joint family." Having been born and raised in a nuclear setup, Aditi, like many, feels a pressure on her generation to adjust to the joint family system.

This adjustment got complicated especially for the daughter-in-law. "We grew up in a nuclear setting, so it is not very easy for us too to throw away all that we grew up with and dance to the tunes of what is expected of us," Aditi explained. What kind of expectations? Aditi expanded, "Expectations such as adjusting to a joint family setting. For example, almost every decision that we take has to be taken as a family, and not just between husband and wife. Or daily practices like serving dinner to the male members of the family first and then having your own food. Now, we have not grown up in a joint family so we are not familiar with the expectations. Don't think this is just my viewpoint, I can vouch that I am representing a lot of people's viewpoints from our generation. So this is a big problem for our generation." This is an example of how boundaries shifted in family and marriage relations in post-colonial India -- a shift that was negotiated at both the national and the intimate scales. 
Family setups gradually complicated living arrangements in post-colonial India. Arpita, for example, narrated how: "Families have gone along the nuclear household arrangement since the past few decades. They are not nuclear 'families' but they are nuclear 'settings', nuclear living arrangement. But I think that if a couple and [the groom's] parents live in the same city and have totally separate establishments, I don't know how feasible that will be. Rather, I don't know how much 'separate' they will be allowed to be. And moreover, the wife will be constantly bombarded with questions from the husband that 'When my parents are in the same city, why do I have to live separately?' So a question of adjustment comes in there. Either I [the daughter-in-law] am not being able to adjust with my mother-in-law or my mother-in-law is not being able to adjust with me. So irrespective of whether you call it a nuclear household or a nuclear family, I don't know how feasible that will be. Of course, nevertheless, there are people who believe in this and who are living like this." Arpita continued with her example, "Take for example my neighbor-family [in Kolkata]. The mother is quite old; she is in her late eighties. She has a son, a daughter-in-law, and two grandsons. She is an elderly lady, and she stays on the second floor [third floor by U.S. standard]. Her son and his wife and children live on the first floor [second floor by U.S. standard]. So they have made that nuclear arrangement in the same house and they are quite comfortable living with that. So it is also a question of whether the elderly member of the family accepts this or not. And definitely, it depends on spousal tussles and who adjusts to whom. So nuclear households became quite common in the past thirty years in Kolkata but the family bonds have not gone nuclear." It was not clear to me why will they not qualify as a nuclear family and so I asked her, "Why do you call such an arrangement a 'nuclear household' and not a 
'nuclear family'?" To my question, Arpita responded, "This is not nuclear family. It cannot be. Staying in the same city, it is not possible to ignore everyone. It is definitely not possible to lose touch with parents and the extended family. Especially for Bengali men, they have been brought up in such a manner that they have to meet their parents at least once a day if they are staying in the same city."

Arpita's reference to historical gendered geographies of Bengalis is directly relevant to my discussion on the bhadralok class construction in Chapter Three. Her remark is reminiscent of the gender arrangements in family that have continued to define middle class Bengalis historically and into the twentieth century. I examine the evolution of the Bengali middle-class -- the bhadralok class -- in the twentieth century further below. Arpita continued, "In that case, it is not a nuclear family. Because either way, there will be interference. So I cannot call this a nuclear family. To me, a nuclear family is that where the couple, with their children, are staying in the a different city than the parents, and the husband has to fend for himself and the wife maybe working, and maybe the child is left back at home at the mercy of some domestic help. So that is a nuclear family. And in that city, the parents should not reside. This is how I understand a nuclear family to be. Little to zero interference from the in-laws." Curious to know how she would describe her current living arrangement with her husband in the U.S and the family in India, I asked her, "Would you call your setup in the U.S. a 'nuclear family' following what you said just now?" Arpita responded, "No. Even here [U.S.] although we have a nuclear household setup, we still have some amount of involvement from our parents. So we are not completely nuclear even here. If we have to go back to India now, I doubt if 
we will be allowed to have our separate unit if we live in the same city as his parents live in."

Arpita's response sheds light on an important dimension in this dissertation -- the fluidity of the joint family "roof"-- first extending as a setup in the twentieth century and then extending transnationally in the twenty-first century (next chapter). The fluid roof -first as a setup and then as a transnational roof -- is also a measure of distance that Bengalis have between the ideal joint family of the nineteenth century and their real manifestations in the forms of family settings and setups in the twentieth century. My field data reveal that even if the physical roof no longer covers everyone in a family as it once could in the ideal compound of the nineteenth century, it is imagined to still cover all even if that has to span across continents transnationally. This is a central contribution that this dissertation makes by bringing in the extended roof -- the extended family -- in spousal negotiations across transnational spaces. I engage in this discussion in details in my next chapter where I examine the transnational family dynamics of spouses and their family members.

Returning to the discussion on family setups, these family forms are a kindred concept to describe a household or a paribar. This is reflected in my interviewees' responses and as exemplified above in Piya, Aditi, and Arpita's responses. In its most fundamental form, a paribar is a household composed of patrilineal descent. People who live together in a paribar share household resources although the eldest male member holds supreme authority. The paribar (also termed as pariwar or parivar depending on the regions in South Asia) is the major unit of both production and consumption throughout 
Bengal (Stone 2010). Keeping in parlance with the basic patrilineal framework, a paribar is characterized by (1) male supremacy, and (2) assurance that the patrilineal lineage should continue (that is sons should marry and marry well and their wives should procreate to carry on the lineage) (ibid.). This arrangement reflected on a gendered negotiation in patrilineal families that was largely upheld as the ideal and aspired model nationally.

Contrary to popular belief, there is no baseline or longitudinal data that can be used as evidence for the rapid decline of the joint family in India and the growth of nuclear families (for details see Cohen 1992; Lamb 2000; Martin 1990; and Vatuk 1991). In fact, the few longitudinal studies that are found point towards an increase in the percentage of joint families than what the numbers used to be before. The above examples from my field data support this claim. But in addition, my data also illustrate how the joint family form gave rise to alternative forms (setups) of family keeping alive the idealization of the joint family in general.

Despite the paucity of data and lack of consensus in scholarship, the trend of characterizing the ideal Indian family structure as the patrilineal joint family structure continued during the decades of the twentieth century (Nuckolls 1993; Segal 1999; Uberoi 2001). Scholars continued to chart the basic and common form of a patrilineal joint family as consisting of a couple, their children, and the husband's parents all sharing a same household (Uberoi 2001). In rare cases, all of the husband's kin (his parents, his brothers and their families, and his unmarried sisters) lived together (Madan 1993). It is also evident from this scholarship that the patrilineal joint family is also patriarchal, 
where elder males enjoy the most power, and the daughters-in-law, especially the youngest, are socially located at the bottom of this hierarchy of adults (Rangaswamy 2000; Segal 1999). Scholarship also reveals that patriarchal relations existed even if the household size was restricted to husband and wife; husbands were usually the breadwinners and heads of households, whereas wives continued to be primarily homemakers, even if they are employed (Uberoi 2006). This patriarchal joint family structure continued to be considered as the norm for most Indian regional groups (Derné 1995, 1999; Uberoi 2001, 2006). Of relevance to this study and as the South Asian migration literature (details in next chapter) reveals (Derné 1999), this structure rests upon gender inequalities which are justified by contrasting the virtue of Indian women against the lack of virtue in Western women. "Identifying unrestrained sexuality with Western cinematic stories and clothing styles, filmmakers and filmgoers identify Indianness with a restrained sexuality and a focus on family duties ... with respect for emotion ... [and with] gender hierarchy" (1999:18-19). This [migration] literature also notes how relocation into a new culture renders cultural differences more apparent (Hurtado et al., 1994; Thoits \& Virshup, 1997) and which I examine in my next chapter. However, it is important here to note that post-colonial feminist scholars like Parameswaran (2001), Ahmed-Ghosh (2003) and Oza (2006) have used a theoretical framework of masculine domination while examining the identity of the Indian woman as the site of contestation and inscription for the definition of morality, family "values," and nationalism. Feminist scholarship asserts that women's bodies and sexuality often become the "material and discursive sites where nation [is] performed, values [are] contested, and borders and boundaries [are] policed and controlled" (Oza 2006). Feminist 
theory also addresses presumption that women are often categorized into homogenous groups of actors that react, adopt and adapt to policies, identities, and structures in a uniform manner. In this discussion on patriarchal arrangements in the family and as these scholars argue, it is important to remember that the contestation of family "values" is usually sited in a woman's body and its disciplining where ideological notions (such as of dharma and grihalakshmi) are asserted and contested (Puri 1999).

While the joint family with its nuanced gendered arrangements remained as the national ideal, it was not possible to maintain joint families structurally in large cities such as Kolkata that increasingly became crowded with smaller apartments. Family setups were a response to the changing socio-political fabric. However, while the idealization of the joint family system continued as an aspiration nationally, how did the idealization reflect specifically for the Bengalis?

\section{The "ideal" Bengali family in the twentieth century}

My respondents described their conceptualization of family with respect to a single most yardstick that they thought is important: an ideal Bengali family. "What is the 'ideal' Bengali family?” I asked my interviewees. Rita, who migrated to the U.S. eight years back with her husband Shishir, and now lives in South Florida, imagines an ideal Bengali family as one which "should be comprised of at least five to six members, where at least two members are the eldest, who have their children and then the children are married. So a kind of a family tree is formed." Rita's view of an "ideal" Bengali family appears to coincide with the joint family arrangement where multiple generations 
live under the same roof and which may include in-laws and other people typically characteristic of "extended families."

Idealizing the "Bengali family" as multiple generations living together has been voiced by many others in my interviewee pool. For example, in his description about his family, Arpita's father Shekhar used the term "extended family" a couple of times. In order to be clear what he meant by "extended family," I probed for further details. "[I used the term "extended family" to] convey the idea that it was a very large family which consisted of relationships across the generations and which are usually understood as 'extended' family elsewhere in the world," Shekhar clarified. "For example, [I would include] my grandparents, my uncles, aunts, and cousins. That is why I made that distinction. At the same time, there were several people who were not connected to us by blood or marriage in anyway, yet they were very much part of the family...They were Baba's [father's] friends, or Ma's [Mother's] childhood friends...but they were very close, as close as family. They may not be blood relatives, but as you may say, definitely extended family," he concluded.

Another example of the multi-generational joint family arrangement as being the ideal form was provided by Aditi's cousin Sneha. Sneha is married and lives in Kolkata with her husband and in-laws in a three-storied house in Kolkata. She works as a teacher in a primary school and is also a freelance journalist. I met Sneha on a pleasant February evening at her in-laws' house. After some discussion about my research, I asked Sneha what she thinks to be an "ideal" Bengali family. Sneha responded, "Ok, let's start with my maiden family. Basically, I do come from a joint family. I stayed with my grandparents, 
and parents. I am the only child. My father was the only child too. But he had a lot of cousins -- my uncles and aunts," Sneha responded referring to Aditi's parents as her uncle and aunt. "So they are all like my own uncles and aunts," Sneha continued. Now after they married, they had their own setups. I lost my father when I was eleven months-old ... so the kind of family in which I grew up was one comprising my grandparents, my mother, and myself. But we had plenty of outside people [workers who lived inside the household but were not family] staying in our house. For example, we had a huge setup where people stayed and took care of our fields. They were basically the domestic helps. But if I have to talk about the family only, then it was just the four of us - my grandparents, my mother, and myself. After marriage, I did not see my father-in-law as he died four years before our marriage. After marriage, I now live with my husband, mother-in-law, and brother-in-law. So, both my maiden family and my married family are not 'complete' families by [the Bengali] idealized standard. The point I want to make is, sometimes family can be ideal theoretically, but structurally it is hardly ideal."

Overall, my interviewees responded quite similarly about the ideal Bengali family — much as the responses just provided. It is still important to recall from chapter Three, however, that no matter how fixed these ideals may be in people's minds, over generations they prove to be very fluid. For example, referring to Chapter Three, there were different notions of the ideal Bengali family before and following the Bengali Renaissance. However, as scholars have argued, there are important debates about the idealization of the past as well (Lamb 2000). Notwithstanding the debates, many of my interviewees have remarked on how they feel that the ideal of the Bengali family has shifted during their lifetimes and it continues to shift. 
Unlike how the majority of the literature on the nature of Indian families has portrayed gendered arrangements within the family, the Bengali family from around the early twentieth century characterized a shift in gender negotiations within the family. This shift can be attributed to the changing social location of the daughter-in-law within the family, which I examine in the following section. Typically, following the patriarchal arrangement in the family as explained above, such an arrangement will succeed as excellent for subordinating women since the women, after marriage, move into the men's family. Anthropologists refer to this as patrilocal post-marital residence. A wife moves from a family where owing to gender she occupies a low position vis-à-vis the males in that family and moves to a family where she occupies the lowest position. Thus, the new wife is the object of the most intense gendered boundary work, work done by her husband but more importantly by his mother. The husband's mother becomes the main enforcer of her daughter-in-law's virtues, her alignment with the ideologies of dharma and grihalakshmi and, in so doing, reinforces her and her family's social status. Imagine how different the gendered geographies of power within the family would be if the opposite were true, that is, if the husband would move in with his wife's family?

\section{How have practices in marriage and the family evolved for the Bengalis in the twentieth century?}

Nandini and her husband, Naren, live in their four bedroom flat [apartment] in south Kolkata. They are Priti's parents. Nandini is in her late fifties, and she is a counselor by profession. Naren is a retired bank officer. Nandini's family migrated from Bangladesh to India after the second partition of Bengal. She recalled stories from the 
previous generations and offered a detailed account of the changes in family and marriage relations: "OK, let me use three generations to explain this: my parents' generation, my generation, and my daughter's generation. When we were children, I have seen my parents having an unconditional relationship, just like all others around them in their generation. The father was the breadwinner and perhaps the only earning member, and often the sole decision maker. The wife was the homemaker, care giver. The husband was never that involved in child-raising. In spite of that, they had a great influence on the children, maybe because of the setup of the household. The mothers were often left out of the decision making process, and because they accepted that to be natural, there was minimum to no conflict." Nandini's description exemplified a gendered geography of power that prevailed in the family setups in the twentieth century after India was independent and a gendered arrangement that has consistently been referred to by my respondents. It is important here to bring in the GGP lens and emphasize that the disadvantageous social location of the wife across one geographic scale does not necessarily mean she occupies a subordinated position across all other geographic scales, and vice versa. For example, from Nandini's account of the geographic scale of spousal relations, wives in the earlier generation were typically at a disadvantageous position because neither were they part of the formal labor force (and therefore could not contribute to the financial pool) nor were they involved in important decision-making processes in spousal negotiations. However, at the geographic scale of the family, women often played important roles in raising their children. Overall, however, women's social status negotiations across the different spousal and family geographic scales were all heavily informed by the ideology of grihalakshmi - that a "good wife" and a "good 
mother" will never privilege herself or her personal life (if she is allowed to have one that is) over her husband's, children's and in-laws' well-being and desires.

After a short pause, Nandini continued to trace how the gendered negotiation in family and marriage evolved: "In our generation, we have not accepted much. We have sometimes voiced ourselves whenever we felt the need to. And one thing that I am noticing in my age group is - gradually husbands became less and less involved in decision making or suppressive towards the wife." This was a shifting GGP in family and marriage relations that characterized Bengali families during the twentieth century. Nandini provided an example: "For example, my elder brother was not keeping well for some time. He had high blood pressure and so one day while he was shopping for groceries, he fainted in the marketplace. And after that incident, my sister-in-law does not let him go to the market at all. But my brother doesn't force her to let him go. So he feels a little depressed now but husbands are becoming less forceful. Now I don't know if they become less forceful after retirement, or is it something else? But women are slowly taking the upper hand in my age group. And the moment men are at home after retirement, they are physically depressed." Nandini not only exemplified how the gendered negotiations in family and marriage evolved across the generation but also exemplified a boundary work of the Bhadralok around work and retirement discussed above and in the previous chapter. Nandini finally paints the picture for her daughter's generation, "And what about the younger generation? Women are much more responsible now, both at home and outside. But in many respects, this is resulting into social indigestion. As a counselor I encounter many such cases every day. I can now see that women are threatening and therefore misusing their independence too. In fact, new 
legislations are coming up just to combat this. There has been a distinct role change. And in Kolkata, women from the urban middle class are misusing this legislation." Nandini thus traced the evolving gendered negotiations that have characterized Bengali family and marriage over three generations in the twentieth century.

Applying the GGP lens toward understanding how gender relations, particularly spousal relations, evolved over the decades viz-á-viz family and "extended" family reveals important observations. It also chronicles how important it is to view and understand women's negotiations of their social locations across multiple geographic scales simultaneously. For example, in Nandini's generation, women negotiated more privileged social locations with their spouses than did the women of earlier generations. Unlike those previous generations, Nandini's generation could exercise greater power in decision-making processes, even gaining the upper hand. However, during her generation women, particularly daughters-in-law, continued to occupy lower social locations viz-áviz their extended families. They had to focus on being grihalakshmis at the cost of sacrificing their higher education and career aspirations.

In another interview in Kolkata, Neel's parents Nupur and Ashish, capture a similar version of the story of the changing family dynamics. Ashish is a retired marine engineer and heads a private consultancy firm in the city. Nupur, his wife, never pursued a career after she got her master's degree in History from a highly reputed university in the city. After their marriage, Nupur had settled in for a life at home, taking care of the household, family, and children. I spent quite a few afternoons with the couple, having either lunch or tea and snacks together as we discussed my research. In one of our 
interview sessions, Ashish analyzed the changing dynamics in family and marriage that twentieth-century Bengal witnessed. "There are two versions of this," he began, "what used to be, and what it is now. In the past, say thirty or forty years back, when a boy chose a girl to marry, he chose not because she was his type. He chose her because his family will like her and she had the capability to gel well with his family. That used to be the ideal case. And after marrying her, the expectation was that the wife will serve the family members as much as she will serve her husband. Nothing less. Bluntly speaking, she was more of a 'servant', less of a wife. This was in everyone's mindset, irrespective of one's educational accomplishments and economic prosperity. Everyone had this idea. And also yes, she had to serve the next generation too. Procreate first, and then serve her children too. So a boy wanted to marry a girl who would have all the talents to serve all the generations at all the time, and this was supported by his family, her family, and the society at large."

My field data, including Nandini and Ashish's responses, reflect on a crucial facet that informs and is informed by class-based practices of the bhadralok and the associated gendered norms particularly in family and marriage: the cultural practice of servitude. In fact, this class-based practice illuminates how the bhadralok class has evolved in the patriarchal order, and the boundaries they exercise to negotiate their status in the society and across the intimate scale of the home. In Cultures of Servitude (2009), sociologist Raka Roy examines multiple generations of the bhadralok en route to examining the practice of employing domestic help in Kolkata as entwined with a class-based practice. Roy (2009: 53) argues, "Despite the generational differences, the two groups of bhadraloks [older and younger generations] have more in common than not. Both older 
and younger [bhadralok] employers [of household helpers] consciously compare [in Roy's interviews with them] the past life of families and households to present circumstances and attempt, variously invoking sentiment and expedience, to retain aspects of Kolkata's culture of servitude rooted in the feudal past while viewing themselves as the vanguard of an Indian modernity." In her analysis of the bhadralok class en route to analyzing servitude, Roy (2009) echoes an argument already made in my previous chapter: that the bhadralok class continues to be the gatekeepers and vanguards of an imagined Indian modernity.

Servitude, whether inflicted on employed household-helpers, or on the wife, is an important indicator of a boundary work based on which the bhadralok-class grew: their complete abstinence from manual labor. In my interview with Chitra, Aditi's mother, in Kolkata, this was further emphasized. After her husband passed away, Chitra continued to live in their Kolkata home. She worked with a reputed MNC in Kolkata for twentyseven years and retired a few years back. Chitra reflected on a possible reason why the bhadralok class has emerged to be what it is today, "Because it has been grilled into them [Bengali men, the bhadralok class] for generation and generation that you [man] are superior to the woman. You are the bread-earner; she does the house-chores. She raises the children where the man has almost no role to play - it still holds well here [India]. And in certain ways, I would say, Bengali men are mollycoddled by their mothers. And they expect the same from their wife when they marry. That hasn't changed. I think it is ...previously one wouldn't see all these, or wouldn't feel that way, because there were lots of household helps. So if someone ordered that "dadababu ke jol de" [Serve water to the man], there would be someone to serve. Now that variety [of household help] is gone. 
Here [India] too, you have to do your own work, to certain degrees still you have some help, but not like previous times like how he has grown up. And his mother has been doing all that for him. After marriage, the mother is not there. Household helps of the 24/7 variety are not there. But he hasn't changed. [Repeats] He hasn't changed. So he expects that from the wife."

In explaining the social conditions that possibly could have shaped such a class, Chitra further notes, "It is the way that he is being brought up. The social learning process that he is being a part of. The things that he sees around, he tries to replicate them, and thinks that it is all right to do that! He will not even make a cup of tea for himself ...it is always someone will say "Arre, make a cup of tea for him” [Hey, make him a cup of tea]. But that is not applicable for the wife...no one asks about her. When she comes home after work, tired, if you [woman] want to have a cup of tea, you make one for yourself. This is the difference. It still exists in 2012, in Kolkata. That is for sure." My interviewees' convictions are evidence that brings out the fundamental relationship between the bhadralok class and modernity, their boundary work for negotiating a higher social location. Roy (2009: 53) notes, "Today's bhadralok have a complex relationship to their ideas of modernity, both ruing the demise of things as they were (in an idealized past) - holding fast to elements that seem to have withstood the passage of time - and eagerly embracing modernity as social and economic progress in a globalizing age."

How have the dynamics in Bengali family evolved in a globalized age with India moving centrally into a globalized world economy in the later part of the twentieth century? Ashish explained, "In the recent generation, I find this [practice of choosing 
mates] has been diluted vastly. Now the guy only considers the girl's compatibility with him only. He accepts that she may or may not be able to serve, satisfy, befriend, or be compatible with his parents and other family members, and that is normal if she does not. But what matters is how much compatible she is with him. Now eighty percent guys choose their partner thinking along this line. And the girls? Well, they always had chosen their mates like this and set off to a new place, often her husband's place, into a new family. During my mother's generation, the social learning was that the girl was brought up with values and teachings how to become a good wife. My mother is no exception. She knew that after she was married, she had to become the "good wife" to get a good life. But now, the girl is more preoccupied with first, her career, and then the fact that she should be able to be compatible with her husband. She does not have the scope, time, or opportunity to consider the rest of the family members. Eighty percent of the girls that is. And the rest twenty percent remains the carriers of the old value system."

To stay with the example of changing gendered dynamics in family and marriage, Smita's husband, Sanjeev, reflected on a gendered negotiation within the intimate scale of marriage and the family for the Bengalis and as it relates to gendered division of work. Sanjeev linked his response to a larger social change that had started in India towards the end of the twentieth century. "The relationships in marriage and family started to change, because the society in general started to change," he remarked exemplifying the intimate relationship between the geographic scale of the nation and scale of the family and marriage. "In post-Partition India [referring to the political shifts in South Asia since the 1900s], society changed from being very Indian to more Western influenced in many cases. Western liberal values permeated into our [Bengali] society, and our understanding 
of modernity had started to shift. Over time, that influence has been growing with spread of media. I think the infiltration of liberal values has changed our society. And I think the liberal values have come in very rapidly over the past decade of the twentieth century. So society changed very rapidly from around the 1990s." Sanjeev exemplifies this change in family and marriage relations by comparing gendered negotiations across the generations. "For example, I have seen my parents had a slightly different concept of marriage than my grandparents. My grandparents had a relationship that I will not term as 'backward' but their relationship was more like a master-slave relationship," remarked Sanjeev, referring to his grandparents' generation of the bhadralok class. "Something like 'I command, therefore you do.' The man was always the man and therefore demanded all the respect. In my parents' generation, I did not see [patriarchal domination] to that extent, but of course the man of the house was the head of the family and always had the last say. In my case, I have my opinion and my wife has hers and generally the best one wins [laughs]. It's not like, 'You are the man so you win automatically.' And I think for my brother, and my younger cousins, their relationships are even more liberal than ours."

With the practice of servitude on one end of the continuum, on the other end is the trope of consent that many scholars have argued for in explaining evolving family and spousal relations in Bengal (for e.g., see Loomba 1994, Mani 1998, Sarkar 2001, Sinha 1995, and Spivak 1988). Using the lens of the new patriarchal order, these scholars have argued that the trope of consent has defined the nature of conjugality in colonial and nationalist discourses in the Indian context. For example, in the debates on sati (Mani 1998) in the nineteenth century, this conjugality was based on the widow's already willing and chaste, monogamous relationship to her husband. Unconditionally, this was 
by virtue of her Hindu piety. This, in turn, implied that her body and soul was a possession of her husband (see Mani 1998). For colonial authorities and "progressive" nationalists in the nineteenth and early twentieth centiry, the good wife's body (as sati) embodied "consent" as the voluntary fulfillment of her wifely role as companion and benefiter of her husband's good will, maintenance, and protection (ibid.). On the other hand, for "conservative" nationalists (ibid), it signified consent as an always-alreadygiven concession to the strictures of Hindu marriage (Sarkar 2001). Conjugality was also understood in terms of what Tanika Sarkar (2001) calls "the union of souls in a higher love." The trope of consent in conjugality can be traced through nineteenth century and twentieth century legislations and public debates into the post-Independence moment (Agnes 1999, Majumdar 2009, Nair 1996). This incongruity was further strengthened as the post-Independence standoff (discussed above) that resulted in the Hindu Code Bill of the 1950s (Majumdar 2009).

As discussed above, the Hindu Code Bill sought to legislate the family and pertained to marriage, inheritance, maintenance of dependents, and adoption (ibid.). Additionally and specifically for Bengalis, the idealization of the joint family ideal continued as important beyond just the social security of having children in close proximity. Why? This aspiration is rooted in Bengalis' constant pursuit of negotiating a higher social location and achieving high status. Historically and as my field data point out, the urgency to maintain large, joint families is intertwined with the need to achieve high social status. Adhering to the ideal joint family model became the new definition of modernity for the Bengalis towards the end of the twentieth century. As I have argued in the previous chapter, Bengalis have portrayed a different dynamic when negotiating 
modernity as a group than they have while negotiating at the geographic scales of the nation and the family. In the following section, then, I shift focus from the geographic scales of the nation and the family to the geographic scale of the group to examine how Bengalis continued with their gendered negotiations as a group to achieve high status in the twentieth century.

\section{Modernity and the Bengalis in the twentieth century}

Bengalis' negotiations of their high social location in the newly born nation are deeply intertwined with the group's understanding of "modernity." To recapitulate from the previous chapter, during the Bengal Renaissance and the period following the Renaissance, Bengalis have negotiated their social status vis-à-vis other ethnic groups and even the British according to their own perceptions of "modernity." But what exactly was this perception of "modernity" for Bengalis? Lali's sister Neela explained this to me when I asked her about changes in Bengal immediately after the end of colonial rule. "I think most people in India_-rather, most Bengalis-- misunderstand Western modernism," claimed Neela as we were sitting in a local bistro in Kolkata on a wintry afternoon in January. Neela reminisced how she and her elder sister Lali were brought up in a joint family household in the city. Lali earned a Masters in Library Science in Kolkata and Neela earned a Masters in English Literature. Neela narrated how Lali met her husband Sanjoy through a close friend and after a few courtships decided that they wanted to get married. So their marriage was not characteristic of a typical Bengali arranged marriage. Lali and Sanjoy migrated to the U.S. in 2008, Sanjoy on a H1B category work visa and Lali on a $\mathrm{H} 4$ type visa (dependent of the $\mathrm{H} 4$ category). Visa restrictions are a primary 
factor why Lali continues to be a dependent spouse. However, recently Sanjoy's employer has promised him that he will file for their permanent residency, and Neela is hopeful that a successful application will lift away the work visa restriction from her elder sister. Neela returned on the idea of "modernity", "What I mean is that most Bengalis are confused about which aspects of modernism they should embrace and which aspects of their lifestyle they should not change. They are confused. First, to me, my culture that I grew up with is my root. But when I will want to adopt the good aspects of another culture, I will still have to first hold on to my roots on one hand, right? But those who are confused about this, they first abandon their own culture and values. For example, I am Bengali. However, most of the time I converse with my Bengali friends and acquaintances in English because they, like me, are shy of speaking their mother tongue. We feel that our social rank will go down if we speak in Bengali. But to me, I will speak in English, but not by forgetting Bengali. Very few think about this in this way."

Neela thus articulated how Bengalis elevate themselves socially not by reaffirming their own cultural practices, but, rather, by choosing strategies valued by others that they imagine will enhance their status. Certainly learning English was important in this imagination work. Bengalis ironically view what they do as being "modern" while what they are actually emphasizing is their colonial heritage and in so doing their (legacy of) social inferiority.

Neela's response is also a classic example from my field data that relates to the attitudinal changes that informed ideas of modernity for Bengalis historically (Chapter 
Three) and in the twentieth century. As my respondents pointed out, the new middle class (the bhadralok class) in the twentieth century was produced in key sites such as the educational institutions, the workplace, and the home. Relations in workplace, educational institutions, and at within intimate spaces gave rise to class-based practices that are reminiscent of Pierre Bourdieu's study of French practices of distinction and exclusion by various classes. In his landmark study, Bourdieu suggests that there "is an immediate adherence, at the deepest level of the habitus, to the tastes and distastes, sympathies and aversions, fantasies and phobias which, more than declared opinions, forge the unconscious unity of a class" (Bourdieu 1984: 77). The attitudes and beliefs that Bourdieu explains are not individually or consciously held, but they adhere to one's habitus. A classic example of this is the class disposition of the bhadralok in the twentieth century. As my data reveal, the evolving Bengali middle class in the twentieth century reflected processes of conscious and unconscious gate-keeping even in the face of structural and political shifts in the decades spanning the late-nineteenth and the twentieth centuries. Important studies have noted the importance of cultural capital for the bhadralok class and their maintenance of middle-classness and for entry into its ranks (for e.g., Baviskar and Ray 2011; Ganguly-Scrase and Scrase 2011). Following this scholarship, it is evident that the education system continued as a key site for the transmission of cultural capital, and thus for the reproduction of the bhadralok class.

The transmission of cultural capital is importantly tied to Bengalis' understanding of Western "modernism" too. Neela explained how; "there is another thing that most people think is true - that a Western lifestyle is all about comfort and luxury," she critiqued. "This is a dangerous dream bubble. Almost all these people dream to go to the 
U.S. and live a comfortable life. Why? Are luxuries and pleasures absent in India? Or can they not afford those luxuries in India? But this dream bubble that 'my accomplishment will only be fulfilled if I go to the U.S.' is only a product of misunderstanding Western ideas of modernism. And just because going to the U.S. is such a priority now, parents now find an English-medium school for their children. All that matters is 'Will they teach my children English?' That is a must. For my parents, the concern was to find a good school for my sister and me, irrespective of their medium of instruction. But now, the grade of the school hardly matters. As a result, now, our generation and the next, understand 'culture' very differently. There is a constant sense of competition, comparison, and a dream bubble that 'I will be most happy if I go to the U.S.' I have seen this amongst most Bengalis I know. I don't think non Bengalis feel the same way." The urgency of transmission of cultural capital to retain class membership is often plagued by anxieties around possible failure to acquire the cultural capital necessary for children to succeed. Neela's critical response above is an example.

Neela's soliloquy also exemplifies the critical tone interviewees expressed toward shifting Bengali ideas about modernity in the twentieth century. With India entering the globalized world economy, the yardstick for measuring modernity for Bengalis also shifted. As my field data demonstrate, Bengalis started attaching symbolic meaning to transnational lifestyle as a measure of modernity. With increased rates of migration and transnational living towards the end of the twentieth century, Bengalis wanted to be modern and, to them, to be modern meant to migrate. But migration did not mean that they will be better off. Rather, it symbolized that they have improved their social 
location. I engage in the discussion of "transnational modernity" in details in my next chapter.

But to stay with the example of how the ideas of "modernity" shifted for the Bengalis in the twentieth century, I turn to Meghna's cousin, Twisha. Meghna and her husband Neel, 36 and 38 respectively, were born and raised in Kolkata. They both grew up in joint families as they described in their interviews. Meghna and Neel earned their degrees in Computer Engineering in 2005 from a well-recognized university in the U.S. where they met. After some courtship, the couple married soon after their graduation. Both of them now work in the same IT firm in South Florida. The couple has two children, a daughter who is five years-old and a son who is three. Following Meghna's referral, I met her cousin Twisha in Kolkata while conducting my fieldwork. Twisha is in her late twenties, is married to Riju, a young man in his early thirties, and the couple lives and works in Kolkata. We spoke about the structural changes in families after India gained independence. I was curious to know if that affected changes in gendered negotiation between spouses and their family so I asked Twisha and she responded, "When [Bengali] people retire, they look for more employment, they are 'retired but not tired.' Their ambition does not end. So that also overlaps with how they would behave with their children who, by this time, are settled, and married and often with kids." Twisha explained this further by using the ideological lens of dharma that I examined in Chapter Three: "The idea of dharma is that one has lived her or his life to the fullest. She or he has done her or his duties, and has raised a family. So now she or he is supposed to enjoy her or his retirement. She or he should get detached from society if following the prescriptions of dharma. But as I see around me, nowadays many people do not want to 
do it that way." This was a changing gendered geography of power that shed light on the ideology of dharma and, in turn, inflected family relationships. Twisha continued, "Now there are a lot of grievances like 'I gave up a lot for my son or daughter, now it is their turn to give it back to us'".

It is important here to understand how the ideologies that guide this group's dynamics from the supranational to the intimate geographic scale were reshaped in the face of a changing social fabric. To recall from the previous chapter, these were the ideological lenses of dharma and grihalakshmi. One important theoretical explanation of these ideologies in the twentieth century in India can be understood from postcolonial theorist Partha Chatterjee's critical work on the duality of spheres in India, and in Bengal particularly: public/private, material/spiritual, outer/inner, home/work. Chatterjee (1989: 623-624) examines with respect to the anti-colonial struggles, "Briefly, this resolution [to the contradictory pulls on nationalist ideology in its struggle against the dominance of colonialism] was built around a separation of the domain of culture into two spheres: the material and the spiritual. ... What was necessary was to cultivate the material techniques of modern Western civilization while retaining and strengthening the distinctive spiritual essence of the national culture." As Chatterjee (1989) argues, the discourse of nationalism in the nineteenth and the twentieth century shows that the material/spiritual distinction was "condensed into an analogous, but ideologically far more powerful, dichotomy: between the outer and the inner." Chatterjee's argument provides the ideological framework within which the women's question -- a significant preoccupation in nineteenth century Bengal and as argued in the previous chapter -- was now brought into the twentieth century and answered by matching new meaning of the home/world 
dichotomy with the identification of social roles by gender. This was explicitly done via the changing ideologies of dharma and grihalakshmi. New gendered negotiations recreated older strategies of cultural preservation that sought to prevent the feminized private sphere from being essentially westernized. As argued in the previous chapter, the strategies of cultural preservation by this group focused on gender.

Furthermore, Twisha continued to identify this changing trend among Bengalis as a whole: "And I see this especially in Bengali families. In other parts of India, the nonBengalis, such as North Indian families, we will not find parents demanding from their children. But in Bengali families, not all but most, I have seen that [this expectation] never ends. People want to keep living that life." Twisha draws from her own life experiences to assert how her parents and extended family members continue to be a part of spousal negotiations. "One main reason [of continued family involvement in spousal relations] is that, most Bengali families are from [the] service-class." Twisha's response identifies with how the Bengali middle class -- the bhadralok class -- was conceptualized, and also, how that middle class attaches high symbolic meaning to salaried professions or "services." Twisha continued, "So when you come from such a middle- or upper-middle class, your life's contacts and social networking come primarily from the job that you have done all your life. Bengalis generally do better in life professionally than other groups in India. And suddenly, after retirement, all of that goes away. I have seen very few Bengalis accepting retirement gracefully. They often cannot deal with that loss of power. They feel demoralized and seek refuge in other places such as making themselves involved in their children's life. This does not happen with non-Bengalis much. For example, North Indian families have other sources of contact, like their family business. 
So there is no ritualistic retirement for them, and neither do they have to stop going to work one fine morning because they retired."

Twisha's response exemplifies important connections that are vital to this discussion: the evolution of the Bengali middle-class in the twentieth century and the symbolic and material meanings of power attached to this class construction. I have already examined these two dimensions above. However and in addition to that, Twisha's response exemplified an important boundary work that Bengalis have used as a mechanism of the group's status negotiation. Over the centuries, Bengalis have used a variety of techniques in their symbolic boundary work to identify themselves as a modern people: proficiency in English and using it instead of Bengali, achieveing higher education especially among women in addition to the men, and emigrating to a high status country such as the U.S. These all elevate the social status of Bengalis as an ethnic group in India. That is, these are pillars of Bengalis' negotiating their group's social status above and beyond other Indians. In her interview, Piya does not state this explicitly, but to me it is a practice consonant with earlier generations of bhadraloks who mastered characteristics of the colonials in order to enhance their social standing. For Bengalis, socially reproducing privilege involves acquiring an English-medium education. After independence, no longer is the purpose of being able to operate in English serving to identify the Bengali bhadralok class as an intermediary between the colonial elites and the poorer classes and ethnic groups in India. Rather, this education is the gateway to today's more important measure of potential high status: the opportunity to migrate to the U.S. Recapitulating from the previous chapter, since the nineteenth century holding salaried professions forms an important boundary separating the Bengali middle class 
from middle class population of other Indian ethnic groups. Retirement threatens these axes of their identity and in so doing their class belonging as well. To be Bengali is to be a member of a salaried profession.

Intertwined with the transnational status negotiation that my interviewees such as Piya raised, is also another important form of boundary work characteristic of Bengalis that Twisha raised and which I found to be true among my respondents overall. This boundary work is to refer to "other" Indian groups as "non-Bengalis." That is, Bengalis use the terms "Bengali" and "non-Bengali" to categorically differentiate themselves from all other peoples who share Indian nationality. A part of the history of Bengalis imagining and using these two categories, Bengalis and non-Bengalis, can be traced back to important political shifts in South Asia, such as the Partitions of Bengal in 1905 and in 1947, and Indian Independence in 1947, but much of its history lies outside the purview of this dissertation (see for example, Chatterji 1994, Chatterjee 1999). As I have already argued in Chapter Three, what is clearly evident from my field data is that Bengalis have categorically kept themselves separate from what they imagine to be the "non-Bengali" category. They are separate and also categorically superior to non-Bengalis a form of culturally constructed categorical inequality (Massey 2007). This categorical differentiation is expressed in many of their dynamics as a regional group in India; as I show in Chapter Five it is also expressed transnationally. In fact, this categorical distinction is applied regardless of where Indians live. This is an important type of boundary work that has surfaced in my fieldwork and contains potential for important future research in this area. 


\section{Chapter conclusion}

In this chapter, I have examined family and marriage in post-colonial India, immediately after Indian independence. I have examined family dynamics at the national and intimate geographic scales and Bengalis' social status negotiation at the geographic scale of the group. As my field research reveals, ideally people would live under the same roof in these multigenerational families but that is increasingly impossible given (1) the changing structural and political scenes in Indian cities where these compounds are becoming fewer and fewer because of living costs and changing lifestyles, and (2) migration. The idealization of the joint family continues but without the really intense patriarchal order of before and is now imagined in transnational terms where people do not live under the same roof yet still imagine themselves as living in a type of virtual setup. This directly relates to my dissertation focus on the dynamics of families and the distance Bengalis have between ideal and real families and their dynamics and in explaining them according to historical, structural, economic, social forces such as Bengalis' strategies to improve their social status -- leading up to the most recent transnational phase. To understand and examine how the idealization of families has continued in their transnational reality, I now turn to the final data chapter of this dissertation. 


\section{CHAPTER V - GENDERED GEOGRAPHIES OF CONTEMPORARY BENGALI FAMILY AND MARRIAGE ACROSS TRANSNATIONAL SPACES}

With rapid globalization and all its related dimensions, it is not surprising that the trends in Bengalis' gendered social status negotiation continue to change in the twentyfirst century. One reason is that the number of Bengali emigrants has soared in recent decades. Why? As will be discussed in this chapter, a key cause is the continued efforts among Bengalis to enhance their social status. Perhaps ironically but certainly not uniquely, Bengalis negotiate their status within India largely by moving abroad. The appropriate scale of analysis, thus, shifts more from the national to the transnational. Another focus of this chapter and one that I laid out at the onset of this dissertation is the role of the extended family in inflecting transnational spousal dynamics. This is one of my principal contributions to the scholarship on migration and gender. The overwhelming majority of scholarship in this area has limited its examination to husbandwife dynamics, devoting little to family involvement above the nuclear family scale. My study among Bengalis, in contrast, documents the importance of extended families. In this chapter, therefore, focus on the extended family in spousal negotiations, especially when they are negotiated across transnational spaces. That is, the Bengali social status improvement strategy has moved into transnational contexts and these contexts can and should be expected to inflect those same relations even when also inflected by extended families. The key question I examine is: How do gender relations negotiated between Bengali spouses living transnationally reflect the twin forces of extended family and exposure to a new Gendered Geography of Power context? 
To accomplish these tasks and to anticipate, I engage in this chapter in a brief history of transnational migration, particularly South Asian migration to the U.S, and one that locates spousal and family relations centrally. I then examine gender relations amid transnational Bengalis, particularly as they orient and operate within family and marriage realms across transnational social fields. Next, I compare spousal responses against additional family members' views on these gendered relations, keeping in mind the historical ideologies guiding their gender relations discussed in Chapter Three. I use the GGP and Boundary Work analytical frameworks already developed in previous chapters to aid my analysis of how transnational Bengalis continue to utilize gender as they negotiate higher social status.

\section{Revisiting larger literatures on family negotiation and transnational migration to the U.S. in perspective}

Family separation has always been a part of migration but the negotiation of family ties and separation can manifest in many forms (Hondagneu-Sotelo 1994). Historically, unmarried young adults—-particularly men--have migrated and either returned later to their homelands to start families or have permanently settled and started families in their migration destinations. For migrants to the U.S. who settle permanently, U.S. policies for family reunification have provided opportunities for immigrants to request visas for family members to join them, although the process typically takes many years. In the interim, families of migrants to the U.S. often have lives shaped by their anticipation of a future in the U.S. as well as by the realities of the country in which they used to live (Kibria 2005; Min 2005). This is the quintessential case of living 
transnationally. When some members of a family migrate and still retain ties to their non-migrant relatives, everyone can be viewed as transnational, finding themselves caught in a complex web of negotiating family matters across international and cultural lines.

Earlier research on transnational migration and transnational family ties established that "family processes and relations between people defined as kin constitute the initial foundation for all other types of transnational social relations" (Basch et. al. 1994:238). This theorization is based on the conventional understanding of the family as constructed around kinship ties and it also assumes that the motivation for migration is primarily economic. Left unstated in the theorization but common in the literature is the idea that most migrations are male-led with females arriving in order to reunify their families. This assumption was challenged by Hondagneu-Sotelo's (1994) groundbreaking work on Mexican migration to the U.S. when she found that many of the women migrants embarked on their mission to migrate to the United States in order to alter not reaffirm their relationships with their spouses. They were migrating to escape abusive relations and/or to provide for their families themselves when husbands, partners and other male relatives were not dependable. That is, the husband-wife bond was not necessarily the foundational structure for transnational families - at least in her research. More recently, and along the same lines as Hondagneu-Sotelo's research, Nina Sorensen's (2005) study on the transatlantic family ties of the Dominican and Colombian migrants to Europe highlights how "spatially fractured husband-wife" relationships are negotiated in the transnational context. Although previous research on gender in transnational contexts has suggested that migration proves to be beneficial for women 
because it can destabilize rigid gender roles (George 2005; Hirsch 2003), that is not always the case.

While the complexities of transnational lifestyles have destabilized assumptions about gender as lived within rigid roles, some scholars also show how the reassertion of male dominance continues, especially in the context of spousal relations. As Deborah Boehm (2008: 18) argues, the transnational context results in "a complex interplay between males and females" where negotiation between spouses is common, and “...males practice new forms of control as they simultaneously experience loss and are subjected to power imbalances in the United States". Furthermore, and as Sorensen (2005) attests, the issue of social control continues among migrant spouses if they live transnationally. Infidelity is a prominent issue with the non-migrant spouse in particular fearful that the migrant spouse will be unfaithful. In some of not many cases, the nonmigrant wife's fidelity is carefully policed because she lives with her husband's relatives. Her slightest promiscuous move would be noted and reach her husband (e.g., Mahler 2001). Thus, post-marital residence rules play important roles. When wives move in to live among their husbands' kin upon marriage — as is the case of Bengalis--the wives are under the hyper vigilance of their mothers-in-law as well as the rest of the husbands' family. This is one angle through which transnational migration and spousal relations need to be examined with regard to the extended family.

However, though the existing literature extensively analyzes marriage as an important arbiter in the production and transformation of transnational family ties (Bannerjee 1999; Charseley 2005; Charseley and Shaw 2006; Hirsch 2003; Kalpagam 
2005; Mahler 2001), this literature does not adequately address spousal negotiation as understood in extended family contexts when all of these actors (spouses and their families) live transnationally. While the majority of research on transnational marriages portrays wives as following their migrant husbands and thus being passive migrants abiding by traditional rules of arranged marriages that the wife should follow her husband (Grewal 2003; Charseley 2005; Kalpagam 2005; Mand 2005; Palriwala and Uberoi 2007), some literature examines the less-documented experiences of men who migrate to join wives working overseas (George 2005). Still others, such as those examining Latin American transnational families, examine how women and men migrate to societies characterized by very different GGPs than the ones in their societies of origin. A finding of some of this literature is the confrontation among migrants between the "complementary" spousal relations in their homelands and "companionate" spousal relations in the U.S. and European countries (Hirsch 2003). Also, scholarship examines cases in which men do their best to keep their non-migrant wives from finding out about their lives overseas, stressing marital ties to the extreme (Kyle 2000).

If migration of one spouse causes the rearrangement and reorientation of normative understandings of gender roles and relations between migrant spouses and their non-migrant partners, transnational migration further problematizes this rearrangement because transnational migration involves the negotiation of relations across geographic and cultural divides. This means that as migrants continue to live transnationally they negotiate gender across different societies where practices and norms typically vary. Another way to conceptualize this is people living in ways that require them to negotiate their relations given simultaneous immersion within differing gender 
"regimes" (Connell 1987). In this dissertation I prefer to use the analytical frame of the Gendered Geography of Power to signify this same idea, though GGP is very careful to examine the experience across multiple sociogeographic scales simultaneously.

If this were not complex enough to study, the unit of analysis also needs to be factored in. Most transnational research examining gender dynamics takes the unit of analysis typically to be the couple (Boehm 2008; Grewal 2003; Kalpagam 2005; Mand 2005; Sorensen 2005). Some of the scholarship includes examinations of how the couple's children and perhaps parents (who serve as caregivers to the children in the absence of the parents) affect the spouses' relationships but the unit is still couplefocused and largely limited to the transnationalized nuclear family (Dreby 2005, Pribilsky 2004, Waters 2005). For purposes of this dissertation, in the following section I now examine how has the scholarship examined South Asian migration to the U.S.

\section{South Asian Migration to the U.S. through the lens of gender}

Scholars identify three broad phases to explain the history and recent trends of South Asian migration to the United States: (1) Pre-1965; (2) the phase immediately following the 1965 Immigration and Nationality Act; and (3) from the 1980s to the present (Kibria, 2005). The first phase involved the migration of Asian Indians, particularly Punjabi Sikh men who were recruited to build railroads and as farm laborers in California and Washington in the late nineteenth / early twentieth century (Kibria, 2005; Min, 2005). According to Hing (2004), approximately 7,000 Asian Indians immigrated to the United States between the late nineteenth century and the early twentieth century. 
Ethnographic research, such as Karen Leonard's Making Ethnic Choices: California's Punjabi Mexican Americans (1992), vividly explores how many Sikh immigrants from India married local women of Mexican origin and established family units in the United States. The second phase, initiated by the changes in U.S. immigration laws in 1965, produced several changes in South Asian migration to the U.S. This phase was characterized by middle-class, educated migrants including many highly educated doctors, engineers, and scientists (Prashad, 2000). That is, people migrated for work, but the class origins shifted dramatically. However, and in contrast to the second phase, the third (ongoing) phase witnesses a wider spectrum of South Asians migrating to the United States owing to family reunification rather than purely to occupational visa petitions (Min, 2005). In 1996, for example, 34,291 Asian Indians migrated to the United States under the family reunification scheme while only 9,910 Asian Indians migrated under provisions of occupational skills (Prashad, 2000). In addition to these three phases, some scholars identify a fourth phase, one marked by the post $-9 / 11$ period which witnessed an important shift in South Asian migration in the legal and political context (Mohaiemen, 2003; Min, 2005). South Asian immigrants, especially from the Muslim countries of Bangladesh and Pakistan, have been subject to special surveillance measures such as mandatory special registrations and extensive interviews by immigration authorities of the U.S. government (Min, 2005). Although the exact trends of such migrants are not yet clear, scholars foresee a declining rate of Bangladeshi and Pakistani migrants to the United States in the near future (Prashad, 2000).

Notwithstanding the limitations on immigration posed by the U.S. Government, South Asian migration continues to grow in the twenty-first century. According to the 
U.S. Census bureau, in 2008, Asian Indians at 1.5 million have become the fourth largest foreign-born group in the United States after Mexicans at 11.7 million, the Chinese at 1.9 million, and the Filipinos at 1.7 million. Asian Indians, whose primary destinations include New York City, the San Francisco Bay Area, Chicago, Los Angeles, Philadelphia and Washington, D.C., continue to lead the US Census charts as the "best-educated, highest-paid and top-placed community among the 38.1 million foreign-born population in the country" (U.S. Census Bureau,2009).

Feminist scholarship on migration to the United States has asked the following question: How does migration to the United States affect gender relations? Prema Kurien (2003), in her book Gendered Ethnicity: Creating a Hindu Indian Identity in the U.S., argues that scholarly discussion on this question has been polarized in the South Asian context. While some argue that for some migration to the United States is empowering (Bannerjee, 1999; Das Gupta, 1998), others argue that restrictions on women are intensified in the process (Charsley, 2005; Charseley and Shaw, 2006; Das Gupta, 1997). Scholarship documenting that migration imposes increased restrictions on women seems to lean heavily on an intense concern among Asian Indians with the promotion and enforcement of an idealized code of traditional feminine behavior for women (Kibria 2005; Min 2005). This code includes restrictions on migrant women's sexuality, and the constant expectation that women should preserve traditional "Indianness" (through dress, cooking, maintaining family relations, etc.) (Dasgupta and Dasgupta 1996; Kurien 2003; Min 2006). Women who do not conform to these "codes" stand the chance of "loss of honor" for herself, for her husband, and for the entire family, by becoming "un-Indian" (Abraham 2000). Rudrappa (2002) examines how Asian Indian immigrants to the United 
States relate their success in the U.S. society to their ability to maintain such "gender traditionalism": Indian immigrants posit a causal relationship between order in their homes and ordering of their social status in the world. Their frequent understanding is that they are very adept at self-discipline as well as group discipline, especially strictures on women's sexuality. They view this characteristic as enabling them to succeed in the world outside — the basis for their successful social location in the U.S. as a "model minority." Scholars further argue that the gender traditionalism among the Asian Indians is for the most part attributed to the types of Asian Indian migrants (mostly men) to the United States. For example, Kurien's (2003) hypothesis that migration has favored (Asian Indian) men with aspirations and attitudes that are culturally traditional may be supported by the fact that many of these men return back to India in order to get married. This argument is not unique. There is significant scholarship that argues that gender is key to immigrant identity and an avenue to assert cultural superiority over the dominant group (Espiritu 2001). This is a classic example of boundary work -- exemplifying how the "modern" native woman represents low social status for not being sexually pure. This scholarship has pointed out that immigrants raise their social status by disciplining their women's and girl's sexuality (Espiritu 2001; Kurien 2003; Min 2006).

However, parallel to the work focused on gender traditionalism, there is a second set of scholarship in the field that finds that migration has fostered equality in gender relations among Asian Indians (Rayaprol 1997; Khandelwal 2002). They identify the reorganization of the migrants' household structure as critical. Not only do gender roles overlap in this reorganization, such as husbands taking part in domestic work and wives joining the paid labor force, women's economic independence empower them to reshuffle 
their spousal relations also. Married immigrant Asian Indian women are usually more comfortable with this reorganization as they no longer have to follow patriarchal family structures (Kibria 2005; Khandelwal 2002; Kurien 2005; Min 2005).

However, and in contradiction, there is also literature documenting marital violence among Asian Indian migrants in the U.S. - a migrant group that has been perceived as a model minority in the U.S. (Abraham 2000). Abraham (2000) traces such marital violence to notions of immigrant cultural identity, family values and gender relations. While this scholarship is growing, the increasing numbers of NGOs such as Sakhi for South Asian Women, SAHARA, etc. helping victimized married women provide ample evidence of the fact that gender relations among South Asian Indians are being continually negotiated in the new context and that there is no one outcome. Certainly, patriarchy is still present and asserted regardless of changing women's positions both at home and in the workplace (Abraham 2000; Sakhi 1997; Sakhi Collective 1992).

Migration often challenges men and women to think and behave differently toward each other, particularly when they negotiate their relations in a broader GGP that does not match that of their native land. In some cases this results in reorienting spousal relations and their power dynamics. However, the scholarly lens to date has only examined these issues at the marital and migrant household level. In contrast, my interest is to focus on these relations in the context of transnational migration and the impact of extended family ties in particular. Moreover, in cases where migrants are strongly driven 
by pursuits to maintain their cultural ethos, their spousal relations are affected by their extended families through nuanced influences.

It is evident from this literature that marriage and family relations can be extensively reconfigured in the context of migration. Nonetheless, the scholarship on South Asian transnational marriages, by focusing and examining diverse practices and networks, continues to document how marriage is a gendered institution. The literature also questions key issues of gendered agency, especially women's agency, by examining how in many situations women are compelled into marriages by "structural constraints" (Constable 2003; Shaw 2000).

On the whole, this scholarship reflects individual and family aspirations and mobility strategies. An examination of one such strategy -- transnationally arranged marriages -- would open new avenues to explore the motivations for maintaining connections between diasporic populations, Diasporas and homelands (Uberoi 2005) but that is not the focus of this dissertation. This dissertation does address extended families' roles in negotiating spousal relations and the current literature does not engage in that discussion explicitly. Also, in an age of increasing migration and transnational lifestyles, the existing literature is silent in examining one of the most prominent transnational ethnic groups -- Indian-Bengalis -- who continue to negotiate their spousal relations visà-vis their families who are both extended and transnational.

The advances to our understanding of transnational gender relations made by all this literature are remarkable and helpful. They have informed my own perspectives going into this dissertation. However and to reiterate, a weakness that I am addressing in 
this dissertation and in this chapter specifically is that the typical unit of analysis has often been too small, particularly for peoples whose families should be but are not always classified as "extended." Spousal relations in such families cannot be understood adequately as just negotiated between husbands and wives. I took this inquietude into my research and my field data reflect the importance and necessity of adopting an extended family-centered approach for Bengali transnational migrants. Below I make this case more fully, drawing upon the original data from my interviews. Amongst the eight couples that whose family experiences form the bulk of my data, two couples' extended family experiences illustrate this finding best. Those couples are Priti and Rahul and Rita and Shishir who tell their stories now in their own voices.

\section{Redefining Spousal Relations - Bringing in the Extended Family}

"For Bengalis, and like many other cultural groups around the world, marriage is a bond not just between two people but between two families," asserted Rajiv, as we sat on the patio of their two-bedroom apartment in South Florida. Priti, his wife, was attending to their six-month-old baby daughter who was sleeping in the cradle in their bedroom. Priti was aware that I intended to interview Rajiv individually like I had done with all my interviewees. Therefore, she willingly kept herself busy with the baby in the other part of their apartment as I spoke with Rajiv. A look around their living room reinforces Rajiv's assertion above. Strewn across their living room walls are framed photographs of their parents, siblings, cousins, aunts, uncles, and close friends or "family friends just like family," as the couple described. Some of the pictures are from Priti and 
Rahul's wedding, some from the travels with their parents, aunts, and uncles, while some pictures are just about the couple.

As we continued talking, Rajiv told me the story of their marriage and how soon after their marriage they migrated to the U.S. "Family involvement is a certainty in the case for arranged marriages, even if the spouses are not involved [psychologically/emotionally] with each other," Rajiv asserted. Priti and Rajiv were married in India almost eight years before, in Delhi. Rajiv's parents lived in Delhi where he was born and raised. They later moved to Kolkata after Rajiv's father retired. As Rajiv described to me, his marriage to Priti was a typical example of an arranged marriage. Their families had advertised their children's availability for marriage in two national newspapers, specifying not only the qualities their children offered but also the families' requirements for potential matches. After a few rounds of short-listing pictures, resumes, and family backgrounds of prospective brides and grooms by their respective families, Priti and Rahul were imagined by their families to be a perfect match and they were soon married. Arranging marriages in this respect are classic examples of "imagination work" of the GGP framework. While I do not examine arranging marriages as imagination work in my dissertation, I identify this as an important future direction in the final chapter of this dissertation. Continuing to tell the story of family involvement in their marriage, Rajiv queried rhetorically, "Why do you go for an arranged marriage in the first place? Because you think about your family. And especially when educated people, who have 'been there, done that' opt for arranged marriage, you must understand that they place a lot of weight on what their parents want." This is an important gendered geography of power in spousal relations that Rajiv explained and one that involves marriage and is 
orchestrated by the family members. While we were talking, Priti although busy with their baby, did not ignore a Bengali tradition central to their cultural practices, that is, offering a huge platter of savories to the guest. The couple had arranged for samosas and Bengali sweets which they offered me.

I had interviewed Priti a few days earlier. Priti's responses complemented that of Rajiv. "Even if it is an arranged marriage like ours," she told me, "the parents feel insecure, specially the mother-in-law." Priti's response is related to her own experience as a daughter-in-law and she clarified this by saying, "This is the daughter-in-law's version. The mother-in-law's version will be different...but definitely the relation is affected." Priti explained a classic gendered geography of power that takes place between the daughterin-law and the mother-in-law which arises after a marriage in most Bengali families. She explained,"There is a lot of transfer of power and emotions after the marriage. The son will now have his financial or business centered around his wife. The locus [of his attentions] will shift." In most of my interviews, my informants have been unanimous about this tilt in power dynamics after marriage which informs a shifting gendered geography of power between the mother-in-law and the daughter-in-law. Priti continued, "I have heard in many cases that the mother-in-law tries to pick faults with the daughterin-law because the former feels insecure. So, by the time the son comes in the picture and wants to see both his wife and his mother happy, that often doesn't happen! You know, because it is an insecurity thing. The mother thinks that her son is now going to [focus on] his wife and she will never have him back. And so she starts misbehaving with the daughter-in-law. And what does the son do? On the one hand, if he is gentle towards his wife, it adds to his mother's insecurity. But if he misbehaves with his wife to make his 
mother feel secure, he is not living his dharma!" Priti added an additional gendered geography of power relation to her response, "The daughter-in-law cannot strain her relations with the mother-in-law, because if she does that, then she will not be a good grihalakshmi. This insecurity persists no matter where we live. But we cannot detach ourselves from the family. That is unthinkable. So we always have to think about doing the right actions [dharma] and performing our duties towards them [grihalakshmi]. It [family] follows you like a shadow, there is no escape."

In fact, Priti and Rajiv's case of arranged marriage is reminiscent of one of the earliest conventions of arranging marriages known as picture brides. Picture bride arrangements were particularly popular among immigrant workers of Asian decent living in the United States during the years 1908-21 (mostly in Hawaii and the West Coast) and the families of Asian brides-to-be living in their countries of origin (Chai 1992; Gabaccia 1992). The practice was named based on the exchange of pictures of interested parties through the intermediation of matchmakers (ibid.). Typically, migrant men living abroad would seek brides in their home countries/communities this way. This practice was considered as an extension of the original marriage tradition in their countries where the partner selection was achieved through the intermediation of the family members, i.e. the extended family. The picture exchange was seen as a necessary adaptation of the family screening process and the short accounts that accompanied these photographs make up for the interest in the other's family genealogy, wealth and other aspects such as education and health (Chai 1992; Luibhéid 2002). 
However and unlike the convention of picture brides, contemporary Bengali arranged marriages such as Priti and Rajiv's are not always entirely decided by their family with little to no input from the potential spouses. Rajiv cautioned, "There is also another thing. When someone settles for an arranged marriage because their parents want them to, they are also intelligent enough to understand what they want in their partner," Rajiv explained. "So that means when the parents' choice and your expectations do not coincide, a conflict can come into the scene. You may or may not like the person who your parents have chosen for you. So if any such conflict between the spouses arises, the parents, because they had told their son or daughter to marry the person they chose for $\mathrm{him} / \mathrm{her}$, can do two things. They can either jump in and resolve the issue, or stay completely aloof. In either case, they remain an integral part of the spousal negotiation," Rajiv asserted.

Another example of the extended family's involvement in spousal relations transnationally can be understood from Rita and Shishir's experiences. Rita and Shishir migrated to the U.S. almost seven years back, with Shishir on a H1 work visa as an employee of a MNC based in India and working for one of their U.S.-based offices in South Florida. Rita, like most of my female respondents in the U.S., migrated with her husband Shishir on a H4 category dependent spousal visa. A couple of years after they migrated, Rita and Shishir realized that their opportunities were better in the U.S. in spite of Rita remaining as a dependent spouse. Both of them have "large families" in Kolkata although they are not joint families by household structures. In spite of narrating about their large families, in my conversations with the couple, together and in isolation, they have voiced that they preferred to live in the U.S. and maintain close connections with 
their parents, siblings and extended family who live in India. Why? One important reason that Rita pointed out when I had interviewed her is that "Bengalis have always remained conscious about their social position in the society, and in order to not lose that position, they always expect from their younger generation to accomplish far and high. But sometimes those expectations simply skyrocket. For example, it is a popular understanding that a Bengali woman -- that is, a bhadramahila -- should be highly educated, be professionally excellent, and get married before she turns thirty. And once she is married, she will have to continue doing all of the above and have at least one baby. The sooner that happens the better. If she cannot or does not have the baby soon after her marriage, then the parents, in-laws, friends, and neighbors all become involved in the matter. They will tell her 'Oh, you must see a doctor' or they will talk amongst themselves about how unsuccessful the couple's conjugal life might be. Things that are very personal become very public."

The pressures of extended family members can and often do shift, however, when the couple lives overseas. "But when we come to the U.S.," Rita continued," it is like all their expectations are met! Suddenly, they become friendlier toward the couple because the couple now lives in the U.S. So that creates a new dynamic between the couple and the extended family." Rita thus points out, first, that extended family involvement continues after marriage, and second, that the nature of the extended family's involvement changes once the couple migrates but lives transnationally. What are the changes? Rita helps explain: "Take dress codes for example. When I got married, I never thought that I will wear denims in front of my in-laws (at least that is not expected from a 'respectable' woman from a good family). Now [after the couple has migrated to the 
U.S.], a lot of things have changed. It is now all right for me not to wear a sari in front of my in-laws or the rest of the extended family. In fact, sometimes when I am draped in a sari because I wanted to wear it, my mother-in-law will tell me 'It is OK, you do not have to wear a sari. You can wear a skirt."' From Rita's data it appears that gendered norms and expectations tend to become more flexible after couples migrate. However, having said that, Rita's final comments sum up that there is a disjuncture between how the extended family interacts with the couple and the various aspirations that are involved in the interaction. Rita explains, "But the fact is, those [dress codes as she explained above] are very superficial. The serious involvements continue. I still have to play the perfect obedient daughter-in-law [the grihalakshmi], even living thousands of miles away from them. There is no vacation from that. And that expectation is extended from the extended family to even the neighbors or close friends. They pity us if we tell them we had a pizza for dinner instead of a home-cooked three course feast, or that we still do not have a baby. For example, my father-in-law's eldest sister advised my in-laws to encourage us to see a doctor here [U.S.] about why we are still without a baby. I was very angry and hurt when I heard this, and so was Shishir. But because it is Shishir's family, he did not say anything much. That led to a fight between Shishir and I, because, poor guy [Shishir], could not take a single side. I mean, it is our choice in the end, but it is practically impossible to make them [our extended family] understand that."

I had interviewed Shishir a few days after I had interviewed Rita. Shishir, too, had raised the issue of the extended family's involvement in their spousal dynamics. But he brought out the point on a question about marriage, not when I spoke with him about family. To my question on if the nature of marriage for Bengalis is changing, he 
responded, "To an outsider, probably yes. They [outsiders] might think we [Bengalis] are becoming more liberal, that divorce is becoming a way of life rather than a social taboo. But I really don't think so, at least for Bengali society, no. Why? Because our premise of marriage has been built firmly on practices and understandings that had been handed down across the generations. So marriage, how we understand it, has become too deeprooted a practice to be completely uprooted." Shishir refers to the historical gendered geographies in family and in marriage for Bengalis in his response, and which I have already examined in Chapter Three. Shishir continued, "In order to completely uproot these practices, one has to come out of that middle-class fabric. When we talk about the Bengali society, even if we do not say it, we mean the middle-class fabric." Shishir's response is a classic example of how class-based practices continued for Bengalis in the twenty-first century. As argued in the previous chapter, this practice is resonant with Bourdieu's study of French practices of distinction and exclusion by various classes.

It is important here to recall from Chapter Three the gendered dynamics of the Bengali middle-class, especially the dynamics between the bhadralok and the bhadramahila and between them and the larger society. The Bengali bhadralok skillfully negotiated their social location between the colonial elite and the rest of India's peoples by doing gendered boundary work on their women and on other regional groups in India. This worked well during the colonial era but after India's independence Bengalis needed to find another way(s) to enhance their social status in a changing country and one of the most important—and, as it would turn out, gendered—strategies was emigration. Emigration became the new ticket to enhanced social status among Bengalis. But how would this change affect gender relations among couples now living transnationally and 
how would the extended family handle its role with emigrant members? In the classic joint family household model, or even in a "set up," the husband's family could easily rule over the new wife as she lived with them. But as couples moved way far away, how could the wife/daughter-in-law's virtue — and thus the virtue of the entire extended family—be assured, particularly as "modernization" also brought expectations of greater female freedoms such as the ability to work outside the home and to have supra-family friendships?

Priti, Rajiv, Rita, and Shishir's responses, like all the other six couples that I have interviewed in the U.S. for this research, document the continued impact of the extended family on their spousal relationships even across transnational spaces. To this point I have built my argument on this concept -namely, the extended family. But that concept needs clarification particularly given the multitude of shifts in family relations among Indians, especially transnational Indians. I address this critical question now. In their interviews, couples refer to a multitude of family members such as parents, in-laws, cousins, uncles, aunts, but the question remaining that needs greater precision is: Who belongs to the extended family? Shishir, by exemplifying his own family relations, provided the most effective definition to my question. "It [Shishir's family] is like any typical Bengali family, and it goes beyond the father-mother-child model of family. For example, 'extended' for us does not always apply similarly as understood here [U.S.]. My family, that is the family that I grew up in, is very much a Bengali family. I'll give you an example. When I say 'brother' here [in the U.S.], people will immediately assume that it is my own brother, my sibling, right? But when I refer to my 'brothers,' they are actually my cousins [but we treat them as brothers]. They are my father's elder brother's sons. My 
father almost brought them up like his own sons. Not so much in terms of finances, but he guided them throughout their life. They are much older than me. So to me, my brothers are those guys who are not actually my own siblings. My cousins have been part of my family, even though most people will call them my 'extended' family. Whether there are any occasions or not, they are my family. So my family is very much a typical Bengali family."

From Shishir's response, and because he asserts his family to be a typical Bengali family and this is substantiated by other interviewees, it becomes increasingly obvious that there is a blurry not a bright boundary between how Bengalis understand and operate as a family and how they perceive "extended" family. This blurring becomes even more blurry as interviewees delve into how they include in their understanding of family people who are not tied by blood or marriage. For example, Rajiv defined extended familial relations as "the bonds that we create, not necessarily the blood connections that we are born with. For example, my cousins-in-law are my extended family. In-laws are extended as I do not have direct blood relations with them. And apart from that, there are a few others who are not related to us in any way, and yet I share a lot with them. They are part of the family emotionally. Such as my neighbors, and my boss. Over the years, I have developed a relationship with them built on trust and believing in each other. Even they consider us to be part of their family." Rajiv's response begins to reveal an even wider finding in my data -- that the Bengali conceptions of family are not limited to ties through blood or marriage only. Even close friendships and work colleagues enjoy legitimate influence over family matters. Indeed, given more research I might be able to affirm unequivocally that membership in the category "family" is best understood as 
those people who have the right to inflect one's life. Testing this hypothesis would require some creative research in cognitive boundary work. For now, the key point I am making is that the so-called "extended" family is the appropriate unit of social analysis for my study and it may also be far more appropriate beyond Bengalis - just not yet recognized as such.

In the broader anthropology literature, the extended family is regularly understood as analogous to a social security system. The compadrazo system among Latin Americans is an example (Boehm 2012; Hirsch 2003). My data fit that example too. To be clear, my findings that extended families are the norm is not that new in existing scholarship. But given its importance in influencing and inflecting spousal relations transnationally, the discussion on extended families explicitly has been a blind spot in the scholarship -- it has not appeared enough in the transnational family literature. The transnational families of most migrants are extended (George 2005; Hirsch 2003) which is key to this discussion but this dissertation engages with the extended family explicitly while other scholars have tended to do implicitly.

Historically and during prehistory as well, extended families have always been the human norm (Settles 1999). However, the lion's share of scholarship examining spousal and family relations has focused on nuclear family dynamics (husband-wife-only model). There are likely many reasons for this but engaging in those debates lies beyond the purview of this study. My focus is on why people who are exposed to different gender and family GGPs continue to show a preference for the extended family's influence. The 
answer I have uncovered in my research and which I discuss in the next subsection has to do with peoples' motivations for and purposes of migration.

Various South Asian ethnic groups have migrated to the U.S. over the decades for various purposes. While most South Asian groups have migrated over recent decades primarily for economic reasons, Bengalis are motivated to migrate for reasons including but not limited to these. Here, and as my original field research evidences, the transnational family plays a key role. Bengalis practice a transnational strategy akin to the Chinese business elites that Aihwa Ong (1999) studied. As part of what Ong terms the strategy of "flexible citizenship," the overseas Chinese business elite and their families may buy homes in North America and send their children to prestigious American colleges even as they continue to base businesses primarily in Southeast Asia. However, in doing so, they find that their economic capital is not so easily converted into social capital because of the symbolic racial hierarchies already established in the North American places of residence (Lamont and Molnar 2002). Arguing for a migration motivation beyond just economic, Ong examines an interesting gendered geography of power in family relations. She writes, "Family romances do not operate in an apolitical manner but inform the way people imagine the operations of power between individuals and the state, between different ethnic groups, and of course between men and women" (Ong 1999: 143).

The "operations of power" that Ong discusses becomes an expression of boundary work for Bengalis in the U.S. This boundary work is quite similar to the status negotiation dynamics I discussed in Chapter Three. It is geared towards negotiating a 
higher social location vis-à-vis the various other ethnic groups in India. This is history dating back to the bhadralok era. While better economic opportunities have been an important motivation for most Bengalis migrating to the U.S., there is an additional and important motivation for them to migrate and live transnationally. This motivation is one associated with class construction again: of belonging to a transnational bhadralok class. This symbolic boundary work of working toward and then achieving membership in a transnational class comes in part with the formidable economic power. But more importantly, it continues the Bengali's tradition of positioning themselves as the "sentinels of culture" or the most modern of Indians. Being transnational, navigating across different countries and particularly countries with high social ranking enhances the migrants' — and their extended family's—-social status wherever they might be.

Moreover, Bengalis negotiate their social status by categorically differentiating their motivations and migration intentions from those of other South Asian groups that migrate. While most South Asian migration occurs for economic reasons (following the scholarship), Bengalis, as my field data document, attach a symbolic meaning of status to migration and transnational living. To recall from Chapter One, symbolic boundaries are conceptual distinctions made by social actors to categorize objects, people, practices, and time and space (Lamont and Molnar 2002). Symbolic boundaries are the ideas that people attach to a particular phenomenon and that guide the ways in which they go about actually categorizing and valuing them. If these conceptual distinctions are widely shared and practiced, they can be translated into rigid, systematic, and carefully patrolled patterns of social exclusion and inclusion. In the following, final section of this chapter, 
then, I turn to examining the group's social location negotiation as a transnational class and vis-à-vis "modernity".

\section{Material and Symbolic Privilege across Transnational Spaces}

There is a significant Bengali student population in Gainesville due, in large part, to students attending various graduate programs at the University of Florida (UF). In this group of students, there is a young man in his early thirties, whom I will call Ajay, who joined the Department of Engineering at UF three years ago. When I was visiting my cousin's wife in February 2013 in Gainesville, Florida, she told me the following story about Ajay. Ajay had full financial aid from the department when he joined, and he has been maintaining his full financial assistance since then. However, needless to say, a student's stipend alone like the one that Ajay receives is far too little to support an entire family. But, because Ajay's family, who lives in Kolkata, imagined that he is "accomplished" by successfully negotiating student status in the U.S., it is the perfect time for them to arrange for his marriage. To them, that would be the next logical step so they can abide by their dharma. In spite of Ajay's warning that he is not ready financially to support a family, his family looked for a prospective bride for him. Eventually, after rounds of advertisements in local and national newspapers in India, Ajay's family found a young, educated woman for Ajay, whom I will call Vaani. Ajay's parents happily married him to Vaani when Ajay was visiting his parents during a summer break. Vaani's family was excited with the marriage too because the prospective son-in-law was residing in the U.S. After the wedding, Vaani migrated with Ajay to the U.S. on a dependent (F2 type, for dependent spouse of an international student in the U.S.) visa. Within a couple of 
months after the newlyweds arrived in Gainesville, Vaani accidentally became pregnant. Even before the couple was ready to celebrate their first anniversary, Vaani and Ajay had a beautiful baby daughter.

All this while, Ajay had been the sole earner and provider for his wife and, later, their baby daughter. Not surprisingly, with barely a thousand dollars a month, a student's paycheck fell far short of meeting their monthly expenses especially with the needs of the baby. Ajay's savings rapidly depleted and his monthly paychecks fell short for taking care of all his financial responsibilities. Ajay declared bankruptcy. The story of his filing bankruptcy is carefully kept hidden from Ajay and Vaani's respective families and friends in India. The couple is afraid that their experience might taint their status negotiation and will jeopardize their family's position in society in India. During my sojourn in Gainesville, I was able to meet the couple and their baby daughter.

Ajay and Vaani's situation is a vivid example of how family and extended family conceptualize "transnational privilege" and attaching value to a social location to accomplish higher status by enabling a member to migrate to the U.S. Ajay and Vaani's case is far from unique and can be contextualized as the current transnational Bengali status negotiation strategy. During my fieldwork, I have documented instances that my interviewees related to, either directly or indirectly, with regard to negotiating a high status by virtue of their being in the U.S.

Another example in this context can be had from Meghna's cousin sister, Twisha's reflection. I interviewed Twisha on a weekday evening in Kolkata, agreeing to meet her after work. We met at a quiet place in downtown Kolkata, and cooled off with some beer. 
Twisha was born and raised in Kolkata, and having finished her college education, moved to Bangalore for job prospects. She later married, and now works in a Kolkata office. In our conversation about family ties and how she thinks that transnational lifestyle has impacted her relationship with her cousin, Twisha stated quite vividly how she thinks that her cousin and her husband are "more Bengali" in the U.S. than Twisha is in Kolkata. "They are extremely committed to our cultural practices, and they have an invisible bond, which somebody like me... doesn't have probably because I am living in the middle of it, within it." I asked her to tell me more about the "invisible bond." "It is like small little things," she said. "For them, observing all the rituals of the Durga Pujo [the biggest festival for the Bengalis, usually takes place in autumn] such as bishorjon, the arati, and playing with the sindur, is a big thing. But they do it religiously every year. And she [Meghna, her cousin] has to make an effort to do that. You know, she has to take time off from work, or it has to be a weekend, she has to take care of her kids at home, she has to drive some hundred miles to get there [at the place of worship], and she has to get draped in a sari even if the weather is not suitable to wear a sari...So she has to go through a lot of challenges to do something like this. For me or someone else married in Calcutta, you get up and it's right there. You step out of the house and it's there. So you do not have to really make an effort. So in that sense, I think they are much more culturally committed in many ways."

Twisha's description about how strongly her cousins' observe Bengali cultural practices in the U.S. is evocative of the research that other scholars of migration find. Being abroad and being characterized by a particular nationality, brings immigrants' national identity to the fore (cites). In the Bengali case, however and what distinguishes 
it, I believe, from other cases, performing Bengali cultural practices constitutes a continuation of their strategy to achieve and continually assert their high social status. They garner symbolic social capital (Bourdieu 1984) through these efforts.

Ironically, however, the cultural practices that raise Bengalis' social status abroad are the opposite of how Bengalis in India - at least those from Bhadralok backgroundsnegotiate their enhanced social status. "But there is also another thing," Twisha explained. For my friends who are married in Calcutta or elsewhere in India, I know that their kids don't even speak Bengali. But I know for my cousins staying in the U.S. [Twisha has four cousins living in the U.S.], they make it a point to speak to their kids in Bengali, they teach them to read Satyajit Ray [Indian/Bengali filmmaker and one of the greatest auteurs of international cinema], and they will show them Feluda [popular fictional character in Satyajit Ray's stories] movies... and I think that's beautiful! And I think our kids here are growing up with Winnie the Pooh, and Mickey Mouse and what not. They are growing up with Disney characters, whereas my cousin's children in the U.S. are much more aware of the Mahabharata and the Ramayana, which I find very fascinating. So they are much more connected to us than are my friends here in Kolkata."

The above examples illustrate how Bengalis use their transnational social location flexibly depending upon local and transnational contexts but always in efforts to negotiate higher symbolic capital or social status vis-à-vis their family, extended family, friends and nation. Pierre Bourdieu's notion of symbolic capital, when approached though his conception of gender, provides us with an additional lens through which we can examine what it means to be "respectable" in the larger society. For example, in Ajay and 
Vaani's case, their "respectability" has been maintained vis-à-vis their families, friends and neighbors by not disclosing their financial problems. Vaani continues to be the perfect grihalakshmi to her in-laws because she had a baby soon after their marriage, and she keeps in touch with them regularly. Ajay's "respectability" has been maintained vis-àvis his family and in-laws because he married when his parents wanted him to, married who his parents wanted him to, and plays the role of primary breadwinner for his wife and child. For Meghna and Neel, their "respectability" has been maintained vis-à-vis their family and extended family by continuing to live in the U.S. and observing Bengali cultural practices in the U.S. while their cousins and friends in Kolkata do not make much effort to observe those practices. In Bourdieu's treatment of social capital, its bearers exert power from a dominant position but this dominance is "misrecognized" as natural, thus making it appear as if the dominant group is not exerting power at all (Bourdieu 1990, 1991, 1995). The strength of Bourdieu's emphasis on symbolic capital as cultural authorization, as I use the concept here, thus opens up significant space for discussing the embeddedness of gender in these processes. This renders the conceptualization of "respectability" as a constitutive element of symbolic capital of the middle-class, an avenue for a higher status negotiation. This status negotiation is akin to the Bengali strategy for negotiating a higher social location vis-à-vis other groups historically and across multiple sociogeographic scales. The family's privilege in this case is also embedded in the national and domestic hierarchies in India, global capitalism, and in India's evolving class structure. The gendered geographies of power and privilege in this case, in a classic way, thus relates to a status negotiation involving paying attention 
to symbolic, material and economic privileges, while always remaining attentive to the role of geographical mobility in establishing and reinforcing those privileges.

Bengalis have long been concerned with maintaining high individual and family status in general. In fact, some of the strategies of negotiating higher social status are visibly carried out in their contemporary practices too. For example, their concern with women's education to raise the entire group's social location is reflected in this dissertation's discussion of the women's question onward. As exemplified above, Vaani is an educated woman but her family educated her with the purpose of improving her marriage prospects and this strategy worked. When Vaani, in spite of her high education, migrated with Ajay as his dependent, she was not able to use her education to her and her family's benefit. Her predicament recalls how in the 19th century Bengalis pursued a strategy for balancing the needs of modernization with those of patriarchy leading to a modicum of education for women, but by no means so much that they might disturb the existing patriarchal order (Chatterjee 1993).

Aditi, who also reflected on the women's question and education in nineteenth century Bengal, expanded her explanation to contemporary practices: "Educating the girl child became a social norm in Bengal unlike the rest of the subcontinent, since the nineteenth century. And since then this has continued being on auto-pilot. However, how much of that education she actually decides to use or gets to use in her future was not and still is not an important factor in the society." So the strategy of achieving and maintaining a higher social location through gender and yet keeping a control on female sexuality is clearly visible from Aditi's response. Bengalis continue with their strategy of 
status negotiation where their women must shine but not outshine the men. However, the advantages that living transnationally offers make this negotiation for the women more powerful. Those women who acquire the skills and higher education such as Smita and Meghna become upwardly mobile and possess a significant amount of economic and symbolic capital. They thus can control their gendered negotiations with their families, especially with their in-laws. Education thus continues to prevail as a powerful tool for boundary work, raising the question of not who, but how this group performs their position in society and across transnational spaces.

Educating females by their families must also be analyzed a risky trade-off. If families educate their daughters they might think for themselves and diminish their chances for a "good" marriage (for the family that is). There is solid data in my dissertation that shows this can and does happen. However, daughters will also not be eligible to marry good Bengali boys if they are not educated. And education is also a key form of Bengali boundary work vis-à-vis other Indians. This finding does not appear to be reflected in other literature to my knowledge.

\section{Chapter conclusion}

In his groundbreaking book Categorically Unequal: The American Stratification System (2007: 1), sociologist Douglas S. Massey opens the book with his following words: "All human societies have a social structure that divides people into categories based on a combination of achieved and ascribed traits." He continues to hone this idea of the enduring formula for establishing "categorically unequal" groups: 
...the basic means by which people are granted more or less access to scarce material, emotional, and symbolic resources have remained remarkably similar through the ages. Indeed, all stratification processes boil down to a combination of two simple but powerful mechanisms: the allocation of people to social categories, and the institutionalization of practices that allocate resources unequally across these categories. Together, these two social processes produce what Charles Tilly (1998) calls 'categorical inequality'-a pattern of social stratification that is remarkably durable' in the sense that it is reproduced across time and between generations (2007: 5-6).

According to Massey, inequality is generated and perpetuated by two basic mechanisms exploitation of one group by another and opportunity hoarding — a "socially defined process of exclusion." Opportunity hoarding is when one group restricts other's access to resources, retaining as much as possible for the favored in-group. Inequality is reinforced and reproduced via "emulation" (where people copy social distinctions and apply to another group) and "adaptation" where microsocial behaviors become oriented toward ranked categories, structuring decisions about whom to help, marry, share with, etc.

Massey's (2007) work is an important reference point in this dissertation because Bengalis negotiate themselves to be categorically superior to others. Throughout history and in their contemporary practices too, Bengalis have continually negotiated their social location as a special category. Historically within colonial India they negotiated their social location vis-à-vis other ethic Indian groups so they could get unequal resources from the British and then opportunity hoard them so other Indians could not access them. 
Their negotiations have continued in their current practices and this is why arranging marriage is so important even today. Therefore, although I did not research this practice explicitly in this dissertation, I view it is an important future direction. Bringing in women as outsiders - as occurs with arranged marriages--is risky to a family's structure and dynamics. So the patriarch (and his main assistant—-his wife) arrange a marriage to suit their needs first and foremost but find someone acceptable to the son. And parents of daughters want to enhance their status by finding good matches for those female members.

This chapter's discussion on female sexuality and its relationship to an immigrant population's self- and ethnic social status is in conversation with the larger anthropological scholarship that women have largely been treated as a resource governed by men (Mead 1935; Collier and Yanagisako 1987; Parkin and Stone, 2004; Stone 2010) . Initially their fathers control them and later they pass to their husbands. With my research population, this gendered possession approach is shifting in that with education women earn incomes and exert agencies but they still have to live according to old rules (such as those guided by dharma and grihalakshmi). Those norms have proved highly adaptable to changing circumstances but always reflect the importance of gender to families' social status. The higher the social status of the family from which the women (as resource) are derived, the more control over them so that the men can bargain for more resources as they engage in negotiating marriages. Grihalakshmi as a guiding principle in family and marriage serves to have women and girls do gendered boundary work on themselves as well as on each other to keep them in line. 
Moreover, through the control of their sexuality by men, Bengali girls and women have played key roles in how "modernity" gets reconciled with a perceived imagination of an "authentic" culture. As I have examined earlier, in early Indian nationalist discourse, middle class Bengali women came to represent the true essence of Indian culture. That spiritual essence was a domestic image while Bengali men were located outside the home, engaged in the realm of the material. Thus Bengali men represented efforts to modernize the nation while Bengali women, in contrast, represented the pure essence of tradition. Over time, representations of the idealized Bengali family, of manhood and of womanhood have all shifted, reflecting sociopolitical and economic changes. A constant, however, has been the central role of gender in all these imaginaries and realized configurations. 


\section{CHAPTER VI - CONCLUSION}

This dissertation was originally designed to investigate the role of the extended family in the relationships of spouses living transnationally. I set out to examine these relationships using the theoretical frameworks of Gendered Geographies of Power (GGP) and Boundary Work. However, and not surprising for a research designed on the principles of Grounded Theory, the dissertation focus shifted during my fieldwork and analysis of the field data owing to the perspectives of my research subjects. The focus of the study needed to reflect accurately the focus of the data they provided. The result is that the dissertation examines how Bengalis as an ethno-linguistic and transnational group have negotiated their social locations historically and contemporaneously. This examination includes but is not limited to the original objective for my research for I learned, as is commonplace in social science research, that the reality I set out to study was more complicated than I anticipated. In sum, this dissertation now takes as its primary focus how Bengalis have adopted various strategies to improve their social status leading up to the most recent transnational phase. Gender figures prominently in each of these strategies but not surprisingly its manifestation as a force inflecting social relations and locations shifts over time and in response to different other forces.

I have utilized the GGP framework and Boundary Work frameworks as my "gender optic" in this research. The GGP framework of analysis developed by Mahler and Pessar $(2001,2006)$ was presented first as a theoretical perspective. Within this dissertation I then applied their framework specifically to understanding transnational Bengalis. In doing so, I examined and illustrated the utilization of social locations across

multiple geographic scales - from the supranational to the intimate — and, examined how 
they negotiate their gendered as well as group's social locations in their pursuit of negotiating family relations transnationally. This is the first focus of my dissertation -the dynamics of families and the distance Bengalis have between ideal and real families and their dynamics and explains them according to historical, structural, economic, social forces.

\section{Analysis and Major Findings}

Through analysis of the extensive data, understandings of how gendered negotiations are fluid and how they vary historically and contextually have been enhanced in several ways.

First, this dissertation employed ethnographic methods to generate rich qualitative data in contrast to the quantitative data collected in most studies on Asian Indians to date (Hing 2004; Kibria 2005; Prashad 2000). Through participant observation and intensive interviews, I was able to socialize with my participants in a variety of settings. Such settings ranged from their homes, cars, public places such as supermarkets, public events, or at private gatherings. Through on-site interviews new dimensions emerged that shed light on Bengali gender relations which have not arisen in previous research or which have arisen but have neither been adequately understood nor contextualized. For example, by tracing Bengali history through major time periods of the nineteenth, twentieth, and twenty-first centuries, this dissertation renders an enhanced understanding of how gender relationships can and often do evolve historically and contextually. The engagement with various geographic scales from the supra-national to the intimate brings added scalar dimension to this analysis. 
Second, this dissertation uses a comparative frame and compares the experiences of Bengali men and women and negotiations of "manhood" and "womanhood" over time and across geographic scales. My field data is evidence that gender relations are fluid and how they vary historically and contextually. While this is hardly a new theory, what is most interesting are the perceptions and attitudinal changes in gender relationships that bring about the fluidity in these relationships. The adaptation of ideologies of dharma and grihalakshmi across the various time periods is an example. My interviewees have constantly used dual or multiple timeframes of references while talking about these ideologies in their responses explaining how gender relations amid Bengalis evolved over the decades and across the scales.

One bright example of the changing gender relations that this dissertation documents and analyzes is women's changing social locations in the family. Historically and as examined in my dissertation, highly gendered joint families worked so long as women were kept subordinate. But when Bengalis adopted education as a strategy to elevate themselves vis-à-vis the British and then vis-à-vis other Indian ethnic groups in the new nation, that strategy set in motion changed that accelerated with migration into new gender "regimes" as well as globalization and internal shifts in Indian society. These changes ushered in more nuclear household types (or stem-families but not the full joint family arrangement as it used to be historically). Voices of the couples in my research show a much more companionate relationship where decision-making is more shared than in India and the pivot point of the family has shifted from patriarch-sons to husbandwife. 
Closely related to the above is the changing position of the daughter-in-law in the family. In the evolving patriarchal arrangements examined in chapters Three and Four, the daughter-in-law was brought from the lowest position within the family, the "doormat" position as used to be historically, to the second highest position in the family. The highest position was occupied by her husband. Education was one primary reason for the changing social locations of the daughter-in-law in the family. Scholars argue that this shift in gendered geography of the spouses is a blend between the Victorian model of companionate marriage yet indigenizing the companionate couple form by binding them with ties to hold together the joint family, including and at the very least, their children and the bride's in-laws (Majumdar 2009). This is particularly important because it points towards why the institution of arranged marriage arose in my field work as central to this dynamic. While the institution of arranged marriage may be viewed as adapting to changing social contexts, it still faces a solid challenge. What is that challenge? Just behind it lurks the shadow of the joint family, an institution that has undergone many changes during and after the colonial rule and yet continues to subordinate the person to the family even in its transnational form. However, one theme has continued to be blended in these changing family forms -- the companionship between the husband and the wife. In a large way, this companionship continues to be informed by the spouses' relationship with the extended family.

The changing social locations of women within the family coupled with their continued but varying subordination have interesting parallels to the larger scholarship on controlling families and female sexuality. For example, some researchers have documented that controlling female sexuality is accentuated among immigrant 
populations. Immigrant families do aggressive sexual boundary work on female teens and young adults in particular so that they can be held up as examples of their group's virtue in contrast to the dominant society's vice (i.e., allowing its girls and young women to be sexually alluring and/or active) (Eastmond 1993; Espiritu 2001). This social construction of a group's cultural superiority is also often asserted through family "closeness." That is, the good (immigrant) family is close while the families in the broader society are characterized as more distant, less united. This is certainly the case among Bengalis. But the claim that family "closeness" constitutes a measure for group superiority is not unique to Bengalis. Studies on Filipino migrants by Yen Le Espiritu (2001), on Vietnamese migrants by Kibria (1993), and on Italian Americans by di Leonardo (1984) have all emphasized how the close-knit character of their families is used to argue for their cultural superioriority vis-à-vis the larger society.

What is likely more unusual in the Bengali case, however, is that the close-knit character of the family and the grihalakshmi are utilized to negotiate their enhanced social status in both places -- their home and host countries and communities. Not surprisingly, the brunt of maintaining and continuing this close family falls disproportionately on women.

Third, my dissertation documents and analyzes the dynamics of the extended family across transnational spaces. These dynamics are then analyzed for their relationship to the group's negotiation of status. This negotiation can be understood using the lens of being "categorically unequal" - of doing Boundary Work— and which frequently involve gender. In particular as the dissertation has examined, gendered 
Boundary Work is often conducted via education and later employment of the wife/daughter-in-law in the family. This Boundary Work is necessary to creating a special, elite category within India for Bengalis and then Boundary Work to maintain it. To maintain Bengalis' special category, they had to be united and this meant close family ties, particularly making sure that the children married well and stayed loyal to the patriarch/central hub of the social system. With changing socio-political scenarios such as urbanization and later migration, staying close could no longer be achieved structurally by living in the same household but people could live nearby and continuously visit. This has been illustrated in this research via the examples of the setups of the joint families. Moreover, with transnational migration the whole idea of emotional (if not physical) propinquity and social control over younger Bengalis became even more difficult to achieve. So the joint family arrangement is now conceptualized as being extended across transnational spaces. This conceptualization has potential to be examined as an "imagination work" using the GGP framework where the idea is that the setup's roof extends thousands of miles across to these emigrants' households. This is an important future direction that this dissertation identifies. But at the same time, from the spouses' accounts that I have examined, it seems that that while they still feel part of these extended families, in daily life they are moving toward more independent, nuclear family units. So it appears that the ideal of the joint family has to work harder to overcome for shifts in real life.

Fourth, the findings from my dissertation help to inform the ongoing conversation in social sciences about whether or not migration studies is too narrow and that the focus should be expanded to mobilities. Broadly speaking, advocates for what is often referred 
to now as the "new mobilities" paradigm (Hannam et al. 2006; Sheller and Urry 2006; Urry 2007) argue that human movements, migrations, are best analyzed and understood with and not in contrast to other types of movements, particularly the massive flows of capital and goods characterizing globalization. Moreover "mobilities" scholars promote a more multiscalar frame in which all forms of movement, whether across districts or international boundaries, can and should be conceptualized within a singular framework.

While the proposed paradigm shift has many adherents, it is also subject to critique and this counter perspective is just arriving (see Glick Schiller and Salazar, 2012). One rising criticism of "mobilities" is that today's timeframe is not truly unique, that for humans and our activities mobility has always been the norm, not the exception. Therefore, a paradigm based on mobilities assumes, whether articulated or not, that there have been epochs in human history where movement was absent. This does not appear to be the case, at least in terms of trade. Second, while the paradigm appears all-inclusive, it does so at some analytical cost. Not all people who move are the same and migration studies has done a very nuanced job of capturing this variation by examining what causes people to move, the decision-making processes involved, and the regulation of movement. There is need for distinguishing between different categories of mobile peoples -- independent and dependent migrants, tourists and visitors, students and scholars, high- and low-skilled laborers and contractors, etc. Migration studies has done an excellent job in bringing to light this much more granular level of analysis. That helps justify a less unitary paradigm. Similarly, the 1990s effort to document that people do not just move across borders to settle and stop moving; many continue to participate in transnational activities that circulate goods, service, people as well as ideas and values 
such that the unit of analysis should not be individuals, but webs of intertwined individuals(Glick Schiller and Salazar, 2012). The latter approach is certainly the one I have utilized in this dissertation.

To overcome these limitations but to recognize the importance of the "new mobilities" approach, anthropologists Nina Glick Schiller and Noel Salazar have proposed studying "regimes of mobility." Borrowing from Deleuze and Guattari's (1987) "deterritorialization" and Latour's (2005) actor-network theory, Glick Schiller and Salazar (2012:8) argue that the regimes of mobility approach "must move beyond the ready equation of mobility with freedom by examining not only movement as connection but also as an aspect of new confinements and modes of exploitation." As the authors note, "to understand the changing definition of mobility and immobility, we need to put these concepts within a theory of unequal globe-spanning relationships of power" (Glick Schiller and Salazar, 2012: 14). To me, these "relationships of power" can and should be effectively understood as power geometries -- a central component of the GGP framework and one that addresses relationships through social locations and agency. The "regimes of mobility" framework also sheds light on US immigration policies that inform why some of my informants migrated as independent migrants and the others followed them as dependent migrants. In sum, there is much worth to the "new mobilities" approach but this approach does not completely capture the nuanced transnational lifestyle that many migrants including my informants live. There are not yet enough academic consensuses to embrace a new paradigm shift. Conversely, I believe that the counter debate which always accompanies new paradigms is just beginning and I look 
forward to the possibility that the debate produce more ideas useful for analyzing my own data.

Whether living transnationally or not, the ideal family has continued to remain as a joint family and there are happy memories of these large households. But the ideal never is the same as real and ideal can persist even generations after it no longer really exists. As examined, the "setups" or "settings" are examples of the latest expression of the ideal joint family even across transnational spaces. The evolving reality of the ideal joint family structure is impacted by structural changes that in turn impact families. The ideal remains the joint family but it is not possible to maintain in large cities with apartments. So ideally people would live under the same roof in these multigenerational families but that is increasingly impossible given (1) transnational migration and (2) Indian cities where these compounds are fewer because of the cost and construction of apartments and other living expenses. The ideal remains as the joint family, but without

the really intense patriarchal order of before. Instead, the joint family is now imagined in transnational terms where people do not live under the same roof yet still imagine themselves as living in a type of virtual setup.

\section{Contributions to Theory}

This dissertation makes three significant contributions to theory:

The first significant contribution that this study makes is to the field of gender studies, specifically the field of intersectionality studies. Recapitulating from chapter One, intersectionality refers to the active interaction of the various relations of inequality such as race, class, sexuality, gender, and age within and across all of the institutions of 
society (Anderson 2005; Ferree 2009, 2010; hooks 2000; Hernandez and Rheman 2002).

Few studies have compared and examined Bengali middle-class men and women -- the Bhadralok and Bhadramahila -- as a linguistic, class, and gendered construction. And fewer such as this dissertation have examined intersectionality across a time-space continuum - historically over three centuries, contemporaneously, and across geographic scales of the nation, the group, and the family. This dissertation accomplishes this task. In addition, I have examined how collective identity formation of Bengalis as a middle-class group historically and contemporaneously has shaped, reshaped and re-informed their family and spousal dynamics. This makes an important contribution to the canon of intersectionality studies in a significant way. By using the GGP framework in my case, I provide an enhanced analysis of intersectionality across historical as well as spatial scales. To be clear, I have not only examined Bengali gender relations in the context of their ethnicity, class, and sexuality over key historical timeframes, I have also examined their mutual constitutiveness across geographic scales of the nation, the group, the family, and at the intimate scale of spousal relations. While this is often asserted in theories addressing gender and feminist theory in particular, the number of well researched and argued cases that document intersectionality—particularly for multiple time periods - is far smaller than needed. This dissertation adds to that small but important list.

Second, the findings from this study extend and enrich the literature in migration and transnational migration studies. This research brings to the forefront the extended family and its impact in transnational migration contexts. Why is it important to include extended families when examining gender and spousal relations transnationally? There 
has been a growing and important literature in the area of gender and transnational migration studies since the mid-1990s when the transnational perspective on migration first appeared and yet did not centrally theorize the importance of gender (HondagneuSotelo 1992; Mahler 1999; Pessar and Mahler 2003; Mahler and Pessar 2001, 2006). Moreover, very few researchers have located spousal relations as a principal focus of analysis when bringing gender into transnational migration research. Additionally, the "extended" family has rarely been an explicit focus of research in this field. This present research builds upon yet extends these literatures by focusing on a quintessentially extended family population, Indian Bengalis, and by examining gender across not only different geographic scales (local to transnational) but also across different family scales (spouses, "nuclear" and "extended").

The third contribution that this research makes is amplifying and extending the use of the analytical framework "gendered geographies of power" or the GGP framework (Mahler and Pessar 2006). I have utilized the GGP framework not only to examine a new population, Bengalis, but across different historical and contemporary timeframes. To date the GGP framework has been applied only on the contemporary period and for transnational migrants (for example, see Cogua-Lopez 2010; Thimm 2013). My work, however, illustrates the utility of this approach beyond its limited engagement to date. Throughout this dissertation I have examined how my informants negotiate inequalities and discrepancies of their geographic scales and social locations. They have voiced to be constantly challenging such categorical inequalities and thus negotiating their social locations across multiple scales. I bring an additional analytical lens to GGP which has not been applied previously, viz., Boundary Work. As examined throughout this 
dissertation, Boundary Work analyzes of how various actors actively participate in maintaining, creating and/or transgressing the gendered social categories operative in their world. By implementing the GGP framework in both historical and contemporary contexts, this research provides for an empirically based perspective utilizing the GGP framework and one that transcends any one timeframe or spatial context. This research therefore amplifies the application of the GGP framework in historical and contemporary contexts as it relates to gender relations, power distribution, and agency.

\section{Limitations of this research}

One limitation of this study that characterizes all case studies is that of focusing on only one ethnic transnational group. However, in spite of concentrating on only one group, this research does do historical comparative research; it therefore includes a comparative frame that offers greater promise to identify patterns globally and transnationally. Another limitation that I have encountered in this research is that the literature on "Indian" families before the twentieth century is weak. There is little written and that which does exist engage Indian families (understood to mean various peoples within what is now the country of India) addresses family structures or forms and not family dynamic. This research addresses dynamics as well as structures. A final limitation is that although I have gathered data from websites, interviews, and participant observation, I rely largely on the interview data. This is because the interview data drove my shift in focus and because it best captured people's perspectives on the dynamics of gender. The last limitation also reflects the fact that I went into the research focusing on spouses and their relations to their extended families. The website data primarily 
illustrated a topic I did not intend to research — the arranging of marriages. Arranging marriages, however, arose as a key factor in how Bengalis negotiate and maintain their social status. Therefore it is an important future direction that I will pursue.

\section{Future Directions}

The dissertation has identified two important future directions of research:

The first future direction is to examine arranged marriage as "imagination work". As I have indicated in this dissertation, arranging marriages is a classic case of what is termed "imagination work" within the GGP framework. People imagine who would be appropriate spouses for their children and then negotiate marriages as part of their social status negotiation across multiple geographic scales. Significant ethnographies and scholarship until have drawn attention to the tradition of arranged marriages in India whereby the onus for matchmaking is less on the individuals to be married and more on the family (Charsley and Shaw 2005, 2006). However, when such marriages are arranged across international borders, especially if the prospective partner resides in the West, conventional residence patterns are often reconfigured and migrating to the West is often prioritized over the patrilocal post-marital residence rule. As Charsley and Shaw (2006: 336) observe, "the opportunity for migration westward may take precedence over gendered conventions of movement in marriage so that, in some cases, men migrate to join their wives." There is considerable scholarship examining the geographic imaginings within which transnational marriages take place. Scholars identify the process of seeking a spouse in the homeland as extremely gendered. Men seek brides from South Asia expecting them to be "traditional" especially with regard to how they will behave vis-à- 
vis their husbands, while some migrant women fantasize finding an Indian husband living in the West to be more "modern" (Ballard 1987; Constable 2003; Danneker 2005; Kalpagam 2005; Mand 2002; Shaw 2000). Such Diasporic marriages are quite prevalent among Indian Tamil Brahman families who enhance their social location by arranging their children's marriages to co-national partners studying or working in the United States (Kalpagam 2005). As mentioned earlier, arranging such transnational marriages traditionally relies on a variety of networking: neighbors, professional matchmakers, newspaper advertisements, as well as internet dating sites (Bannerjee 1999; Charseley 2005; Charseley and Shaw 2006; Del Rosario 2005).

However, studies thus far have not utilized the GGP framework to examine arranging marriages as a classic case of "imagination work." Following the GGP framework, imagination work refers to the role that imagination plays in both men's and women's agency. This has been under-researched and theorized to date. Although not examining arranging marriages centrally in this dissertation, I have collected data from matrimonial websites which informed my interview protocol. In the future, I plan to collect primary data via interviews and participant observation of these key family dynamics. Family involvement and the extent of "imagination work" that inform this practice can be understood broadly through the premise of this dissertation -- that family's social status resides in the sexual fidelity and having virgin brides and gender and sexuality as being significant part of negotiating social status particularly by men.

The second important future direction that this dissertation identifies is one that examines Boundary Work of achieving elite status. This dissertation has identified a 
classic case of Boundary Work -- between Bengalis and "non Bengalis." In this dissertation and as my informants have used this Boundary Work in their responses, "non Bengalis" are often reduced to a homogenous Indian ethnic category: not Bengali. I have identified this important Boundary Work of Bengalis as an ethnic group's collective identity formation over the centuries. However, are these categories homogenous categories or are they based on graded choices (such as based on nationality, linguistic groups, ethnicity, etc)? Not only will future research on this expand our understanding of how groups use Boundary Work to negotiate social status, but future research on this will also link this research to broader processes of classic ways of building social hierarchies beyond the research population. These processes can be compared with transnational social status strategies of other Indian ethnic groups such as those form Andhra Pradesh migrating to the U.S. as a transnational strategy to claim higher dowry during marriage.

\section{Chapter conclusion}

As this dissertation has examined, with larger socioeconomic changes, Bengalis have to keep raising the ante on their privilege to keep one categorical step ahead from the other groups who seek to topple them from their privileged status. Transnational migration is just the most recent means to keep ahead. Gender has been central to every form of Bengalis' social status negotiation. Arguably the pivotal point was the women's question and the beginning of investments in educating girls. That makes women's subordination more difficult despite boundary work done on them to keep them categorically unequal to men. Urbanization and transnationalization make it even more difficult to achieve the "joint" patriarchal family system replete with women's 
subordination. This is similar to how it has been difficult in U.S. to keep women down when they go into the workforce in huge numbers. The ideal family in the U.S. has been nuclear but in the 1950s the ideal was stay-at-home mother with breadwinning father. That is still largely an ideal but no longer reflects reality for any demographic.

Historically, Bengali men and women have not shared equal social locations in Bengali society, and yet they imagine GGPs which sometimes make them on par with each other and sometimes different from each other. They differ when imagining gendered norms and practices within the marriage (between spouses) yet aspire to be the dyadic companionate couple form to negotiate their family relations. As this dissertation also explicitly shows, family involvement in spousal negotiation continues albeit geographical proximity can sometimes influence in their involvement.

In conclusion, although it appears from the stories of transnational Bengali men and women that they embrace the tenets of "modernity" in their lifestyle choices and worldview, yet the strong roots of gendered hierarchies have continued to anchor their lives as they maneuver across the various time frames and geographic scales. Their contemporary gendered spaces are being transformed by forces of transnational lifestyle but these changes are often countered by the ideologies such as dharma and grihalakshmi. Men and women who occupy and negotiate these gendered spaces are engaged in daily negotiations of recreating and countering these ideologies. Their negotiations expand our understanding of transnational gender relations across broad social and historical scales, particularly the transnational. By focusing on transnational family dynamics and 
identifying the practice of arranging marriages as "imagination work," this research has provided a significant premise for gendered imaginings of future transnational families. 


\section{BIBLIOGRAPHY}

Abraham, M. 2000. Speaking the Unspeakable: Marital Violence among South Asian Immigrants in the United States. New Jersey: Rutger University Press.

Ahmed, Imtiaz. 2005. "Futures Beyond Nationalism." Futures 37 (9): 905-924.

Allen, Katherine R. and Alexis J. Walker. 2000. Constructing Gender in Families. In Robert M. Milardo and Steve Duck (Eds.), Families as Relationships. New York: John Wiley \& Sons, 1-17.

Anderson, M. 2005. Thinking about women: A quarter-century's view. Gender and Society, 19, $337-355$.

Augustine, L. 2005. "Migrants in the Mistress's House: Other Voices in the "Trafficking" Debate." Social Politics: International Studies in Gender, State and Society 12 (1): 96-117.

Bagchi, Jasodhara. 1990. "Representing Nationalism: Ideology of Motherhood in Colonial Bengal." Economic and Political Weekly: WS65-WS71.

Bald, Vivek. 2013. Bengali Harlem and Lost Histories of South Asian America Harvard University Press.

Ballard, R. 1994. Desh Pardesh: the South Asian Presence in Britain. London: Hurst

Ballard, R. 2001. The Impact of Kinship on the Economic Dynamics of Transnational Networks: Reflections on some South Asian developments In Workshop on Transnational Migration Princeton University.

Basch, L. (Ed). 1994. Nations Unbound: Transnational Projects, Postcolonial Predicaments and Deterritorialized Nation-states. Taylor and Francis Ltd.

Bannerjee, K. 1999 Gender Stratification and Contemporary Marriage Market in India. Journal of Family Issues 20 (5):648 - 676.

Baviskar, Amita and Raka Ray, eds. 2011. Elite and Everyman: The Cultural Politics of the Indian Middle Class: Routledge.

Bhat, P. N. and S. S. Halli. 1999. "Demography of Brideprice and Dowry: Causes and Consequences of the Indian Marriage Squeeze." Population Studies 53 (2): 129149.

Bhattacharya, Tithi. 2005. The Sentinels of CUlture: Class, Education, and the Colonial Intellectual in Bengal Oxford University Press.

Blume, L. B., \& Blume, T. W. 2003 Towards a dialectical model of family gender discourse: Body, identity and sexuality. Journal of Marriage and Family, 65, 785794. 
Boehm, Deborah A. 2012. Intimate Migrations: Gender, Family, and Illegality among Transnational Mexicans New York University Press.

Boehm, D. 2008. "'Now I Am a Man and a Woman!": Gendered Moves and Migrations in a Transnational Mexican Community." Latin American Perspectives 35 (1): 1630 .

Bourdieu, Pierre. 1997. 'The forms of Capital', in A.H Halsey, H. Lauder, P. Brown and A.S. Wells (eds) Education: Culture, Economy, Society, Oxford: Oxford University Press.

Bourdieu, P. and L. J. D. Wacquant .1992. An invitation to reflexive sociology. Chicago: University of Chicago Press.

Boyd, M. 1989. Family and Personal Networks in International Migration: Recent Developments and New Agendas. International Migration Review (Silver Jubilee Issue) 23:638-671.

Butler, J. 1990. Gender Trouble: Feminism and the Subversion of Identity. New York: Routledge.

. 1993. Bodies that Matter: On the Discursive Limits of "sex.". New York: Routledge.

Cancian, Sonia. 2010 Families, Lovers, and their Letters: Italian Postwar Migration to Canada. University of Manitoba Press.

Chai, Alice Yun. 1992. Picture Brides: Feminist Analysis of Life Histories of Hawaii's Early Immigrant Women from Japan, Okinawa, and Korea. In Seeking Common Ground Multidisciplinary Studies of Immigrant Women in the United States. D. Gabaccia, ed. Westport, Connecticut: Greenwood Press.

Chapman, M. and Prothero, R.M. (eds). 1985. Circulation in Population Movement: Substance and Concepts from the Melanesian Case. London: Routledge.

Charsley, C. 2005. Vulnerable Brides and Transnational ghar Damads: Gender, Risk, and 'Adjustment' among Pakistani marriage migrants to Britain. Indian Journal of Gender Studies 12 (2):381 - 408.

Charsley, C. and A. Shaw. 2006. "South Asian Transnational Marriages in Comparative Perspective." Global Networks 6 (4): 1470-2266.

Chatterjee, I.

1999 Gender, Slavery and Law in Colonial India. Oxford University Press.

2004 Unfamiliar Relations: Family and History in South Asia. Rutgers University Press 
Chatterjee Partha. 1993. The Nation and its Fragments: Colonial and Postcolonial Histories. Princeton University Press

Chatterjee, Partha.

1999. "On Religious and Linguistic Nationalism: The Second Partition of Bengal." In Nation and Religion: Perspectives on Europe and Asia, edited by Peter Van Der Veer and Hartmut Lehmann, 112.

2005. "The Nation in Heterogeneous Time." Futures 37 (9): 925-942.

Cons, Jason. "Narrating Boundaries: Framing and Contesting Suffering, Community, and Belonging in Enclaves Along the India-Bangladesh Border." Political Geography $(0)$.

Constable, Nicole.

1997 Maid to Order in Hong Kong: stories of Filipina workers. New York: CornellUniversity Press.

2003 Romance on a Global Stage: Pen Pals, Virtual Ethnography and "MailOrder" Marriages. Los Angeles: University of California Press.

2005 A Tale of Two Marriages: International Matchmaking and Gendered Mobility. In Cross-Border Marriages: Gender and Mobility in Transnational Asia. N. Constable, ed. Pp. 166 - 186. Philadelphia: University of Pennsylvania Press.

2006 Brides, Maids and Prostitutes: Reflections on the Study of 'Trafficked' Women. Portal, A Journal of Multidisciplinary International Studies 3(2):2-25.

Connell, R.W. 1987 Gender and Power: Society, the person, and sexual politics. Stanford University Press.

Crenshaw, K. 1991 Mapping the margins: Intersectionality, identity politics, and violence against women of color. Standford Law Review 43:1241-99.

Dalmia, S. and P. G. Lawrence. 2005. "The Institution of Dowry in India: Why it Continues to Prevail." The Journal of Developing Areas 38 (2): 71-93.

Dannecker, P. 2005.Transnational Migration and the Transformation of Gender Relations: The Case of Bangladeshi Labor Migrants. Current Sociology 53(4): $655-674$

Das Dasgupta, S.

1998. "Gender Roles and Cultural Continuity in the Asian Indian Immigrant Community in the U.S." Sex Roles 38 (11/12).

1998. A Patchwork Shawl: Chronicles of South Asian Women in America. New Jersey: Rutgers University Press. 
Das Gupta, M. 1997. "“What is Indian about You?”: A Gendered, Transnational Approach to Ethnicity." Gender and Society 11 (5): 572-596.

Davis, S. N and T.N. Greenstein. 2009. Gender Ideology: Components, Predictors, and Consequences. Annual Review of Sociology 35: 87-105

Del Rosario, T. 2005 Bridal Diaspora: Migration and Marriage among Filipino Women. Indian Journal of Gender Studies 12 (2):253 - 275.

Deleuze, G. and Guattari, F. (1987) A Thousand Plateaus: Capitalism and Schizophrenia. Minneapolis: University of Minnesota Press.

Dhruvarajan, V. 1990 Women and well-being. Canadian research Institute for the Advancement of Women

di Leonardo, M. 1984. The Varieties of Ethnic Experience: Kinship, Class, and Gender among California Italian-Americans. Ithaca, NY. Cornell University Press.

Eastmond, M. 1993. "Reconstructing Life: Chilean Refugee Women and the Dilemmas of Exile." In Gina Buijs (Ed) Migrant Women: Crossing Boundaries and Changing Identities. Oxford. 35-53.

Espiritu, Y.L.

1996. Asian American Women and Men: Labor, Laws, and Love. AltaMira Press. 1999 "Gender and Labor in Asian Immigrant Families." American Behavioral Scientist 42(4):628-648.

2000 " 'We Don't Sleep around like White Girls Do': Family, Culture, and Gender in Filipina American Lives." Signs 26 (2): 415-440

Feldman, Shelley. 2010. "Shame and Honour: The Violence of Gendered Norms Under Conditions of Global Crisis." Women's Studies International Forum 33 (4): 305315.

Fernandes, Leela. 1997. "Beyond Public Spaces and Private Spheres: Gender, Family, and Working-Class Politics in India." Feminist Studies 23 (3): 525-547.

Ferrari, Fabrizio M. 2010. Guilty Males and Proud Females: Negotiating Genders in a Bengali Festival Seagull Books.

Ferree, M., J. Lorber,B.Hess, ed. 1999. Revisioning Gender.: Thousand Oaks, Sage Publications.

Ferree, M.

1990. "Beyond Separate Spheres: Feminism and Family Research." Journal of Marriage and the Family 52 (4): 866-884; 866. 
2010. "Filling the Glass: Gendered Perspectives on Families." Journal of Marriage and Family 72 (June 2010): 420-439.

Flood, G. 1996 An Introduction to Hinduism. Cambridge University Press

Foner, N.

2003 Introduction: Anthropology and Contemporary Immigration to the United States - Where We Have Been and Where We Are Going. In American Arrivals: Anthropology Engages the New Immigration. Santa Fe: School of American Research Press.

2008. Gender and Migration: West Indians in Comparative Perspective. International Migration. 47 (1):4 - 31.

Gabaccia, Donna.

1992. Introduction. In Seeking Common Ground Multidisciplinary Studies of Immigrant Women in the United States. D. Gabaccia, ed. Westport, Connecticut: Greenwood Press.

1994 From the Other Side: Women, Gender and Immigrant Life in the U.S., 1820- 1990. Bloomington: Indiana University Press.

Gardner, Katy. 2006 The transnational work of kinship and caring: Bengali-British marriages in historical perspective. Global networks 6(4): $373-387$

Georges, E. 1992 Gender, Class, and Migration in the Dominican Republic: Women's Experiences in a Transnational Community. In Towards a Transnational Perspective on Migration: Race, Class, Ethnicity, and Nationalism Reconsidered, edited by N Glick Schiller. New York: New York Academy of Sciences.

George, S. M. 2005. When Women Come First: Gender and Class in Transnational Migration University of California Press.

Ghosh, D. 2006 Sex and the Family in Colonial India: The Making of Empire. Cambridge: Cambridge University Press.

Ghosh, S. 2007 Transnational ties and intra-immigrant group settlement experiences: A case study of Indian Bengalis and Bangladeshis in Toronto. GeoJournal 68:223 242

Gillis, John R. 1996. A World of their Own Making: Myth, Ritual, and the Quest for Family Values Basic Books.

Glick Schiller, N. et al

1992 Towards a Transnational Perspective on Migration: Race, Class, Ethnicity, and Nationalism Reconsidered. Annals of the New York Academy of Science. 
1992.Towards a Definition of Transnationalism: Introductory Remarks and Research Questions. In Towards a Transnational Perspective on Migration: Race, Class, Ethnicity, and Nationalism Reconsidered. N.G. Schiller, L. Basch, and C. Blanc-Szanton, eds. Annals of the New York Academy of Science, Vol. 654. New York: The New York Academy of Sciences.

Glick Schiller, N. and Noel Salazar. 2012. "Regimes of Mobility Across the Globe." Journal of Ethnic and Migration Studies. Pgs 1-18.

Grewal, M. 2003. Mass Media and the Reconfiguration of Gender Identities: The Bharatiya Nari in the United States. . Gender Technology and Development. 7 (1):53 - 77.

Grieco, E., and Monica Boyd. 1998 Women and Migration: Incorporating Gender into International Migration Theory. Working Paper WPS 98-139. Center for the Study of Population, Florida State University.

Goldring, Luin. 1998 The Power of Status in Transnational Social Fields. In Transnationalism from Below, Michael Peter Smith and Luis Eduardo Guarnizo, eds. Pp. 165-194. New Brunswick, NJ: Transaction Publishers.

Hannam, K., Sheller, M. and Urry, J. 2006. "Editorial: mobilities, immobilities and moorings". Mobilities, 1(1): 1-22.

Hing, Bill Ong. 2004 Defining America Through Immigration Policy. Edited by J. Carrillo, Mapping Racisms. Philadelphia: Temple University Press.

Hirsch, J. 2003 A Courtship After Marriage: Sexuality and Love in Mexican Transnational Families. University of California Press.

Holy, L. 1996 Anthropological Perspectives on Kinship. London: Pluto Press.

Hondagneu-Sotelo, $\mathrm{P}$.

1992 Overcoming Patriarchal Constraints: The Reconstruction of Gender Relations among Mexican Immigrant Women and Men Gender and Society 6 (3):393 - 417.

1994. Gendered Transitions: Mexican Experiences of Immigration University of California Press.

1999. Introduction: Gender and Contemporary U.S. Immigration. American Behavioral Scientist 42 (4):565-576.

2003. Gender and U.S. Immigration: Contemporary Trends. Los Angeles: University of California Press.

Hondagneu-Sotelo, P and E. Avila. 1997 "I'm Here, but I'm There": The Meanings of Latina Transnational Motherhood Gender and Society 11 (5):548 - 572. 
Hondagneu-Sotelo, Pierrette, and Cynthia Cranford. 1999. Gender and Migration. In Handbook of the Sociology of Gender. J.S. Chafetz, Ed. New York: Plenum Publishers

Kalpagam, U. 2005 'America Varan’ Marriages among Tamil Brahmans: Preferences, Strategies and Outcomes. Indian Journal of Gender Studies 12 (2):189 - 217.

Kibria, Nazli. 1993. Family Tightrope: The Changing Lives of Vietnamese Immigrant Community. Princeton, N.J.: Princeton University Press.

Kibria, N. 2005. "South Asian Americans." In Asian Americans, edited by P. Min: Pine Forge Press.

Kimmel, M. S. 2004. The Gendered Society. New York: Oxford University Press.

Knudsen, Susanne V. 2004. Gender paradoxes and power - theoretical reflections with empirical awareness. NORA 2, 102-12

Kroska, A. 2003. Investigating gender differences in the meaning of household chores and child care. Journal of Marriage and Family, 65, 456-473

Kurien, P. 1999. "Gendered Ethnicity: Creating a Hindu Indian Identity in the United States." American Behavioral Scientist 42 (4): 648-670.

Latour, B. 2005. Reassembling the Social: An Introduction to Actor-Network Theory. Oxford: Oxford University Press.

Levitt, Peggy. 2001 The Transnational Villagers. Berkeley: University of California Press.

Levitt, P. and N. Jaworsky. 2007 Transnational Migration Studies: Past Developments and Future Trends. Annual Review of Sociology.

Loomba, Ania and Ritty A. Lukose, eds. 2012. South Asian Feminisms: Duke University Press.

Luibhéid, Eithne. 2002 Entry Denied: Controlling Sexuality at the Border. Minneapolis: University of Minnesota Press.

Mahler, Sarah J. 1999 Engendering Transnational Migration: A case study of Salvadorans. The American Behavioral Scientists 42(4):690 - 719.

Mahler, S. and P. Pessar.

2001 Gendered Geographies of Power: Analyzing Gender Across Transnational Spaces. Identities 7 (4):441 - 460.

2006 Gender Matters: Ethnographers bring gender from the periphery toward the core of migration studies. International Migration Review 40(1):27 - 63. 
Mand, K. 2005 Marriage and Migration through the Life Course: Experiences of Widowhood, Separation and Divorce amongst Transnational Sikh Women. Indian Journal of Gender Studies 12 (3):407 - 427.

Maira, S. 2002. Desis in the House: Indian American Youth Culture in NYC. Philadelphia: Temple University Press.

Majumdar, Rochona. 2009. Marriage and Modernity: Family Values in Colonial Bengal Duke University Press.

Mani, Lata. 1998. Contentious Traditions: The Debate on Sati in Colonial India. University of California Press

McKinnon, S. and S. Silverman, ed. 2005. Complexities: Beyond Nature and Nurture.: University of Chicago Press.

Massey, D. 1999 Why Does Immigration Occur? A Theoretical Synthesis. In The American Experience, edited by C. Hirschman. New York: Russell Sage Foundation.

Menjívar, C. 2003 The Intersection of Work and Gender: Central American Immigrant Women and Employment in California. In Gender and U.S. Immigration: Contemporary Trends. Ed. P. Hondagneu-Sotelo. Los Angeles: University of California Press. Pp. 101-126.

Min, P (Ed). 2005. Asian Americans: Pine Forge Press.

Mohanty, Chandra Talpade. 1988. "Under Western Eyes: Feminist Scholarship and Colonial Discourses.” Feminist Review, no. 30, 61-88.

Morokvasic, Mirjana. 1984 Birds of Passage are also Women... International Migration Review 18(4):886 - 907.

Ong, Aihwa.1999. Flexible Citizenship: The Cultural Logics of Transnationality.

Orozco, M. 2006. Transnational Families: lives on the edge, but in pursuit of change.

Orsi, R. A. 1985. The Madonna of 115th Street: Faith and Community in Italian Harlem, 1880-1950. New Haven. Yale University Press.

Oye`wu 'mi, Oye`ro'nke'. 1997. The Invention of Women: Making an African Sense of Western Gender Discourses. Minneapolis: University of Minnesota Press.

Palriwala, R. and P. Uberoi.2005. Introduction: Marriage and Migration in Asia: Gender Issues. Indian Journal of Gender Studies 12 (3): - xxix

Narayan, Anjana and Bandana Purakayastha. 2009. Living our Religions: Hindu and Muslim South Asian American Women Narrate their Experiences. Sterling, VA: Kumarian Press. 
Narayan, U. 1997. Dislocating Cultures: Identities, Traditions, and Third World Feminism. NY: Routledge.

Naregal, Veena. 2001. Language, Politica, Elites, and the Public Sphere. New Delhi: Permanent Black.

Palriwal, R. and P. Uberoi. 2005. "Introduction: Marriage and Migration in Asia: Gender Issues." Indian Journal of Gender Studies 12 (3).

Patil, V. 2013. "From Patriarchy to Intersectionality: A Transnational Feminist Assessment of How Far We've Really Come." Signs 38 (4): 847 - 867

Pessar, P. 1999. The Role of Gender, Households, and Social Networks in the Migration Process: A Review and Appraisal. In The Handbook of International Migration. New York: Russel Sage Foundation.

Pessar, P. and S. Mahler. 2003 Transnational Migration: Bringing Gender in. International Migration Review 37 (3):812-846.

Poggendorf-Kakar, Katharina. "Reinventing Women: Family Politics of the HindutvaMovement in India1."

Prothero, R.M. and Chapman, M. (eds).1985. Circulation in Third World Countries. London: Routledge.

Radhakrishnan, Smitha. 2011. Appropriately Indian: Gender and Culture in a New Transnational Class Duke University Press.

Raju, Saraswati, M. Satish Kumar, and Stuart Corbridge, eds. 2006. Colonial and PostColonial Geographies of India. New Delhi, London: Sage Publications.

Raju, Saraswati and Kuntala Lahiri-Dutt, eds. 2011. Doing Gender Doing Geography: Emerging Research in India. New Delhi: Routledge.

Ray, Bharati. 1991. "Bengali Women and Politics of Joint Family, 1900-47." Economic and Political Weekly: 3015-3021.

Reddy, G.

2005. With Respect to Sex: Negotiating Hijra Identity in South India. Chicago: University of Chicago Press.

2004. "Crossing "Lines" of Subjectivity: The Negotiation of Sexual Identity in Hyderabad, India." In Sexual Sites, Seminal Attitudes: Sexualities, Masculinities and Culture in South Asia. New Delhi: Sage.

Ridgeway, C. and S. Correll. 2004. "Unpacking the Gender System: A Theoretical Perspective on Gender Beliefs and Social Relations." Gender and Society 18 (4): 510-531. 
Risman, B. 2004. "Gender as a Social Structure: Theory Wrestling with Activism." Gender and Society 18 (4): 429-450.

Roy, Manisha. 2010. Bengali Women University of Chicago Press.

Sardar, Ziauddin. 1997. "Coming Home: Sex, Lies and all the '1' in India." Futures 29 (10): 891-908.

Sarkar, Tanika. 2002. Hindu Wife, Hindu Nation: Community, Religion, and Cultural Nationalism: Indiana University Press.

Sassen, Saskia.

1988 The Mobility of Labor and Capital. Cambridge: Cambridge University Press.

1999 Transnational Economics and National Migration Policies. In Free Markets, Open Societies, Closed Borders? Trends in International Migration and Immigration Policy in the Americas. M. Castro, ed. Miami: North South Center Press, University of Miami.

2003 Global Cities and Survival Circuits. In Global Women: Nannies, Maids, and Sex Workers in the New Economy. B. Ehrenreich and R. Hochschild, eds. Pp. 254 - 274. New York: metropolitan Books.

Schiebinger, L. 2004. Nature's Body: Gender in the Making of modern Science. Rutgers University Press.

Sinha, Mrinalini. 1995. Colonial Masculinity: The "Manly Englishman" and the "Effeminate Bengali" in the Late Nineteenth Century. New York: Manchester University Press.

Schrover, M., J. V. D. Leun, L. Lucassen,and C.Quispel, ed. 2008. Illegal Migration and Gender in a Global and Historical Perspective. IMISCOE Research: Amsterdam University Press.

Sheller, M. and Urry, J. 2006. "The new mobilities paradigm". Environment and Planning A, 38(2): 207-26.

Skeldon, R. 1986 "On migration patterns in India during the 1970s", Population and Development Review, 12(4): 759-79.

Sorensen, N. 2005. "Transnational Family Life Across the Atlantic: The Experience of Colombian and Dominican Migrants in Europe." Wassenar, The Netherlands.

Sullivan, O. 2004. Changing Gender Practices within the Household: A Theoretical Perspective. Gender and Society 18 (2):201-222.

Stone, Linda. 2010. Kinship and Gender Westview Press. 
Thakur, H. 1998. "Practical Steps Towards Eradicating Dowry and Bride-Burning in India." In South Asians and the Dowry Problem, edited by W. Menski. Stoke on Trent: Trentham Books.

Uberoi, Patricia

1993. Family, Kinship and Marriage in India. OUP

2000. The Family in India: Beyond the Nuclear Versus Joint Debate Institute of Economic Growth.

2001 Imagining the family: An ethnography of viewing Hum Aapke Hain Koun ! In R. Dwyer \& C. Pinney (Eds.), Pleasure and the nation: The history, politics and consumption of public culture in India (pp. 309-351). New Delhi, India: Oxford University Press.

2006 Freedom and Destiny: Gender, Family and Popular Culture in India

Urry, J. 2007. Mobilities. Cambridge: Polity Press.

Walsh, Judith E.

2004 Domesticity in Colonial India: What Women Learned WhenMen Gave Them Advice. Rowman \& Littlefield.

2005. How To Be The Goddess Of Your Home: An Anthology of Bengali Domestic Manuals: Yoda Press.

West, C. and D. Zimmerman. 1987. Doing Gender. Gender and Society 1:125-151.

West, C. and S. Fenstermaker.1995. Doing Difference. Gender and Society 9:8-37.

Zlotnik, Hania. 1995 The South-to-North Migration of Women. International Migration Review 29(1, Special Issue: Diversity and Comparability: International Migrants in Host Countries of four Continents):229 - 254. 
VITA

\section{MAYURAKSHI CHAUDHURI}

Born, Calcutta, India

1999-2002

B.Sc., Geography

The University of Calcutta

Calcutta, India

2002-2004

M.S., Geography, The University of Calcutta

Calcutta, India

2004- 2005

M.A., Town and Regional Planning

University of Sheffield

Sheffield, U.K.

2005-2007

Researcher

Center for Care of Torture Victims

Calcutta, India

2007-2009

M.A., Comparative Sociology

Florida International University

Miami, Florida

2009-2014

Doctoral Candidate

Florida International University

Miami, Florida

2014

Graduate Certificate in Women's and Gender Studies.

Center for Women's and Gender Studies.

Florida International University.

Miami, Florida

\section{PUBLICATIONS AND PRESENTATIONS}

Chaudhuri, Mayurakshi and Sarah J. Mahler. Forthcoming. "Scaling Intersectionality: Gender and Family Relations across Transnational Spaces." Invited to be submitted for a special issue entitled, "Feminist Perspectives on Family Relationships", for Sex Roles: A Journal of Research. 
Chaudhuri, Mayurakshi, Viola Thimm, and Sarah J. Mahler. In press. " Gendered Geographies of Power: Their value for analyzing gender across transnational spaces." In Julia Gruhlich and Birgit Riegraf (ed) Transnational Spaces and Gender

Mahler, Sarah J. and Mayurakshi Chaudhuri. 2014. "Gender and the Undocumented: Avanzando or Abject?" in Lois Lorentzen's (ed) Hidden Lives and Human Rights: Understanding the Controversies and Tragedies in Undocumented Immigration, Vol. 2 Chap 7. Praeger Press.

Presenter. 2013. Invited Roundtable Presentation at the American Anthropological Association meetings, Chicago, IL. Session Title: Bringing Gender from the Periphery to the Core of Migration Studies: Honoring Patricia R. Pessar. Co-panelist with Nina Glick Schiller (University of Manchester), Karen Richman (University of Notre Dame), Eugenia Georges (Rice University), Denise Brennan (Georgetown University), Jasney Cogua-Lopez (Florida Atlantic University), Viola Thimm (Institute for Social \& Cultural Anthropology, Goettingen University) and Sarah J. Mahler (Florida International University).

Presenter. 2013 "Mapping the Colonial Present: Gendered Power Geographies of Family and Marriage in India." The 13th Annual Conference on Gender, Race, and Sexuality in a Globalized World, organized by the Women Studies Graduate Students Association, Florida International University.

Presenter. 2013 "Gendered Geographies of Family and Marriage." Graduate Scholarly Forum. Florida International University.

Presenter. 2012. "Gendered Ties in Motion: U.S.-based transnational Asian Indian Bengalis' negotiation of spousal and family relations." Symposium organized by Department of Geography and Sociology. University of Calcutta, India.

Presenter. 2010. "Ties in Motion: Transnational Bengalis' negotiation of Gender and Family Relations in Motion." The $10^{\text {th }}$ Annual Women, Gender, and Sexuality Student Conference organized by the Women Studies Graduate Students Association, Florida International University.

Presenter. 2010. "Negotiating Gender in Motion: Bengali Transnational Extended Families' Influence on Migrants' Spousal relations." The Trans-Atlantic Summer Institute (TASI). University of Minnesota. 